\title{
Methods for collection of dissolved sulfate and sulfide and analysis of their sulfur isotopic composition
}

By Rebecca W. Carmody, L. Niel Plummer, Eurybiades Busenberg and Tyler B. Coplen

\section{U. S. GEOLOGICAL SURVEY}

Open-File Report 97-234

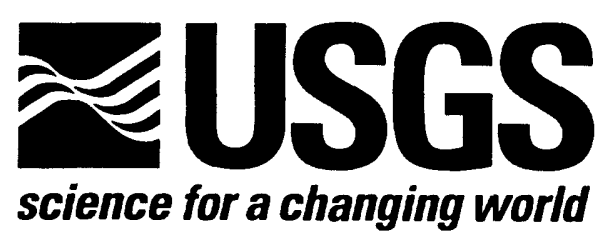

Reston, Virginia 


\title{
U. S. Department of the Interior Bruce Babbitt, Secretary
}

\author{
U. S. Geological Survey \\ Tom Casadevall, Acting Director
}

For additional information write to:

Chief, Isotope Fractionation Project

U. S. Geological Survey

MS 431 - National Center

Reston, Virginia 20192
Copies of this report can be purchased from:

U. S. Geological Survey

Branch of Informaiton Services

Box 25286, Federal Center

Denver, Colorado 80225-0286 


\section{CONTENTS}

Page

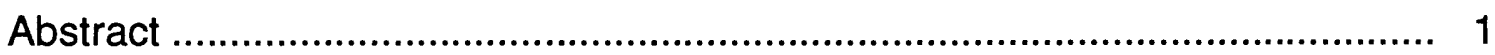

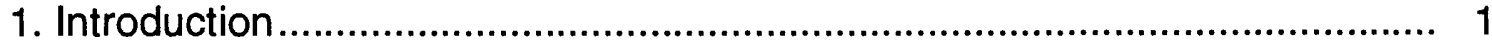

1.1 Sulfur isotope nomenclature .......................................................... 2

2. Field Collection Techniques ……………………………………………... 3

2.1 Sulfate Collection ....................................................................... 3

2.1.1 Estimation of the sulfate content of the sample .................. 7

Procedure.................................................................. 7

2.1.2 Deciding how to collect the sulfate.................................... 7

2.1.3 Measuring and stripping dissolved sulfide .......................... 8

2.1.4 Collection of "high-sulfate" ( $\geq 20 \mathrm{mg} / \mathrm{L})$ samples ................ 10 In bottles ....................................................................... 10

Precipitation of $\mathrm{BaSO}_{4}$ in the field .................................10

2.1.5 Collection of sulfate from dilute $(<20 \mathrm{mg} / \mathrm{L})$ samples using anion exchange resin ............................................ 10

Preparing the Resin ......................................................... 11

Capacity of the anion exchange resin ............................... 11

Procedure........................................................................... 11

2.2 Dissolved Sulfide Collection Methods.............................................. 14

Procedure for $S^{2-}$ collection by nitrogen stripping .............. 15

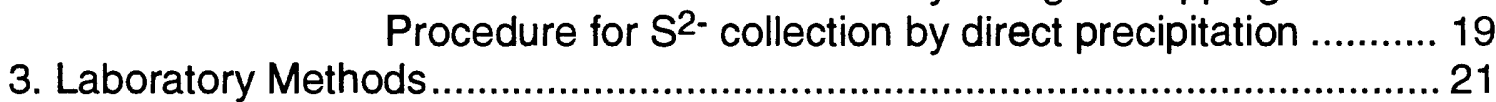

3.1 Precipitation of sulfate from samples collected as water in

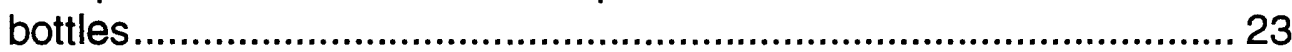

Procedure......................................................................... 23

3.2 Elution and precipitation of sulfate samples collected on anion

exchange resin ........................................................................ 25

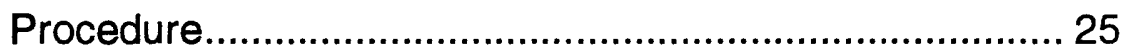

3.3 Laboratory preparation of dissolved sulfide collected as $\mathrm{Ag}_{2} \mathrm{~S}$.........26

3.4 Preparation of $\mathrm{SO}_{2}$ from $\mathrm{BaSO}_{4}$ and $\mathrm{Ag}_{2} \mathrm{~S}$ for isotopic analysis......27

3.4.1 Combining $\mathrm{Ag}_{2} \mathrm{~S}$ and $\mathrm{BaSO}_{4}$ samples with reagents in preparation for vacuum extraction................................... 28

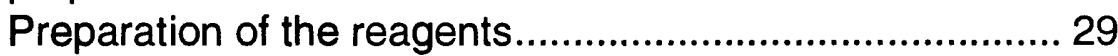

Weighing Silver Sulfide $\left(\mathrm{Ag}_{2} \mathrm{~S}\right)$..................................... 29

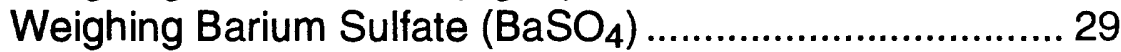

3.4.2 Conversion of $\mathrm{Ag}_{2} \mathrm{~S}$ and $\mathrm{BaSO}_{4}$ to $\mathrm{SO}_{2}$ in vacuum

extraction line ............................................................... 30

3.5 Analysis of $\mathrm{SO}_{2}$ on an isotope-ratio mass spectrometer ..................31

4. Testing of field collection procedures. ........................................................... 33

4.1 High-concentration sulfate collection experiments in the

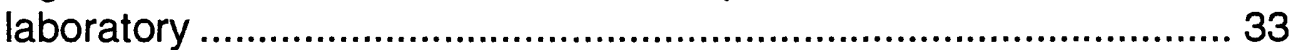

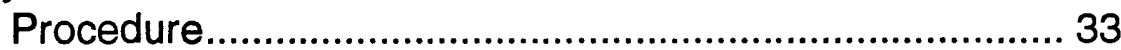

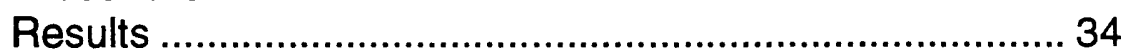


4.2 Low-concentration sulfate collection experiments in the laboratory.

Procedure

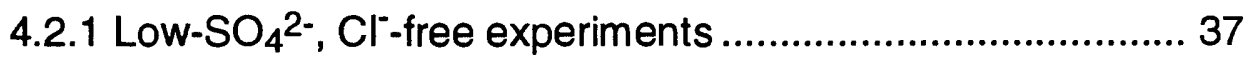

4.2.2 Low-SO ${ }^{2-}$, high- $\mathrm{Cl}^{-}$experiments .....................................37

4.2.3 Sulfate collection on anion exchange resin

(with low $\mathrm{Cl}^{-}$) revisited .................................................... 39

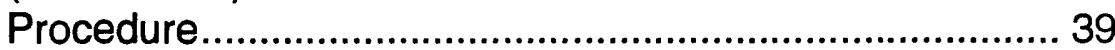

Sulfate collection by batch method .................................. 40

Sulfate collection by flow-through method ........................ 40

Elution of the sulfate ...................................................... 40

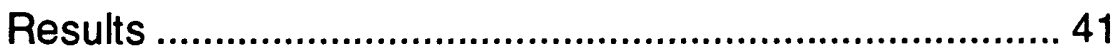

4.3 Field testing of sulfate collection techniques .................................. 42

4.3.1 Stripping of $\mathrm{H}_{2} \mathrm{~S}$ prior to collection of sulfate ......................43

Procedure........................................................................ 43

"DI water first" dilution method .......................................... 45

"Reagents first" dilution method ....................................... 45

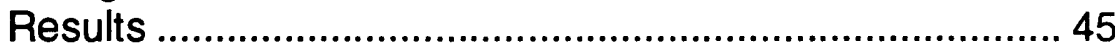

Stripping rate and effect of nitrogen flow rate ................. 45

Recommendations ......................................................... 49

Evaluation of "DI water first" dilution technique ................. 51

Evaluation of "Reagents first" dilution technique ............... 52

Conclusions regarding dilution techniques........................ 53

Dissolved sulfate in stripping experiments ........................ 53

4.3.2 Testing sulfate collection techniques in the field.................. 54

Procedure for direct precipitation ..................................... 54

Procedure for sulfate collection on anion exchange

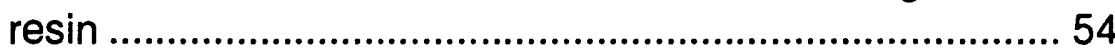

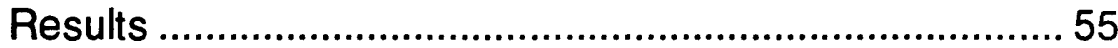

Suggestions for sulfate collection in the field .................... 57

4.4 Sulfide collection by direct precipitation........................................... 58

4.4.1 Sulfide collection by direct precipitation in the

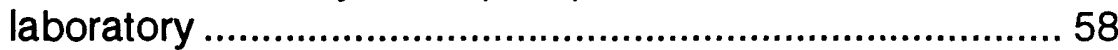

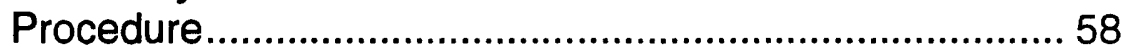

Results .......................................................................... 58

4.4.2 Sulfide collected by direct precipitation in the field ............. 59

Procedure ........................................................................ 59

4.4.3 Results and implications from direct precipitation experiments.................................................................... 61

4.5 Experiments on the nitrogen stripping method for collection of dissolved sulfide.

4.5.1 One-trap sulfide-collection-by-nitrogen-stripping

experiments in the laboratory.......................................... 62

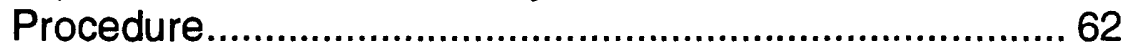

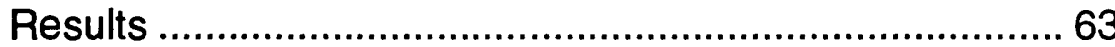


4.5.2 One-trap sulfide-collection-by-nitrogen-stripping

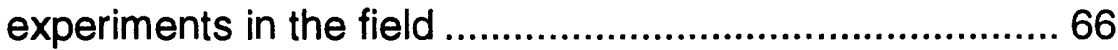

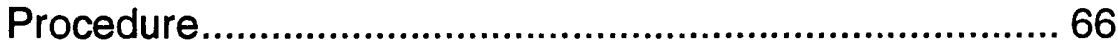

4.5.3 Six-trap (fractional) sulfide-collection-by-nitrogenstripping experiments in the field...................................... 70

4.5.4 Six-trap (fractional) sulfide-collection-by-nitrogenstripping experiments in the laboratory ............................. 71

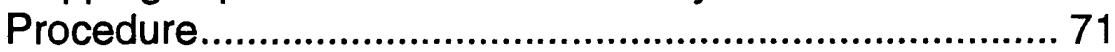

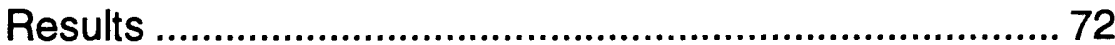

4.5.5 Evaluation of the sulfide-collection-by-nitrogenstripping experiments ...................................................... 74

4.5.6 Conclusions regarding the sulfide-collection-bynitrogen-stripping technique............................................ 79

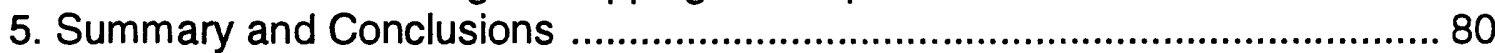

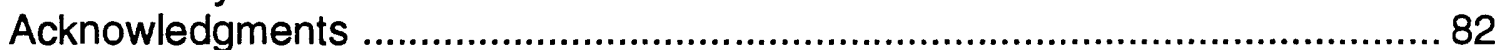

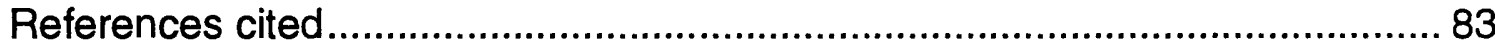

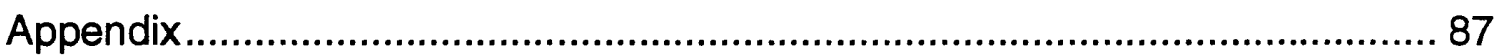

Correction of data to Vienna Canyon Diablo Troilite

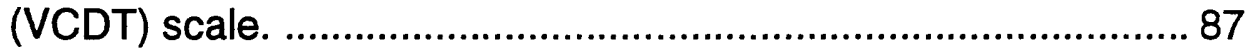

Oxygen-isotope correction for sulfate samples......................... 87

Long-term reproducibility and uncertainty of $\delta^{34} S$ data .............. 89

\section{ILLUSTRATIONS}

Figure 1. (a) Flowchart outlining steps in collection of "high-sulfate" samples

(b) Flowchart outlining steps in collection of sulfate from dilute samples on anion exchange resin

2. Set-up of equipment for stripping dissolved $\mathrm{H}_{2} \mathrm{~S}$ by bubbling nitrogen gas, in preparation for collection of sulfate for isotopic analysis

3. Set-up of equipment for collection of dissolved sulfate from dilute $\left(<20 \mathrm{mg} / \mathrm{L} \mathrm{SO}_{4}{ }^{2-}\right)$ samples on anion exchange resin

4. Set-up of equipment for nitrogen stripping of $\mathrm{H}_{2} \mathrm{~S}$ from a carboy of acidified ground water and collection of dissolved sulfide as $\mathrm{Ag}_{2} \mathrm{~S}$ in an $\mathrm{AgNO}_{3}$ trap.

5. Flowchart outlining steps in laboratory preparation of dissolved sulfate samples for sulfur isotopic analysis

6. Plot of $\log \mathrm{fO}_{2}$ versus $1000 / \mathrm{T}$, illustrating the importance of controlling oxygen fugacity during the reaction producing $\mathrm{SO}_{2}$ to minimize $\mathrm{SO}_{3}$ production 
7. Schematic diagram of the vacuum extraction system used in this study for the preparation of $\mathrm{SO}_{2}$ from $\mathrm{BaSO}_{4}$ and $\mathrm{Ag}_{2} \mathrm{~S}$ samples 30

8. Schematic diagram of the inlet system of the Finnigan MAT 251 isotope-ratio mass spectrometer used in this study, including customization

9. Plots of $\mathbf{S}^{2-}$ concentration versus time illustrating results of 1994 sulfide stripping experiments:

(a) in the laboratory and (b) at the Suwannee well 48

(c) comparison of all three experiments 49

10. Plots of $S^{2-}$ concentration versus time illustrating results of 1995 sulfide stripping experiments: (a) experiment with $\mathrm{N}_{2}$ flow rate of $4 \mathrm{~L}$ minute, compare to figure $9 \mathrm{a}$, and (b) comparison of all three experiments, at $\mathrm{N}_{2}$ flow rates of 4,6 and $7.7 \mathrm{~L}$ /minute

11. Plot illustrating inverse relationship between increasing nitrogen flow rate and time to strip sample to $0.01 \mathrm{mg} / \mathrm{L} \mathrm{S}^{2-}$

12. Histograms illustrating results of sulfate collection experiments at (a) the Suwannee well and

(b) the Upper Intermediate well

13. Fraction of sulfide recovered with time for one-trap laboratory experiments with different initial sulfide concentrations

14. $\delta^{34}$ SVCDT versus fraction of sulfide recovered for one-trap sulfide collection experiments and direct precipitation experiments in the laboratory

15. Photograph of sulfide-collection-by-nitrogenstripping apparatus set up in the field

16. Histograms illustrating results of sulfide collection experiments at (a) the Suwannee well and

(b) the Upper Intermediate well

17. Plots of $\ln \left[\left(\delta^{34} S\right) g+1000\right]$ versus $\ln f$ for (a) fractional sulfide collection experiments at the Suwannee well and (b) fractional sulfide collection experiments in the laboratory

18. Plot of $\Delta=\delta^{34} S_{\text {calc. }}-\delta^{34} S_{\text {direct precip. versus } f \text {, }}$ illustrating that $\left(\delta^{34} S\right)_{\text {so }}$ is best predicted by the calculated fractionation factor when $f$ is high

19. Diagram showing the scheme for correction of sulfur isotopic data from the Tank $\mathrm{SO}_{2}$ scale to the VCDT scale

20. Plot of $\delta^{34} S$ of NBS 127 with time, illustrating a method for eliminating outliers among values used to apply daily correction factors to $\delta^{34} S$ data on sulfates. 


\section{TABLES}

Table 1. Equipment used to determine approximate sulfate concentration in the field, strip dissolved sulfide by bubbling nitrogen gas and collect high-concentration (greater than $20 \mathrm{mg} / \mathrm{L}$ ) sulfate-bearing water samples

2. Solutions needed for determining approximate sulfate concentration in the field, strip dissolved sulfide by bubbling nitrogen gas and collect high-concentration (greater than $20 \mathrm{mg} / \mathrm{L}$ ) sulfate-bearing water samples

3. Capacity of the anion exchange resin

4. Equipment needed to collect dissolved sulfate from dilute samples (less than $20 \mathrm{mg} / \mathrm{L}$ ) using anion exchange resin

5. Guidelines for stripping sulfide from samples with low sulfate concentrations

6. Equipment needed for sulfide-collection-by-nitrogenstripping technique

7. Solutions needed for sulfide-collection-by-nitrogenstripping technique

8. Volume of water sample needed for various sulfide concentrations

9. Guidelines for collection of sulfide by direct precipitation

10. Solutions needed for preparation of $\mathrm{BaSO}_{4}$ from dissolved sulfate samples collected as water in bottles and on anion exchange resin

11. Compositions of synthetic water samples for highconcentration sulfate collection experiments

12. High-sulfate (equal to or greater than $20 \mathrm{mg} / \mathrm{L}$ ) direct precipitation experiments in the laboratory

13. Results from low-SO ${ }_{4}^{2-}, \mathrm{Cl}^{-}$-free experiments in 1993 $\left(\mathrm{SO}_{4}{ }^{2-}\right.$ collected on anion exchange resin)

14. Results of (1993) experiments on low- $\mathrm{SO}_{4}{ }^{2-}$, high- $\mathrm{Cl}^{-}$ synthetic samples

15. Results of experiments (1996) in which sulfate was collected on anion exchange resin by both batch and flow-through methods

16. Information on Florida well sites

17. $\mathrm{H}_{2} \mathrm{~S}$ stripping experiments in the laboratory and the field (1994)

18. $\mathrm{H}_{2} \mathrm{~S}$ stripping experiments in the laboratory (1995)

19. Percentage of dissolved sulfide which could be oxidized by dilution of samples with air-saturated water....

20. Decrease in sulfide concentration of diluted samples with time 
21. Sulfur isotopic analyses of sulfate collected in the field

22. Direct precipitation experiments in the laboratory

23. Direct precipitation experiments at the Suwannee well

24. Sulfide collection by nitrogen stripping -- laboratory experiments

25. Maximum effect of $0.7 \mathrm{mg} / \mathrm{L}$ of dissolved oxygen on sulfide solutions with concentrations ranging from 3.0 to $0.03 \mathrm{mg} / \mathrm{L}$

26. Results of one-trap nitrogen stripping experiments in the field

27. Sulfide concentration of Suwannee water calculated from results of nitrogen-stripping experiments

28. Fractional sulfide collection experiments at the Suwannee well 70

29. Fractional sulfide collection experiments with controlled nitrogen flow rates

30. Fractionation factors and sulfur isotopic composition of original dissolved sulfide $\left(\delta^{34} S\right)_{\text {so }}$ calculated from linear regressions to the data in figure 17

31. Corrections applied to sulfur isotope analyses of sulfate samples.

32. Analyses of NBS 127 made between February 7 and June 15, 1994 


\section{ABBREVIATIONS}

$\begin{array}{ll}\text { CDT } & \text { Cañon Diablo troilite } \\ { }^{\circ} \mathrm{C} & \text { temperature in degrees centigrade } \\ \mathrm{cm} & \text { centimeter } \\ \mathrm{g} & \text { gram(s) } \\ \mathrm{id} & \text { inner diameter } \\ \mathrm{K} & \text { temperature measured in Kelvins }\left(\mathrm{K}={ }^{\circ} \mathrm{C}+273\right) \\ \mathrm{L} & \text { liter(s) } \\ \mathrm{L} / \mathrm{min} . & \text { liters per minute } \\ \mathrm{M} & \text { molar, molarity (see definitions) } \\ \mathrm{meq} / \mathrm{mL} & \text { milliequivalents per milliliter } \\ \mathrm{mg} & \text { milligram(s) } \\ \mathrm{mg} / \mathrm{L} & \text { milligrams per liter } \\ \mathrm{mL} & \text { milliliter(s) } \\ \mathrm{mm} & \text { millimeter(s) } \\ \mathrm{mmoles} & \text { millimoles } \\ \mu \mathrm{L} & \text { microliter(s) } \\ \mu \mathrm{mol} & \text { micromole(s) } \\ \mu \mathrm{S} / \mathrm{cm} & \text { microsiemens per centimeter } \\ \mathrm{N} & \text { normal (see definitions) } \\ \text { od } & \text { outer diameter } \\ \mathrm{p.s.i} & \text { pounds per square inch } \\ \mathrm{VCDT} & \text { Vienna Cañon Diablo troilite (see definitions) }\end{array}$




\section{DEFINITIONS}

Chromatography column -- A chromatography column looks something like a buret but is ungraduated and has a glass frit above the stopcock. The frit is essential for keeping the resin out of the stopcock. An effort should be made to prevent the glass frit from being clogged by the extraneous material found in some resin samples. A $13 \mathrm{~mm}$ glass fiber filter placed above the frit will help to keep it clean. If the frit does become clogged, it can be cleaned using a mixture of concentrated sulfuric acid and chromerge (chromium trioxide solution). To clean the frit, pour this solution into the chromatography column and allow the glass frit to soak in it overnight. The chromerge solution can be saved for repeated cleanings. After cleaning, rinse the column and frit thoroughly to remove all sulfate from the sulfuric acid.

membrane filter -- when a "membrane filter" is specified, this means a $47 \mathrm{~mm}$ diameter, $0.4 \mu \mathrm{m}$ opening polycarbonate membrane filter, unless otherwise noted.

molarity -- moles of solute per liter of solution. For example, a 1-molar (1M) solution is made by adding water to one mole of solute to make exactly one liter of solution.

normality -- equivalents per liter of solution. For example, a 1-normal (1N) acid contains one mole of $\mathrm{H}^{+}$ions per liter of solution.

Vienna Cañon Diablo troilite (VCDT) -- The stable sulfur isotopic scale is defined based on assigning a $\delta^{34} \mathrm{~S}$ value of $-0.3 \%$ oxactly to the $\mathrm{Ag}_{2} \mathrm{~S}$ reference material IAEA-S-1 (NZ 1). Samples reported relative to this value are said to be on the VCDT scale. See Krouse and Coplen (1997) and Coplen and Krouse (1998). 


\title{
Methods for collection of dissolved sulfate and sulfide and analysis of their sulfur isotopic composition
}

\author{
by Rebecca W. Carmody, L. Niel Plummer, Eurybiades Busenberg and \\ Tyler B. Coplen
}

\begin{abstract}
Representative samples for sulfur isotopic analysis of sulfate and sulfide dissolved in ground and surface waters must be collected by methods that do not cause fractionation of the sulfur isotopes. This report presents techniques for collection of dissolved sulfate and sulfide which impose minimal fractionation of the sulfur isotopes. Samples collected by direct precipitation of the dissolved sulfur species show no apparent isotopic fractionation. Procedures are described for collection and preparation of unfractionated sulfate samples from dilute ground and surface waters using anion exchange resin. Dissolved sulfide samples collected by nitrogen stripping are typically fractionated $(-0.2$ to -0.5 per mill) relative to samples collected by direct precipitation. The isotopic composition of $\mathrm{Ag}_{2} \mathrm{~S}$ collected by nitrogen stripping is enriched in ${ }^{32} \mathrm{~S}$ relative to the samples collected by direct precipitation but becomes richer in ${ }^{34} S$ with duration of nitrogen stripping, approaching the direct precipitation value. Recommendations to minimize these fractionations are discussed. Improvements to laboratory techniques for precipitating, weighing, extracting, and analyzing sulfur dioxide $\left(\mathrm{SO}_{2}\right)$ from the dissolved sulfide and sulfate samples are presented. Implementation of these improved procedures yields reliable sulfur isotopic analyses on a wide variety of sample types.
\end{abstract}

\section{INTRODUCTION}

Analysis of the isotopic composition of sulfate and sulfide dissolved in water has many applications in the study of the chemistry and evolution of hydrologic systems. Some of the more important applications include (1) determining the source of dissolved sulfur species, including natural sources such as gypsum or pyrite in rocks and anthropogenic sources such as fertilizer and acid rain, (2) identifying instances of mixing of ground water with sea water or formation water and (3) understanding chemical reactions occurring in ground-water systems, such as the oxidation of sulfide or microbial reduction of sulfate.

In late 1992 the U. S. Geological Survey (USGS) began a series of laboratory experiments to test sulfur isotope sample collection techniques then in use in the USGS. These techniques include (1) collection of dissolved sulfate from samples with concentrations of sulfate greater than $20 \mathrm{mg} / \mathrm{L}$ by direct precipitation as 
$\mathrm{BaSO}_{4},(2)$ collection of dissolved sulfate from dilute samples (less than $20 \mathrm{mg} / \mathrm{L}$ sulfate) on anion exchange resin and subsequent precipitation as $\mathrm{BaSO}_{4}$, and (3) collection of dissolved sulfide by nitrogen stripping and precipitation of sulfide as $\mathrm{Ag}_{2} \mathrm{~S}$ in an $\mathrm{AgNO}_{3}$ trap. The goal of the experiments was to examine whether the dissolved sulfur species were collected quantitatively and without isotopic fractionation by these methods. Because preparation of sulfide solutions in the laboratory was complicated by dissolved oxygen remaining in deionized water used in the experiments even after bubbling with nitrogen, questions about the sulfide collection technique and the importance of stripping sulfide before collection of dissolved sulfate for isotopic analysis were difficult to resolve. Consequently, a series of field experiments was conducted at sites where the ground water is both sulfate- and sulfide-bearing. This report presents results of the laboratory and field experiments that illustrate the capabilities and limitations of the three methods described above. Information is also provided on some alternative collection methods.

While much of this report is devoted to the description of field collection techniques, methods for preparation of samples in the laboratory for isotopic analysis are also discussed in detail, including procedures for preparation of pure $\mathrm{BaSO}_{4}$ from sulfate in solution and on anion exchange resin and purification of $\mathrm{Ag}_{2} \mathrm{~S}$ obtained by direct precipitation. $\mathrm{SO}_{2}$ is produced from $\mathrm{Ag}_{2} \mathrm{~S}$ samples by combining it with $\mathrm{Cu}_{2} \mathrm{O}$ and heating to $1050^{\circ} \mathrm{C}$ in a vacuum extraction line. $\mathrm{SO}_{2}$ is produced from $\mathrm{BaSO}_{4}$ by combining it with $\mathrm{Cu}_{2} \mathrm{O}$ and $\mathrm{SiO}_{2}$ glass and heating at $1150^{\circ} \mathrm{C}$. The isotopic composition of the $\mathrm{SO}_{2}$ gas is analyzed on an isotoperatio mass spectrometer. Standard gases used on the mass spectrometer and precision of the data are presented and compared to other published techniques.

\subsection{Sulfur isotope nomenclature}

Sulfur has four stable isotopes: ${ }^{32} \mathrm{~S},{ }^{33} \mathrm{~S},{ }^{34} \mathrm{~S}$ and ${ }^{36} \mathrm{~S}$ with approximate abundances of 95.02 percent, 0.75 percent, 4.21 percent and 0.02 percent respectively. The ratio of ${ }^{34} S$ to ${ }^{32} S$ is most commonly measured. Stable isotopic ratios of unknowns are reported in parts per thousand (per mill, also \%o) relative to a standard, according to the following equation:

$$
\delta^{34} S \text { (in per mill) }=\left\{\frac{\left.(34 S / 32 S)_{x}-(34 S / 32 S)_{s}\right]}{\left({ }^{34} S / 32 S\right)_{s}}\right\} \times 1000,
$$

where the abbreviations " $x$ " and " $s$ " indicate unknown and standard, respectively. Sulfur isotopic data are reported relative to the Vienna Canyon Diablo Troilite (VCDT) standard, which is defined by assigning a composition of -0.3 per mill exactly to the reference material IAEA-S-1 (formerly NZ 1, Gonfiantini and others, 1995). We do not report the data relative to the traditional Cañon Diablo Troilite (CDT) standard because this material has been demonstrated to be isotopically inhomogeneous (Beaudoin and others, 1994). Krouse and Coplen (1997) and 
Coplen and Krouse (1998) have recommended that sulfur isotope analyses no longer be reported relative to CDT.

Sulfur isotopic values are commonly reported to only one decimal place (0.0 per mill) because the uncertainty on these data is typically \pm 0.2 per mill, and data reported to hundreths of a per mill $(0.00$ per mill) would not be significant. Some data in this report are, however, reported to hundreths of a per mill because the values appear to be significant in this range and the added decimal place was used in calculations.

\section{FIELD COLLECTION TECHNIQUES}

\subsection{Sulfate Collection}

A reliable sulfur isotope analysis depends first of all on collecting a sufficiently large, unfractionated, uncontaminated sample in the field. The methods for collecting samples outlined below depend upon the dissolved sulfate concentration of the sample and upon what equipment is most convenient for use in the field. For samples with sufficiently high sulfate concentration (equal to or greater than $20 \mathrm{mg} / \mathrm{L} \mathrm{SO}_{4}{ }^{2-}$ ), dissolved sulfate is typically collected by direct precipitation as $\mathrm{BaSO}_{4}$. Previous studies utilizing this basic procedure include Thode and others (1961), van Everdingen and others (1982), Fouillac and others (1990), Busby and others (1991) and Fritz and others (1994). In these studies, water is collected in bottles and either brought to the laboratory for $\mathrm{BaSO}_{4}$ precipitation, or $\mathrm{BaCl}_{2}$ is added to an acidified sample in the field. The $\mathrm{BaSO}_{4}$ precipitate is filtered in the field or the laboratory. Anion exchange resin is used to collect sufficient dissolved sulfate from many liters of dilute water sample (less than $20 \mathrm{mg} / \mathrm{L}$ sulfate). This technique was used, for example, in the studies by Perry and others (1982; for details see Grundl, 1980) and Turk and others (1993). Steps for collection of sulfate by all of these techniques are discussed below and illustrated in flowchart form in figure 1a and b. Tables 1 and 2 list equipment and reagents needed to determine approximate sulfate concentration in the field, strip dissolved sulfide by bubbling nitrogen gas and collect highconcentration (greater than $20 \mathrm{mg} / \mathrm{L}$ ) sulfate-bearing water samples. Table 4 lists equipment needed to collect sulfate from low-concentration (less than $20 \mathrm{mg} / \mathrm{L}$ ) samples on anion exchange resin. 


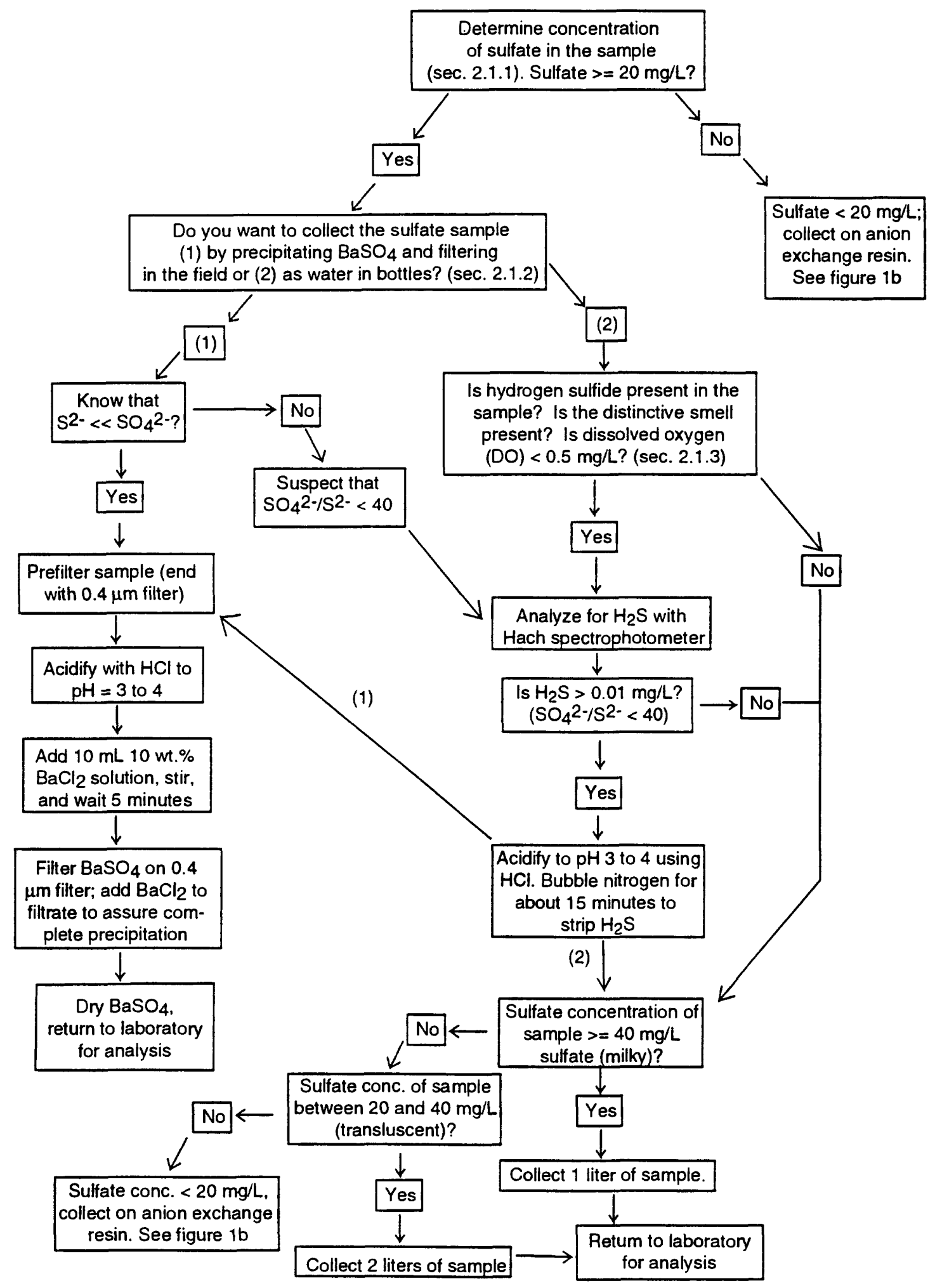

Figure 1a. Flowchart outlining steps in collection of high sulfate concentration (equal to or greater than $20 \mathrm{mg} / \mathrm{L} \mathrm{SO}_{4}{ }^{2-}$ ) samples. Sulfate may be collected by two different methods: (1) precipitating sulfate as $\mathrm{BaSO}_{4}$ and filtering in the field and (2) collecting samples as water in bottles. Flowchart includes factors to consider regarding whether or not to strip dissolved sulfide, if present. 


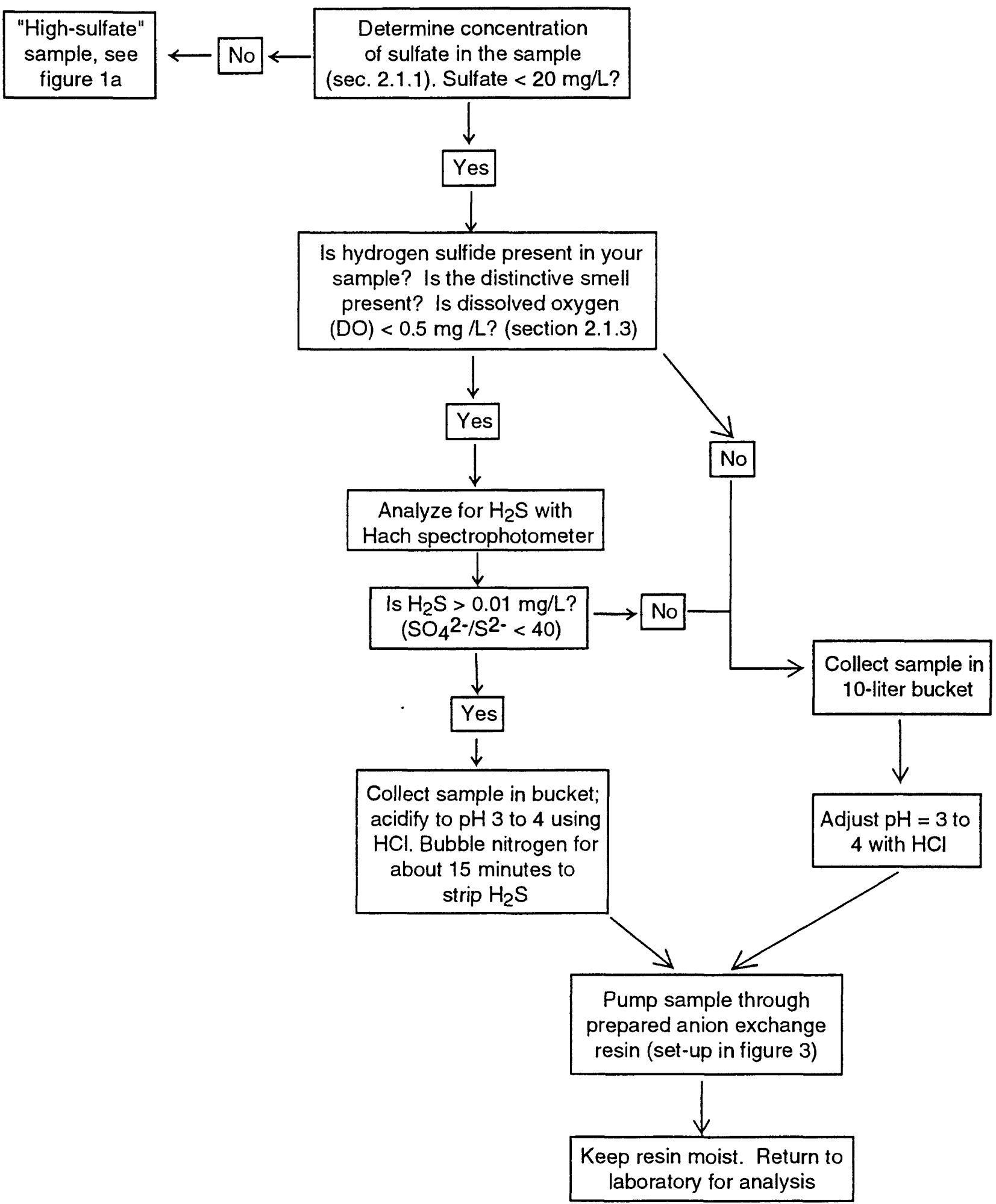

Figure 1b. Flowchart outlining steps for collection of dilute (less than $20 \mathrm{mg} / \mathrm{L}$ sulfate) samples on anion exchange resin. Collection techniques with and without nitrogen-stripping of $\mathrm{H}_{2} \mathrm{~S}$ are included. 
Table 1. Equipment used to determine approximate sulfate concentration in the field, strip dissolved sulfide by bubbling nitrogen gas, and collect high-concentration (greater than $20 \mathrm{mg} / \mathrm{L}$ ) sulfate-bearing water samples [mL, milliliters; L/min., liters per minute; od, outer diameter; id, inner diameter; " indicates inches]

Hach spectrophotometer (or equivalent) with appropriate reagents for sulfide and sulfate determinations.

Clean ${ }^{1}$ plastic bucket (at least 10 liter capacity).

Several clean clear beakers (plastic or glass, $250 \mathrm{~mL}$ ).

$\mathrm{pH}$ paper (with a range of $\mathrm{pH}$ units $=0-6$ ) or $\mathrm{pH}$ meter with buffer solutions for calibration.

Small plastic graduated cylinder for measuring out a few milliliters of $\mathrm{HCl}$.

$\mathrm{N}_{2}$ gas cylinder with regulator (CGA 580).

Flowmeter with range up to about $10 \mathrm{~L} / \mathrm{min} . \mathrm{N}_{2}$.

Tygon tubing or equivalent (od $=7 / 16^{\prime \prime}$ id $=5 / 16^{\prime \prime}$, wall thickness $\left.=1 / 16^{\prime \prime}\right)$.

Plastic sheeting or plastic wrap.

Small graduated cylinder, syringe or pipet for dispensing the $\mathrm{BaCl}_{2}$ solution.

Stirring rods (plastic preferred, large and small sizes for stirring samples in bucket and beakers).

Clean plastic 1-liter sample bottles with tight-fitting (e.g., polyseal) caps.

1 The term "clean" is defined as rinsed 3 times with deionized water so that residual sulfate from previous usage is minimized. After rinsing, equipment should be dried.

Table 2. Solutions needed for determining approximate sulfate concentration in the field, strip dissolved sulfide by bubbling nitrogen gas, and collect high-concentration (greater than $20 \mathrm{mg} / \mathrm{L}$ ) sulfate-bearing water samples

[mL, milliliters; $\mathrm{g}$, grams; $\mathrm{DI}$, deionized]]

Solution

Preparation

$1 \mathrm{M} \mathrm{HCl}$ solution ${ }^{1}$ (sulfate-free) in a dropper $\quad 40.4 \mathrm{~mL}$ of $38 \%$ commercial $\mathrm{HCl}$ solution in bottle. DI water to make $500 \mathrm{~mL} .^{2}$

$\mathrm{BaCl}_{2}$ solution (10 weight \%).

$58.65 \mathrm{~g} \mathrm{BaCl}_{2} \cdot 2 \mathrm{H}_{2} \mathrm{O}$ plus $441 \mathrm{~mL}$ DI water to make about $500 \mathrm{~g}$ of solution.

1 High quality deionized or distilled water and reagent-grade chemicals should be used in preparation of all solutions.

2 All acid dilutions should be made in a fume hood. Remember the rule of thumb "add acid to water". To make $1 \mathrm{M} \mathrm{HCl}$, pour about $400 \mathrm{~mL}$ DI water into a $500 \mathrm{~mL}$ volumetric flask, add 40.4 $\mathrm{mL} 38$ percent commercially-prepared $\mathrm{HCl}$, then add water to fill line on flask to make $500 \mathrm{~mL}$. Use a similar method (water followed by acid and top up with water) to make other acid dilutions described in this report. 


\subsubsection{Estimation of the sulfate content of the sample}

The concentration of dissolved sulfate in natural waters varies by several orders of magnitude, from less than one $\mathrm{mg} / \mathrm{L}$ (milligram per liter) in meteoric and fresh water to thousands of milligrams per liter in sea water and brines, with many ground waters containing tens or hundreds of milligrams per liter of sulfate. Determining the approximate sulfate concentration in a water sample is necessary to decide how large a sample to collect and how it should be collected for sulfur isotopic analysis.

If available, laboratory measurements of dissolved sulfate concentration of the water of interest should be used to determine the most appropriate sulfur isotope collection technique. Ion chromatographic, turbidimetric, titrimetric, gravimetric and other methods are used for precise laboratory determination of dissolved sulfate concentrations. (A more complete summary of these techniques is given in Tabatabai, 1992). Where previous analyses are not available, sulfate concentration must be estimated in the field. This can be accomplished by adding $\mathrm{BaCl}_{2}$ to an acidified sample, causing $\mathrm{BaSO}_{4}$ to form (if sulfate is present). Sulfate concentration is then estimated by eye from the turbidity of $\mathrm{BaSO}_{4}$ in the water sample. Details of this procedure are discussed below. Alternatively, a Hach spectrophotometer ${ }^{1}$ (or equivalent) can be used to measure the turbidity of the sample using specially-packaged aliquots of $\mathrm{BaCl}_{2}$ plus acid provided by the manufacturer.

Procedure -- Required equipment is listed in table 1. Collect $200 \mathrm{~mL}$ of water in a clean, clear beaker. Adjust the $\mathrm{pH}$ of the water to between 3 to 4 using sulfatefree $\mathrm{HCl}$, add 5 to $10 \mathrm{~mL}$ of 10 weight percent $\mathrm{BaCl}_{2}$ solution, stir, and observe the precipitation of the $\mathrm{BaSO}_{4}$. If the precipitate forms immediately, the sample becomes milky and opaque with precipitate (i.e., a printed page cannot be read if placed beneath the beaker while stirring), and a visible layer of precipitate forms on the bottom of the beaker when stirring ceases, then the sample contains greater than $100 \mathrm{mg} / \mathrm{L}$ sulfate. If the precipitate is slower to form (takes about one minute) and the water is cloudy but translucent (i.e., a printed page can be read if placed beneath the beaker while stirring), then the water contains about 20 to $100 \mathrm{mg} / \mathrm{L}$ sulfate. If the cloudiness is faint or a precipitate is not visible, then the concentration of sulfate is less than $20 \mathrm{mg} / \mathrm{L}$.

\subsubsection{Deciding how to collect the sulfate}

Three basic methods are used for collecting sulfate for isotopic analysis. Anion exchange resin is used to collect samples with $\mathrm{SO}_{4}{ }^{2-}$ less than $20 \mathrm{mg} / \mathrm{L}$. Two options are available for collecting "high-sulfate" samples $\left(\mathrm{SO}_{4}{ }^{2-}\right.$ greater than or equal to $20 \mathrm{mg} / \mathrm{L}$ ). These options (shown in figure 1a) are (1) collection

\footnotetext{
1 Use of firm, brand and trade names in this paper is for identification purposes only and does not constitute endorsement by the U. S. Geological Survey.
} 
of sulfate as $\mathrm{BaSO}_{4}$ in the field and (2) collection of bottles of water for precipitation of $\mathrm{BaSO}_{4}$ in the laboratory. All the sulfate collection methods can be complicated by the presence of dissolved sulfide. When a reduced ground-water sample is brought to the Earth's surface, dissolved sulfide will begin to oxidize to sulfate on contact with atmospheric oxygen. Because dissolved sulfide can have $\delta^{34} S$ values that are 65 per mill more negative than the sulfate, oxidation of dissolved sulfide can cause significant alteration of the isotopic composition of the sulfate. Dissolved sulfide can be removed by bubbling nitrogen gas through an acidified sample (discussed below).

Whether or not this procedure, which requires carrying a heavy tank of nitrogen gas into the field, is necessary depends on the relative concentrations of sulfide versus sulfate and how the samples are to be collected. Sulfate concentration will dictate whether anion exchange resin is used for samples that contain no dissolved sulfide. "High-sulfate" samples can be collected either in bottles or by precipitation of $\mathrm{BaSO}_{4}$ in the field. It is easier to collect water samples in bottles for precipitation in the laboratory unless transporting a large number of bottles is difficult. Then it may be preferable to precipitate and filter the sulfate in the field and carry the precipitates in small petri dishes or vials. Dissolved sulfide (concentration measured using the spectrophotometer) should be stripped from the sample before collecting the sulfate unless the following conditions are met. If the concentration of $\mathrm{SO}_{4}{ }^{2-}$ is much greater than $\mathrm{S}^{2-}$ (molar ratio of dissolved sulfate sulfur to sulfide sulfur is greater than 40 , see section 4.3.2) and the sulfate is collected either on anion exchange resin or by direct precipitation in the field, then the sulfate can be collected without first stripping $\mathrm{H}_{2} \mathrm{~S}$. Experiments on samples with sulfate concentrations significantly higher than sulfide concentrations (section 4.3.2, figure 12) show that the sulfate can be collected quickly in the field by these methods without detectable alteration of the sulfur isotopes. The sulfide should be stripped before collecting sulfate if the sample is to be collected in bottles, if the sulfate and sulfide concentrations differ by an order of magnitude or less, or if the relative concentrations of dissolved sulfide and sulfate are unknown.

\subsubsection{Measuring and stripping dissolved sulfide}

Dissolved sulfide concentration is easily measured with a field spectrophotometer. Details of measurement and dilution techniques are discussed in section 4.3.1. Required equipment is listed in table 1. If a spectrophotometer is not available, the distinctive smell of $\mathrm{H}_{2} \mathrm{~S}$ will indicate its presence. If a sample is to be stripped of $\mathrm{H}_{2} \mathrm{~S}$ prior to collection of sulfate for isotopic analysis, set up equipment as shown in figure 2.

Collect 8 to $10 \mathrm{~L}$ of the water in a $10 \mathrm{~L}$ bucket and quickly acidify with $\mathrm{HCl}$ to a $\mathrm{pH}$ of between 3 and 4 . Immediately begin bubbling $\mathrm{N}_{2}$ gas through the sample at a rate of at least 7 to $8 \mathrm{~L} /$ minute. Start a timer at the beginning of the $\mathrm{N}_{2}$ flow so that the stripping time can be measured. Swirl the gas dispersion tube(s) in 


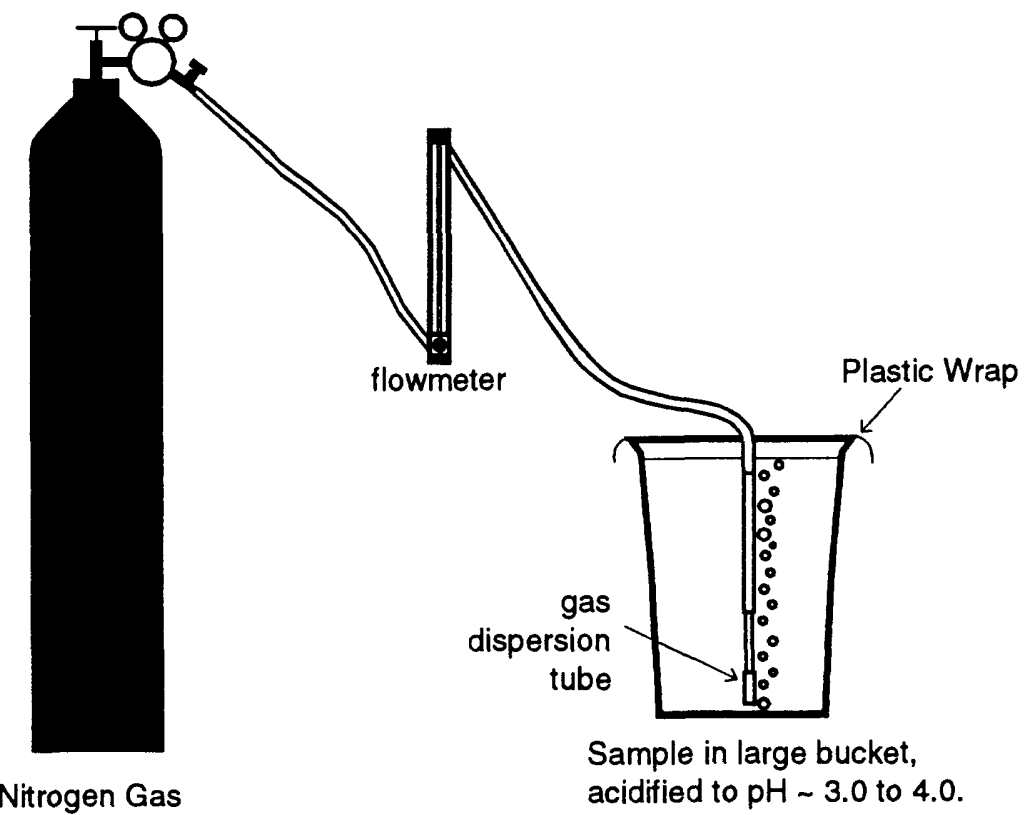

Figure 2. Set-up of equipment for stripping $\mathrm{H}_{2} \mathrm{~S}$ from an acidified water sample by bubbling nitrogen gas. Minotoring $\mathrm{N}_{2}$ gas flow rate with an appropriate flowmeter (range 0 to $10 \mathrm{~L} / \mathrm{min}$.) is recommended. Plastic (e.g., Tygon) tubing is used to conduct nitrogen from the $\mathrm{N}_{2}$ tank to the bucket.

the bucket to keep the water thoroughly mixed while stripping. Cover the bucket loosely with plastic wrap or a plastic sheet to minimize contact of the sample with atmospheric oxygen while stripping (a hole in the center of the plastic sheet or a gap between pieces of plastic wrap will facilitate stirring). Results of experiments to determine the time necessary to remove $\mathrm{H}_{2} \mathrm{~S}$ using this technique are discussed in section 4.3.1. If the recommended $\mathrm{N}_{2}$ flow rate is used, it will take about 10 minutes (for a sample with $0.2 \mathrm{mg} / \mathrm{L} \mathrm{S}^{2-}$ ) to 20 minutes (for a $3 \mathrm{mg} / \mathrm{L}$ sample) to strip the $\mathrm{H}_{2} \mathrm{~S}$. After $\mathrm{N}_{2}$ has bubbled for enough time to remove the $\mathrm{H}_{2} \mathrm{~S}$ (according to these guidelines) collect a sample of water from the bucket and analyze with the spectrophotometer to assure that the sulfide has been removed. Continue bubbling $\mathrm{N}_{2}$ while the analysis is being performed. Stripping should continue until $\mathrm{S}^{2-}$ concentration is less than or equal to $0.01 \mathrm{mg} / \mathrm{L}$.

Experiments discussed in section 4.3.1 show that time needed to remove the $\mathrm{H}_{2} \mathrm{~S}$ is dependent on both initial $\mathrm{S}^{2-}$ concentration and $\mathrm{N}_{2}$ flow rate. If initial dissolved sulfide concentration or $\mathrm{N}_{2}$ flow rate are unknown, and a 
spectrophotometer is not available, stripping should continue for 30 to 40 minutes, until the odor of $\mathrm{H}_{2} \mathrm{~S}$ is completely removed from the sample.

\subsubsection{Collection of "high-sulfate" (equal to or greater than $20 \mathrm{mg} / \mathrm{L}$ ) samples}

In bottles -- A water sample for isotopic analysis of dissolved sulfate is collected in 1 -liter plastic or glass bottles. If the sample was stripped of $\mathrm{H}_{2} \mathrm{~S}$, collect the stripped water from the bucket. If the water contains greater than $40 \mathrm{mg} / \mathrm{L}$ dissolved sulfate, or the sample was milky and opaque when $\mathrm{BaCl}_{2}$ was added, collect one liter of the sample. If the sample contains between 20 and $40 \mathrm{mg} / \mathrm{L}$ dissolved sulfate or the amount of $\mathrm{BaSO}_{4}$ that formed when $\mathrm{BaCl}_{2}$ was added made the sample cloudy but translucent, then collect two liters of the sample.

Precipitation of $\mathrm{BaSO}_{4}$ in the field -- The same method is followed as outlined for precipitation of $\mathrm{BaSO}_{4}$ in the laboratory (section 3.1), with minor simplification. Determine about how much sample will be needed to produce about $100 \mathrm{mg}$ $\mathrm{BaSO}_{4}$ (i.e., a sample volume that contains about $41 \mathrm{mg}$ of $\mathrm{SO}_{4}{ }^{2-}$ ) from the concentration of dissolved sulfate estimated above. The purpose is to produce more-than-adequate $\mathrm{BaSO}_{4}$ for isotopic analysis $\left(20 \mathrm{mg} \mathrm{BaSO}_{4}\right.$ is typically required) while avoiding excessive filtering. The sample is pre-filtered using a 47 $\mathrm{mm}$ diameter, $0.4 \mu \mathrm{m}$ opening polycarbonate membrane filter ${ }^{2}$ (a filter with larger openings can be used first if the sample contains a large amount of sediment or organic material, followed by filtering with a membrane filter). The sample is then acidified with $1 \mathrm{M} \mathrm{HCl}$ to $\mathrm{pH} 3$ to 4 and about $10 \mathrm{~mL}$ of 10 weight percent $\mathrm{BaCl}_{2}$ solution is added to precipitate $\mathrm{BaSO}_{4}$. The sample should be stirred thoroughly during the acidification and precipitation steps. After about 5 minutes, the $\mathrm{BaSO}_{4}$ is filtered using a membrane filter, rinsed with deionized water, and the precipitate stored in a small (50 $\mathrm{mm}$ diameter $\times 9 \mathrm{~mm}$ deep) plastic petri dish. A glass or plastic vial could also be used to store the precipitate. The $\mathrm{BaSO}_{4}$ should be dried in a dust-free place as soon as is practical. For more details on precipitation of $\mathrm{BaSO}_{4}$ see sections 3.1 and 4.3.2.

\subsubsection{Collection of sulfate from dilute (less than $20 \mathrm{mg} / \mathrm{L}$ ) samples using anion exchange resin}

Dissolved sulfate from dilute water samples is collected on anion exchange resin. This procedure allows the sulfate from a large volume of water to be concentrated in a small volume $(200 \mathrm{~mL})$ of $\mathrm{KCl}$ solution, thus facilitating the precipitation and filtering of $\mathrm{BaSO}_{4}$. More details on the resin procedure are given in section 4.2. Laboratory procedures for eluting the sulfate from the resin are discussed in section 3.2.

\footnotetext{
2For brevity, when a "membrane filter" is specified, it means a $47 \mathrm{~mm}$ diameter, $0.4 \mu \mathrm{m}$ opening polycarbonate membrane filter (see definitions), unless otherwise noted.
} 
Preparing the Resin -- Before the resin is used, sulfate on the new resin shipped from the manufacturer should be removed. This procedure should be followed even if the manufacturer has identified the resin as "sulfate-free". The sulfate should be eluted using a $3 \mathrm{M} \mathrm{KCl}$ solution; the procedure is discussed in section 3.2. The resin should be eluted twice to insure complete removal of the sulfate, but after the $\mathrm{BaSO}_{4}$ has been precipitated, it need not be filtered. The solutions can be discarded. The resin is loaded into drying tubes with 5 to $10 \mathrm{~mm}$ thick plugs of glass wool in the ends to hold the resin in the tube. Several liters of high-quality deionized water are pumped through the resin to remove excess chloride from the elution step (set-up of equipment shown in figure 3 is used). Deionized water is pumped through the resin until the conductivity of the water that has passed through the resin approaches that of the deionized water. The deionized water used in our laboratory has a conductivity of $1 \mu \mathrm{S} / \mathrm{cm}$ or less. The conductivity of water pumped through the resin is typically 2 to $4 \mu \mathrm{S} / \mathrm{cm}$ when rinsing is complete.

Capacity of the anion exchange resin -- Anion exchange resin has a relatively high, but limited capacity to collect dissolved sulfate anions. It is important not to exceed this capacity in order to avoid fractionation of the dissolved sulfate. The resin used for this study, Amberlite IRA-400 $\left(\mathrm{RN}\left(\mathrm{CH}_{3}\right)_{3}+\mathrm{Cl}^{-}\right)$, has a capacity of $1.2 \mathrm{meq} / \mathrm{mL}$. A milliliter of resin, therefore, has a total exchange capacity of 0.6 mmoles of $\mathrm{SO}_{4}{ }^{2-}$, so a half-full drying tube of resin (about $20 \mathrm{~mL}$ ) can collect up to $1.15 \mathrm{~g}$ of sulfate. Being conservative and assuming that it is best to avoid trying to collect more than $1 \mathrm{~g}$ of sulfate on $20 \mathrm{~mL}$ of resin, table 3 lists the maximum volume of water that should be passed through the Amberlite anion exchange resin.

Procedure -- For ground-water samples, the presence or absence of dissolved sulfide must be established. If the smell of $\mathrm{H}_{2} \mathrm{~S}$ is detected or the dissolved oxygen concentration of the water is less than $0.5 \mathrm{mg} / \mathrm{L}$, a field spectrophotometer should be used to measure the concentration of dissolved sulfide. If dissolved sulfide concentration is such that the molar ratio $\mathrm{SO}_{4}{ }^{2-} / \mathrm{S}^{2-}$ is less than 40 (origin of this ratio in section 4.3.2) or if sulfide is present and the sulfate concentration is unknown, the sulfide should be stripped as discussed in section 2.1.3. Some examples are given in table 5.

Required equipment for sulfate collection on anion exchange resin is listed in table 4. To collect the sulfate, the equipment is set up as shown in figure 3 . If the sample was stripped of $\mathrm{H}_{2} \mathrm{~S}$, then this stripped water is pumped through the anion exchange resin. If the water sample is sulfide-free, it is collected in a large plastic bucket and acidified with $1 \mathrm{M} \mathrm{HCl}$ to $\mathrm{pH} 3$ to 4 . The peristaltic pump is set on low speed and the sample is passed through the anion exchange resin at about 0.4 liters per minute. If the glass wool at the inflow end of the resin cartridge becomes clogged with debris, turn off the pump, disconnect the tubing and carefully replace the clogged glass wool with clean glass wool. When the sample has been pumped through the resin, decide whether more sample is 
needed in order to obtain a sulfate sample large enough for isotopic analysis (see table 3). Additional buckets of the ground-water sample, prepared by acidifying and stripping, if necessary, are then pumped through the same resin cartridge. After collection of the sulfate sample is complete, the resin must remain moist while it awaits sulfate elution and isotopic analysis. More information on sulfate collection on anion exchange resin is presented in section 4.2.

Collection of dissolved sulfate on anion exchange resin is complicated by the presence of dissolved chloride. $\mathrm{Cl}^{-}$will elute $\mathrm{SO}_{4}{ }^{2-}$ as the sample is passed through the anion exchange resin, resulting in low sulfate recovery and apparent fractionation of the sulfur isotopes. This interference is discussed in detail in sections 4.2.2. and 4.3.2. The problem is most pronounced in samples with very high chloride relative to sulfate (section 4.2.2).

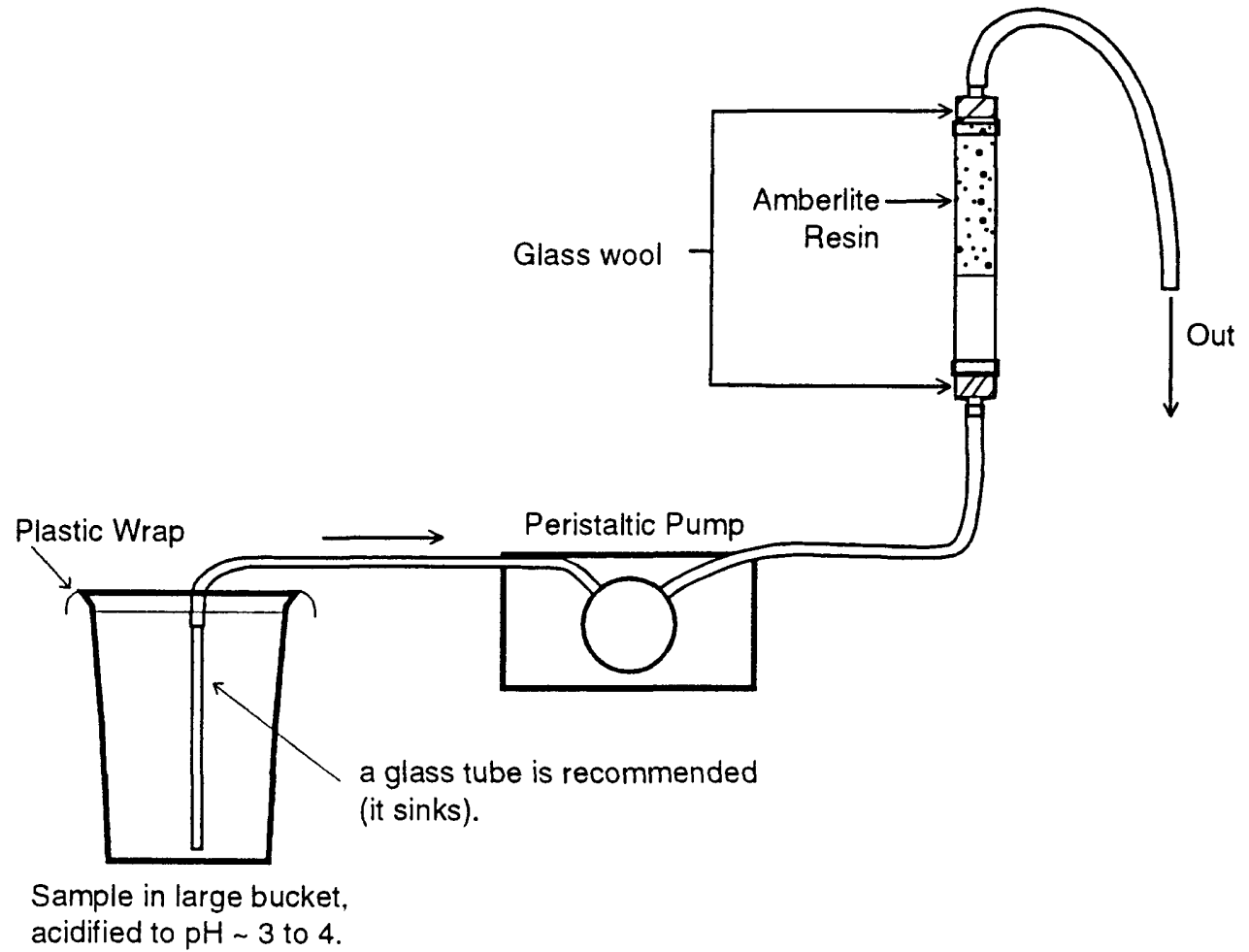

Figure 3. Set-up of equipment for collection of sulfate from dilute samples (less than $20 \mathrm{mg} / \mathrm{L}$ sulfate) on anion exchange resin. All tubing shown should be flexible, inert plastic (e.g., Tygon). Glass wool should be packed to a thickness of at least 5 to $10 \mathrm{~mm}$ in the ends of the drying tube to keep the resin in the tube. The same set-up of equipment is used to remove excess chloride from the resin after elution. In this case the bucket of sample is replaced by a large container of deionized water. 
Table 3. Capacity of the anion exchange resin

$[L$, liters; $\mathrm{mL}$, milliliters; $\mathrm{mg} / \mathrm{L}$, milligrams per liter]

Sulfate conc. of sample Maximum volume (mg/L) resin through resin 1

$\begin{array}{rcr}1 & 1000 \mathrm{~L} & 20 \mathrm{~L} \\ 5 & 200 \mathrm{~L} & 4 \mathrm{~L} \\ 10 & 100 \mathrm{~L} & 2 \mathrm{~L} \\ 20 & 50 \mathrm{~L} & 1 \mathrm{~L} \\ 2100 & 10 \mathrm{~L} & 200 \mathrm{~mL} \\ 2500 & 2 \mathrm{~L} & 40 \mathrm{~mL}\end{array}$

${ }^{1}$ to collect $20 \mathrm{mg}$ of sulfate, considered a minimum target sample size. This is half of the "optimal" $40 \mathrm{mg}$ sample size.

2 Samples with these sulfate concentrations are not normally collected on anion exchange resin. Direct precipitation methods are usually easier and give better results when the sample contains significant chloride (see section 4.3.2). Methods to collect "high-sulfate" samples are discussed in section 2.1.4.

Table 4. Equipment needed to collect dissolved sulfate from dilute samples (less than $20 \mathrm{mg} / \mathrm{L}$ ) using anion exchange resin

[mg/L, milligrams per liter; $M$, molar; DI, deionized; V, volt]

$\mathrm{pH}$ paper $(\mathrm{pH}=0-6)$ or $\mathrm{pH}$ meter with buffer solutions for calibration.

$1 \mathrm{M} \mathrm{HCl}$ in dropper bottle or larger bottle, as needed. For preparaton, see Table 2.

Syringe or graduated cylinder for measuring $\mathrm{HCl}$.

Clean bucket (capacity at least 10 liters).

Plastic paddle for stirring 10 liters of water in the bucket.

Plastic wrap or plastic sheeting.

Amberlite (IRA-400) anion exchange resin in plastic "drying" tubes, eluted to remove all sulfate and rinsed with DI water.

Pyrex glass wool, to hold resin in "drying" tubes.

Peristaltic pump (with automobile, marine or $12 \mathrm{~V}$ gel cell battery for power).

Tygon and glass or rigid plastic (e.g., Teflon) tubing. 
Table 5. Guidelines for stripping sulfide from samples with low sulfate concentrations [mg/L, milligrams per liter]

Sulfate Concentration
Strip sulfide if $\mathrm{S}^{2-}$ concentration exceeds

$0.167 \mathrm{mg} / \mathrm{L}$

$0.083 \mathrm{mg} / \mathrm{L}$

$0.042 \mathrm{mg} / \mathrm{L}$

\subsection{Dissolved Sulfide Collection Methods}

The sulfur isotopic composition of dissolved sulfide in reduced ground-water samples can yield important clues to the types of chemical reactions occurring in an aquifer. Several workers have used direct precipitation methods to obtain samples of the dissolved sulfide for isotopic analysis. Typically these techniques include adjustment of $\mathrm{pH}$ to either strongly basic or strongly acid conditions and addition of a reagent to precipitate the sulfide. Speciation of sulfide, shown in this reaction:

$$
\begin{array}{lc}
\mathrm{H}_{2} \mathrm{~S} \leftrightarrow \mathrm{H}^{+}+\mathrm{HS}^{-} \leftrightarrow 2 \mathrm{H}^{+}+\mathrm{S}^{2-} \\
\text { Acid Neutral } \quad \text { Basic }
\end{array}
$$

indicates that at acid or basic conditions the species $\mathrm{H}_{2} \mathrm{~S}$ and $\mathrm{S}^{2-}$ (respectively) will predominate. For example, Rye and others (1981) precipitated ZnS from samples treated with $\mathrm{KOH}$ and zinc acetate and van Everdingen and others (1982) precipitated CdS from samples treated with $\mathrm{NaOH}$ and cadmium acetate. Fouillac and others (1990) precipitated CdS from their samples with acidified cadmium acetate and Busby and others (1991) used a similar technique. In spite of their careful technique, Busby and others (1991) noted that successful sulfur isotopic $\left(\delta^{34} S\right)$ analyses were obtained on only 70 percent of the samples for which they attempted to collect sulfide.

To overcome these difficulties, as well as the difficulty of filtering large volumes of water in the field for dilute sulfide-bearing samples, Moncaster and Bottrell (1991) reported on a degassing apparatus used to strip $\mathrm{H}_{2} \mathrm{~S}$ from sulfidebearing ground water using a nitrogen stream and precipitating the sulfide as $\mathrm{Ag}_{2} \mathrm{~S}$ in an $\mathrm{AgNO}_{3}$ trap. Plummer and Busenberg (unpublished data, 1985) developed a method to extract dissolved sulfide which utilizes the same principles as the Moncaster and Bottrell (1991) degassing method. The apparatus used in this method is listed in table 6, necessary reagents are listed in table 7, and equipment set-up is illustrated in figure 4. Advantages of the "degassing" or "nitrogen stripping" procedure include the ability to concentrate sulfide from a large volume of dilute sample into a small amount of $\mathrm{AgNO}_{3}$ solution and to precipitate dissolved sulfide as pure $\mathrm{Ag}_{2} \mathrm{~S}$. $\mathrm{Ag}_{2} \mathrm{~S}$ has several advantages over $\mathrm{CdS}$ and $\mathrm{ZnS}$ including (1) $\mathrm{Ag}_{2} \mathrm{~S}$ is about 10 orders of magnitude less soluble than CdS or ZnS (Lide and Frederikse, 1994, p. 4-47, 4- 
96 and 4-113), (2) $\mathrm{Ag}_{2} \mathrm{~S}$ is stable in air (does not oxidize), and (3) $\mathrm{Ag}_{2} \mathrm{~S}$ can be precipitated as pure $\mathrm{Ag}_{2} \mathrm{~S}$ in the $\mathrm{AgNO}_{3}$ trap and, after drying, is ready for combustion on the vacuum extraction line. It is typically necessary to convert $\mathrm{CdS}$ and $\mathrm{ZnS}$ to $\mathrm{Ag}_{2} \mathrm{~S}$ in the laboratory before $\mathrm{SO}_{2}$ can be obtained for sulfur isotopic analysis (Rye and others, 1981).

Procedure for $S^{2-}$ collection by nitrogen stripping -- The Hach spectrophotometer should be used to analyze the dissolved sulfide concentration of the water of interest to confirm that sufficient $\mathrm{S}^{2-}$ is present for isotopic analysis. If the $\mathrm{S}^{2-}$ concentration is greater than $0.03 \mathrm{mg} / \mathrm{L}$, then use table 8 to decide how many carboys to fill for the sulfide extraction.

Required equipment is listed in table 6. Set up the equipment as shown in figure 4. One or two additional carboys can be placed in series with the first carboy if needed (figure 15). When the equipment is set up, begin filling the carboys. The hose from the pump or well should discharge in the bottom of the carboy. It is important to fill the carboys as quickly as well conditions allow. If the carboys are filled slowly, $\mathrm{H}_{2} \mathrm{~S}$ will probably be lost to the atmosphere, producing fractionation of the sulfur isotopes (see section 4.5.2 and Szaran, 1996). After filling, the flow of water into the carboy should continue until at least 20 percent of the water that originally filled the carboy has been displaced from the bottom of the carboy upward by water that has not come in contact with the atmosphere. Next, pour some water out of the top of the carboy to create a small head space, add $100 \mathrm{~mL}$ of $6 \mathrm{~N}$ sulfuric acid (sulfur isotope exchange between sulfate and sulfide is very slow at low temperature ${ }^{3}$, see Pearson and Rightmire, 1980), attach venting / filling cap with gas dispersion tubes to carboy, connect all plastic tubing and turn on nitrogen flow. A timer should be started along with the $\mathrm{N}_{2}$ flow to measure the length of the extraction. The carboy is rocked in order to mix the acid thoroughly with the water sample. A maximum flow rate of $1.4 \mathrm{~L} \mathrm{~N}_{2}$ per minute was determined (section 4.5.4) for the equipment shown in figure 4. The extraction should be allowed to continue for at least 3 hours to maximize recovery of the sample's sulfide and thereby minimize isotopic fractionation associated with this method. Dependence of sulfur isotopic composition of the $\mathrm{Ag}_{2} \mathrm{~S}$ on the length of the extraction is discussed in section 4.5. Alternatively, the $\mathrm{Ag}_{2} \mathrm{~S}$ can be collected for a shorter time (30 minutes, or until $30-40 \mathrm{mg}$ of $\mathrm{Ag}_{2} \mathrm{~S}$ have been collected). The sulfur isotopic composition of sulfide in the ground water can be calculated if the kinetic fractionation factor is known (section 4.5.5 and 4.5.6).

\footnotetext{
${ }^{3}$ Robinson (1973) measured rates of exchange of ${ }^{34} \mathrm{~S}_{-}{ }^{32} \mathrm{~S}$ between $\mathrm{H}_{2} \mathrm{~S}$ and $\mathrm{HSO}_{4}{ }^{-}$and concluded that below $200^{\circ} \mathrm{C}$ the exchange is "very slow" (p. 447). Sulfur isotopic exchange during the time needed for a sulfide collection experiment should not be significant even at elevated temperatures found in some ground waters $\left(60-100^{\circ} \mathrm{C}\right)$. It is also true, however, that reaction rate increases approximately two-fold for a $10^{\circ} \mathrm{C}$ increase in temperature for this exchange reaction. To avoid any possible isotopic exchange between sulfuric acid and dissolved sulfide, $\mathrm{HCl}$ can be used to acidify the sample. In this case, the addition of a potassium acid phthalate trap before the silver nitrate trap is recommended. Follow procedure discussed in section 4.5.4.
} 
Table 6. Equipment needed for sulfide-collection-by-nitrogen-stripping technique

$[\mathrm{L}$, liters; $\mathrm{mL}$, milliliters, od, outer diameter; inner diameter; ", indicates inches; $\mu \mathrm{m}$, micrometers]

$\mathrm{N}_{2}$ gas cylinder with regulator.

Flowmeter (range up to at least $2 \mathrm{~L}$ per minute $\mathrm{N}_{2}$ ).

3 plastic carboys, 50 liter capacity (make mark on side indicating 50-liter level).

Venting/Filling caps for 50 liter carboys.

Branching connectors, rigid plastic tubing (od $=5 / 16^{\prime \prime}$ id $=3 / 16^{\prime \prime}$, wall thickness $=1 / 16^{\prime \prime}$ ), and gas dispersion tubes for bubbling $\mathrm{N}_{2}$ through sample in carboys.

Three $250 \mathrm{~mL}$ plastic graduated cylinders with lipped tops cut off for Traps 1 to 3 .

Rubber stoppers (to fit graduated cylinders) with two holes; rigid plastic tubing inserted.

Clean 1/4" glass tubes (with fire-polished ends) for $\mathrm{AgNO}_{3}$ trap. Tubes should be of sufficient length to extend from just below the rubber stopper to about an inch from the bottom of the $250 \mathrm{~mL}$ cylinder.

Rigid plastic tubing for piping into traps, od $=1 / 4^{\prime \prime}$ id $=1 / 8^{\prime \prime}$, wall thickness $=1 / 16^{\prime \prime}$.

Tygon tubing or equivalent (od $=7 / 16^{\prime \prime}$ id $=5 / 16^{\prime \prime}$, wall thickness $=1 / 16^{\prime \prime}$ and od $=5 / 8^{\prime \prime}$, id = $1 / 4$ ", wall thickness $=3 / 16^{\prime \prime}$ ). Use thick-walled tubing between $\mathrm{N}_{2}$ cylinder and carboy and between carboys (if needed).

Plastic couplings for tubing.

Squeeze bottle of deionized water for rinsing precipitate and large bottle or carboy of deionized water for rinsing equipment.

Filter funnel and filter flask $(250 \mathrm{~mL})$.

Peristaltic pump with battery or hand pump.

Polycarbonate membrane filters ( $0.4 \mu \mathrm{m}$ opening).

Small plastic petri dishes or vials to hold filters with $\mathrm{Ag}_{2} \mathrm{~S}$ precipitate.

Blunt-tip tweezers (forceps).

Plastic graduated cylinder for measuring $100 \mathrm{~mL}$ of sulfuric acid.

Protective goggles.

Rubber gloves for handling acid and $\mathrm{AgNO}_{3}$ solution.

Test tube brush for cleaning equipment. 
Table 7. Solutions needed for sulfide-collection-by-nitrogen-stripping technique [g, grams; $\mathrm{N}$, normal (see definitions); L, liter; $\mathrm{mL}$, milliliters, DI, deionized]

Solution

10 weight $\% \mathrm{AgNO}_{3}$ solution stored in an opaque dark-colored plastic bottle.

$6 \mathrm{~N}$ sulfuric acid $\left(\mathrm{H}_{2} \mathrm{SO}_{4}\right)$
Preparation

$20 \mathrm{~g} \mathrm{AgNO}_{3}$ mixed with $180 \mathrm{~mL}$ DI water to make about $200 \mathrm{~g}$ solution.

$166 \mathrm{~mL} 96.6 \%$ commercial $\mathrm{H}_{2} \mathrm{SO}_{4}$ solution, add to $\mathrm{DI}$ water to make $1 \mathrm{~L}$. See note $(2)$ in Table 2.

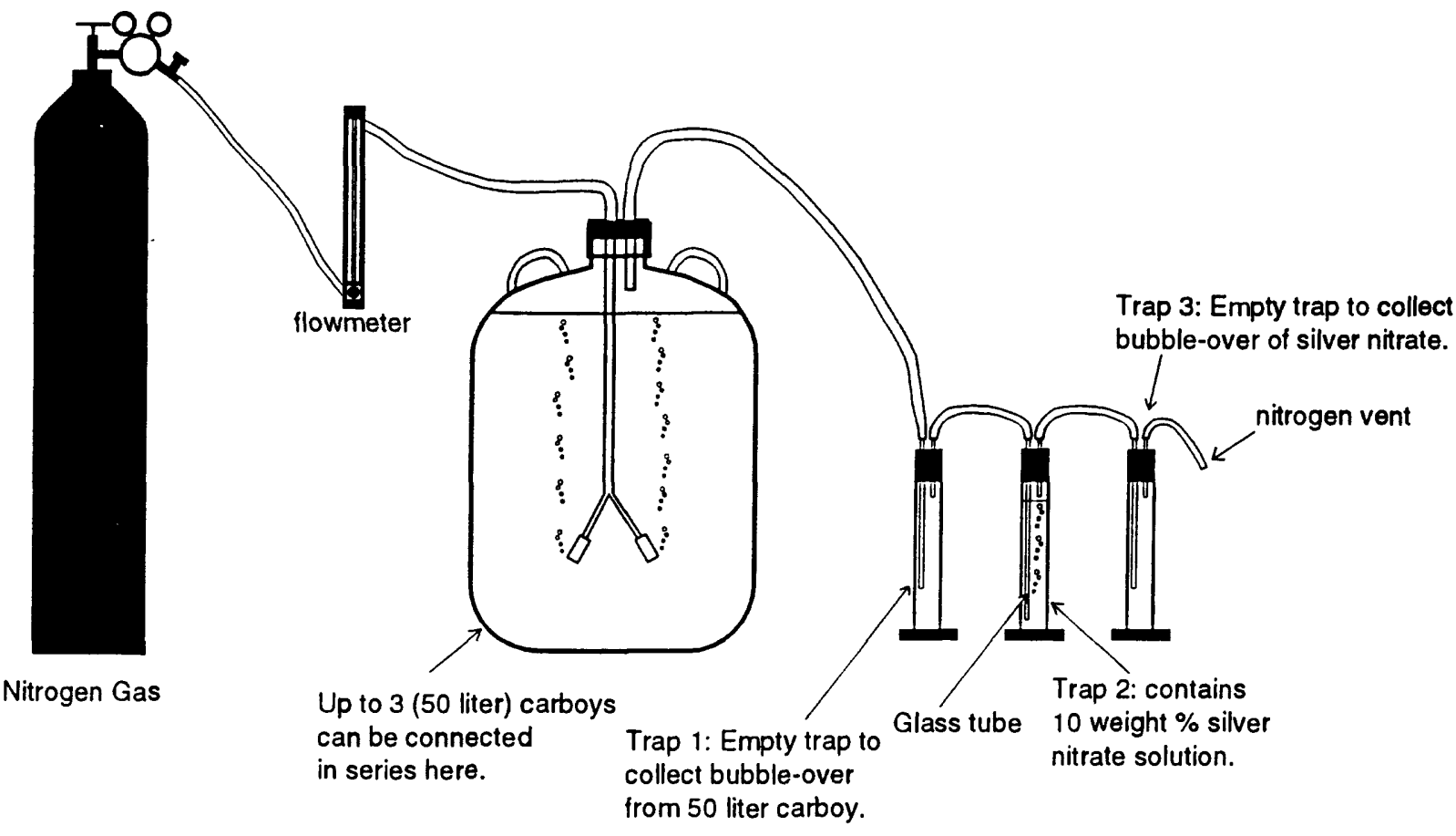

Figure 4. Set-up of equipment for nitrogen stripping of $\mathrm{H}_{2} \mathrm{~S}$ from a carboy of acidified ground water and collection of dissolved sulfide as $\mathrm{Ag}_{2} \mathrm{~S}$ in a $\mathrm{AgNO}_{3}$ trap. Rigid plastic tubing is used inside the carboy and traps (a glass tube is used in the $\mathrm{AgNO}_{3}$ trap) and flexible plastic tubing is used to connect the nitrogen tank to the carboy and traps. A flowmeter should be used to set and maintain the nitrogen-gas flow rate at the maximum sustainable by the equipment. The traps are made from plastic $250-\mathrm{mL}$ graduated cylinders that have had the lipped tops sawn off. The first trap is empty and is used to prevent transfer of the water sample from the carboy into the silver nitrate trap. The second trap contains 10 weight percent $\mathrm{AgNO}_{3}$ solution; sulfide is collected in this trap as $\mathrm{Ag}_{2} \mathrm{~S}$. In the field, the second trap can be stabilized by clamping it to a ring-stand (tripod base). The third trap is empty and is used to collect bubble-over of $\mathrm{AgNO}_{3}$ and $\mathrm{Ag}_{2} \mathrm{~S}$ from trap 2. 
Table 8. Volume of water sample needed for various sulfide concentrations [mg, milligrams; $\mathrm{mg} / \mathrm{L}$, milligrams per liter]

\begin{tabular}{ccc} 
Conc. of $\mathrm{S}^{2-}$ in sample & Volume of sample & $\mathrm{Ag}_{2} \mathrm{~S}_{\text {produced }}$ \\
$3 \mathrm{mg} / \mathrm{L}$ & 50 liters & $1159 \mathrm{mg}$ \\
$0.5 \mathrm{mg} / \mathrm{L}$ & 50 liters & $193 \mathrm{mg}$ \\
$0.1 \mathrm{mg} / \mathrm{L}$ & 50 liters & $39 \mathrm{mg}$ \\
$0.1 \mathrm{mg} / \mathrm{L}$ & 100 liters & $77 \mathrm{mg}$ \\
$0.05 \mathrm{mg} / \mathrm{L}$ & 100 liters & $39 \mathrm{mg}$ \\
$0.05 \mathrm{mg} / \mathrm{L}$ & 150 liters & $58 \mathrm{mg}$ \\
$0.03 \mathrm{mg} / \mathrm{L}$ & 150 liters & $35 \mathrm{mg}$ \\
\hline
\end{tabular}

When ending the extraction, disconnect the tubing between the traps and carboys, starting at the "downstream" end of the apparatus, and then turn off the nitrogen flow. Collect a sample of water from the carboy and analyze its $\mathrm{S}^{2-}$ concentration with the Hach spectrophotometer to determine how much of the sulfide remained in solution at the end of the extraction. The $\mathrm{Ag}_{2} \mathrm{~S}$ is carefully filtered on a membrane filter. After filtering, the $\mathrm{AgNO}_{3}$ solution is saved for reuse in additional sulfide extractions. The $\mathrm{Ag}_{2} \mathrm{~S}$ is rinsed with deionized water and stored in a plastic petri dish or vial. Dry the $\mathrm{Ag}_{2} \mathrm{~S}$ in a dust-free environment as soon as is practical.

In experiments on this sulfide collection technique (discussed in section 4.5), the sulfur isotopic composition of the $\mathrm{Ag}_{2} \mathrm{~S}$ that forms in the $\mathrm{AgNO}_{3}$ trap is initially enriched in ${ }^{32} S$ relative to the sulfide in solution and approaches the $\delta^{34} S$ of the original sulfide in solution with time. $\delta^{34} \mathrm{~S}$ of $\mathrm{Ag}_{2} \mathrm{~S}$ collected during a three-hour extraction is 0.2 to 0.5 per mill more negative than $\mathrm{Ag}_{2} \mathrm{~S}$ collected from the same water sample by direct precipitation. Laboratory experiments suggest that even six-hour extractions are not sufficient to remove all the dissolved sulfide in the carboy(s) and eliminate the observed sulfur isotopic fractionation.

Other disadvantages to this sulfide collection technique include the amount of equipment required, the length of time required for an extraction (usually at least 3 hours unless the short-collection method is used) and the loss of sulfide during the filling of carboys. Advantages of this technique include ability to collect sulfide from dilute samples and production of a pure $\mathrm{Ag}_{2} \mathrm{~S}$ precipitate. Sulfur isotopic fractionation observed in the experiments is small and section 4.5.6 outlines suggestions to minimize this fractionation. The method used in this study imparts a consistent shift to the $\delta^{34} S$ values of about -0.2 to -0.5 per mill. In contrast, for samples collected with their degassing apparatus, Moncaster and Bottrell (1991) reported shifts in excess of 1 per mill in both the positive and negative directions from their direct precipitation control experiments. 
At wells producing water with high $\mathrm{S}^{2-}$ concentration, it may be preferable to collect the sulfide by direct precipitation of $\mathrm{Ag}_{2} \mathrm{~S}$ by adding $\mathrm{AgNO}_{3}$ to the water sample. The main disadvantage of this technique is that if $\mathrm{AgNO}_{3}$ were added to a very dilute sulfide-bearing water, a tremendous amount of filtering in the field would be required to separate a small amount of $\mathrm{Ag}_{2} \mathrm{~S}$ from a large volume of water. Second, $\mathrm{AgCl}$ will coprecipitate with the $\mathrm{Ag}_{2} \mathrm{~S}$ when the $\mathrm{AgNO}_{3}$ is added, so the $\mathrm{Ag}_{2} \mathrm{~S}$ obtained is impure. However, treating the mixed precipitate with $\mathrm{NH}_{4} \mathrm{OH}$ solution has been found to be very effective in removing the $\mathrm{AgCl}$ to produce a pure $\mathrm{Ag}_{2} \mathrm{~S}$ precipitate (see sections 4.4.2 and 4.4.3).

Procedure for $\mathbf{S}^{2-}$ collection by direct precipitation -- To collect dissolved sulfide by direct precipitation, first determine the dissolved sulfide concentration of the sample using the field spectrophotometer. Then determine how much sample is needed to produce sufficient $\mathrm{Ag}_{2} \mathrm{~S}$ for isotopic analysis (collect at least $5 \mathrm{mg}$ sulfide, that is, about $39 \mathrm{mg} \mathrm{Ag} 2 \mathrm{~S}$, see table 9). The sulfide concentration measured above also will assist in determining how much 10 weight percent $\mathrm{AgNO}_{3}$ to add to the sample.

Adding $\mathrm{AgNO}_{3}$ is a critical step because, if the amount of $\mathrm{Ag}^{+}$added is insufficient to precipitate the available sulfide, the $\mathrm{Ag}_{2} \mathrm{~S}$ produced will be fractionated (see section 4.4.1). If a large excess of $\mathrm{AgNO}_{3}$ is added, however, a large amount of $\mathrm{AgCl}$ may be produced, which will greatly slow the filtering process. Results of the field experiments, summarized in section 4.4.2, suggest that a three-times excess of $\mathrm{AgNO}_{3}$ is an appropriate amount to add to the water sample for direct precipitation of $\mathrm{Ag}_{2} \mathrm{~S}$. Table 9 shows the amount of fresh 10 weight percent $\mathrm{AgNO}_{3}$ solution to add to samples with different sulfide concentrations and the amount of $\mathrm{Ag}_{2} \mathrm{~S}$ that should be obtained from a liter of water with these sulfide concentrations.

Table 9. Guidelines for collection of sulfide by direct precipitation [mg, milligrams; $\mathrm{mL}$, milliliters; $\mathrm{mg} / \mathrm{L}$, milligrams per liter]

\begin{tabular}{|c|c|c|c|}
\hline $\begin{array}{l}\mathrm{S}^{2-} \text { concentration of } \\
\text { sample }(\mathrm{mg} / \mathrm{L})\end{array}$ & 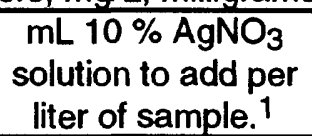 & $\begin{array}{l}\mathrm{mg} \mathrm{Ag}_{2} \mathrm{~S} \text { produced } \\
\text { per liter of sample. }\end{array}$ & $\begin{array}{r}\text { Liters of sam } \\
\text { process to } \mathrm{me} \\
\mathrm{mg} \mathrm{Ag}_{2} \mathrm{~s}\end{array}$ \\
\hline 3.0 & 0.88 & 23.2 & 1.7 \\
\hline 2.5 & 0.73 & 19.3 & 2.0 \\
\hline 2.0 & 0.58 & 15.5 & 2.5 \\
\hline 1.5 & 0.44 & 11.6 & 3.4 \\
\hline 1.0 & 0.29 & 7.7 & 5.0 \\
\hline 0.5 & 0.15 & 3.9 & 10.1 \\
\hline
\end{tabular}

1 These volumes will yield a 3-times excess of silver relative to sulfide sulfur present in one liter of sample. 
After determining how much sample to collect and how much $\mathrm{AgNO}_{3}$ to add, fill a clean bucket, large beaker, or bottle with water directly from the well as quickly as possible and allow the bucket to overflow and the water that contacted air in the initial filling to be displaced. Quickly pour off some of the water, retaining the amount of sample needed, and add a three-times excess of $\mathrm{AgNO}_{3}$ solution (see table 9). Stir and allow precipitate to form for about 5 minutes. Cover bucket with plastic wrap to keep out dust and debris. Using a filter flask, funnel and hand pump, filter the mixed precipitate on a membrane filter. Change filters, using several if necessary, to filter all the precipitate. Store each filter in a plastic petri dish or vial. If the flow of water from the well is slow, precipitate $\mathrm{Ag}_{2} \mathrm{~S}$ from several small volumes of water instead of one large volume in order to minimize the loss of $\mathrm{H}_{2} \mathrm{~S}$ to the atmosphere while the bucket fills.

Direct precipitation of dissolved sulfide as $\mathrm{Ag}_{2} \mathrm{~S}$ may be preferable to sulfide collection by nitrogen stripping, especially for water containing more than about $0.5 \mathrm{mg} / \mathrm{L}$ dissolved sulfide. Typically, a smaller amount of $\mathrm{Ag}_{2} \mathrm{~S}$ will be produced than that produced in a nitrogen-stripping extraction and the $\mathrm{Ag}_{2} \mathrm{~S}$ will not be pure, but this latter problem is remedied by treatment of the precipitate with $\mathrm{NH}_{4} \mathrm{OH}$ solution (for details, see section 4.4.2). Advantages of the direct precipitation method for collection of dissolved sulfide include (1) less bulky equipment required, (2) for most samples, it will take less time to collect the sulfide by direct precipitation than the three hour extraction time required (unless the short-collection method is used, see section 4.5 .5 and 4.5.6) for the nitrogenstripping technique (filtering can be time-consuming, however) and (3) addition of sufficient $\mathrm{Ag}^{+}$to precipitate all the sulfide as $\mathrm{Ag}_{2} \mathrm{~S}$ should produce an unfractionated sample for sulfur isotope analysis. 


\section{LABORATORY METHODS}

Laboratory preparation for both high- and low-concentration sulfate samples are illustrated in flowchart form in figure 5. Preparation of solutions utilized in these methods is outlined in table 10.

Table 10. Solutions needed for preparation of $\mathrm{BaSO}_{4}$ from dissolved sulfate samples collected as water in bottles and on anion exchange resin [M, molar (see definitions); $\mathrm{g}$, grams; $\mathrm{mL}$, milliliters]

Solution

$3 \mathrm{M} \mathrm{KCl}$ solution

$1 \mathrm{M} \mathrm{HCl}$ solution (sulfate-free) in a dropper bottle.

$\mathrm{BaCl}_{2}$ solution (10 weight percent).

6 weight $\% \mathrm{H}_{2} \mathrm{O}_{2}$ solution

saturated bromine solution ("Br-water") 4
Preparation

$223.74 \mathrm{~g} \mathrm{KCl}$ (reagent-grade, low sulfate) in $1000 \mathrm{~mL}$ volumetric flask, add deionized (DI) water to make $1000 \mathrm{~mL} .1$

$40.4 \mathrm{~mL}$ of $38 \%$ commercial $\mathrm{HCl}^{2}$ solution in DI water to make $500 \mathrm{~mL}^{3}$

$58.65 \mathrm{~g} \mathrm{BaCl}_{2} \cdot 2 \mathrm{H}_{2} \mathrm{O}$ plus $441 \mathrm{~mL}$ (DI) water to make about $500 \mathrm{~g}$ of solution.

Measure $95.5 \mathrm{~mL}$ of $30 \% \mathrm{H}_{2} \mathrm{O}_{2}$ solution, pour into a $500 \mathrm{~mL}$ volumetric flask. Add deionized water to make $500 \mathrm{~mL}$ of solution.

10 to $20 \mathrm{~mL}$ reagent-grade bromine in about $400 \mathrm{~mL}$ of deionized water.

1 Dissolution of $223.74 \mathrm{~g}$ of KCl crystals causes the solution to cool significantly. This is due to the $\mathrm{KCl}$ absorbing its latent heat of crystallization from the deionized water. To make a more precise $3 \mathrm{M} \mathrm{KCl}$ solution do not fill the volumetric flask completely to the $1000 \mathrm{~mL}$ line until the solution has come to room temperature.

2 High quality deionized or distilled water and reagent-grade chemicals should be used in preparation of all solutions.

3 All acid dilutions should be made in a fume hood. Remember the rule of thumb "add acid to water". To make $1 \mathrm{M} \mathrm{HCl}$, pour about $400 \mathrm{~mL}$ DI water into a $500 \mathrm{~mL}$ volumetric flask, add 40.4 $\mathrm{mL} 38$ percent commercially-prepared $\mathrm{HCl}$, mix, and then add water to fill line on flask to make $500 \mathrm{~mL}$. Use a similar method (water followed by acid and top up with water) to make other acid dilutions described in this report.

${ }^{4}$ Always prepare, use and store $\mathrm{Br}$-water in a fume hood. Wear appropriate gloves, lab coat and goggles when preparing and using this solution. To prepare, pour about $400 \mathrm{~mL}$ of deionized water into a $500 \mathrm{~mL}$ Teflon PFA or heavy-duty glass reagent bottle. Add a small amount (10-20 $\mathrm{mL}$ ) of reagent-grade bromine. Close bottle tightly with a Teflon cap or stopper and shake to mix. After mixing, some undissolved bromine should remain in the bottom of the bottle. 


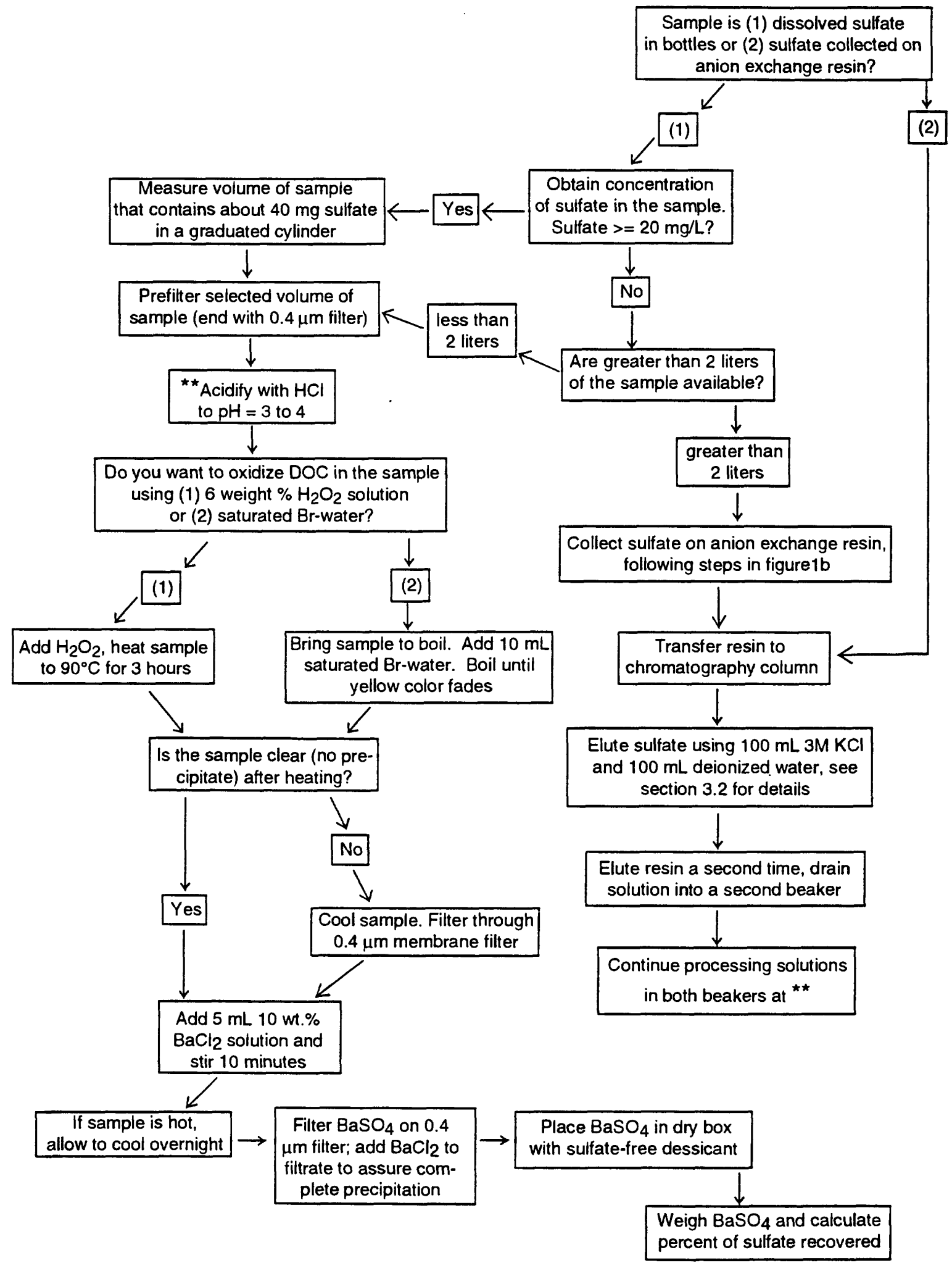

Figure 5. Flowchart outlining steps in laboratory preparation of dissolved sulfate samples for sulfur isotopic analysis. Methods for preparation of samples collected both as water in bottles and on anion exchange resin and all essential steps including pre-filtering, elution, acidification, oxidation of organic material and filtering of the preciptate are included. The goal is to produce an uncontaminated, isotopically unfractionated $\mathrm{BaSO}_{4}$ precipitate. 


\subsection{Precipitation of sulfate from water samples collected in bottles}

Samples of water with greater than or equal to $20 \mathrm{mg} / \mathrm{L}$ sulfate in solution can be processed in the laboratory to produce a pure $\mathrm{BaSO}_{4}$ precipitate for isotopic analysis. It is necessary to obtain the approximate sulfate concentration of the sample so that an appropriate volume of sample to process can be calculated. Sulfate concentration may be available from an ion chromatographic analysis or analysis in the field with the spectrophotometer. If no analysis is available, a "test precipitation" (i.e., gravimetric determination) can be made on a small volume of sample (less than about $50 \mathrm{~mL}$ ).

In our laboratory, an "appropriate volume" of sample is the amount needed to produce about $100 \mathrm{mg}$ of $\mathrm{BaSO}_{4}$ precipitate (i.e., a volume of sample containing about $41 \mathrm{mg}$ dissolved sulfate). This amount of precipitate provides sufficient material for duplicate $\mathrm{SO}_{2}$ extractions (see section 3.4) and is small enough to be filtered readily. If it is determined that the sulfate concentration of the sample collected in bottles is less than $20 \mathrm{mg} / \mathrm{L}$, sulfate from the sample can be collected on anion exchange resin, following the technique discussed in section 2.1.5, and eluted as described in section 3.2. Collecting sulfate on anion exchange resin is recommended if more than two liters of a dilute sample are available.

Procedure -- Instructions for preparation of $\mathrm{HCl}$ and $\mathrm{BaCl}_{2}$ solutions are given in table 10. An appropriate volume of the water sample is pre-filtered using a membrane filter (the sample is filtered first using a glass fiber filter if it contains a large amount of particulate material). The sample is poured into a clean beaker of appropriate size and. a clean stir bar is added. Next, the sample is acidified to $\mathrm{pH}$ between 3 to 4 using $1 \mathrm{M} \mathrm{HCl}$. A pH below about 4 is needed so that nearly all dissolved carbonate will be present as $\mathrm{CO}_{2}(\mathrm{aq})$. In basic solutions the dissolved carbonate species is $\mathrm{CO}_{3}{ }^{2-}$. This will precipitate as $\mathrm{BaCO}_{3}$ when the $\mathrm{BaCl}_{2}$ solution is added, contaminating the $\mathrm{BaSO}_{4}$ precipitate. On the other hand, if the $\mathrm{pH}$ is below $2, \mathrm{HSO}_{4}{ }^{-}$will be the dominant sulfate species instead of $\mathrm{SO}_{4}{ }^{2-}$. Precipitation of $\mathrm{BaSO}_{4}$ will be somewhat slower from a solution containing sulfate as $\mathrm{HSO}_{4}^{-}$rather than $\mathrm{SO}_{4}{ }^{2-}$ (although allowing the sample to stand overnight is adequate to precipitate $\mathrm{BaSO}_{4}$ quantitatively from a solution containing predominantly $\mathrm{HSO}_{4}{ }^{-}$).

After acidification, the sample is covered with a watch glass and heated to $90^{\circ} \mathrm{C}$ (or to boiling for treatment with $\mathrm{Br}$-water, see footnote 5). Heating the sample accomplishes three ends: (1) heating helps to drive off dissolved $\mathrm{CO}_{2}$ from the sample before $\mathrm{BaSO}_{4}$ is precipitated, (2) heating is a necessary part of the oxidation step to remove dissolved organic material, and (3) after the sample is oxidized and $\mathrm{CO}_{2}$ has been driven off by heating, $\mathrm{BaCl}_{2}$ solution is added to the heated sample and the sample is allowed to cool slowly. This is thought to produce a coarser-grained $\mathrm{BaSO}_{4}$ precipitate. If the sample is known or suspected to contain dissolved organic material 4 , it is treated with 6 weight

${ }^{4}$ measured as dissolved organic carbon (DOC). 
percent $\mathrm{H}_{2} \mathrm{O}_{2}$ solution ( $10 \mathrm{~mL}$ is used for a $200 \mathrm{~mL}$ sample) to oxidize and remove the organic material ${ }^{5}$. This step is necessary because if dissolved organic material is not removed before $\mathrm{BaCl}_{2}$ is added, a contaminated $\mathrm{BaSO}_{4}$ precipitate will be produced. Impure $\mathrm{BaSO}_{4}$ will produce unwanted gases on the extraction line and expanding an impure gas into the mass spectrometer can contaminate the source and necessitate difficult and time-consuming repairs to the instrument. After adding the peroxide solution, the sample is heated and held at $90^{\circ} \mathrm{C}$. When a sample containing dissolved organic material is treated with peroxide the sample will turn yellowish or brownish. This color will disappear after 2 to 3 hours of heating at $90^{\circ} \mathrm{C}$. If the sample is clear and free of precipitates after the oxidation step is complete, 5 to $10 \mathrm{~mL}$ of 10 weight percent $\mathrm{BaCl}_{2}$ solution are added and thoroughly mixed with the sample. Precipitation of $\mathrm{BaSO}_{4}$ is complete after about 5 minutes; the sample is heated for an additional 15 minutes to one hour and then the heat and stirring are turned off and the sample is allowed to cool and settle overnight.

If the sample contained precipitate after the acidification and oxidation steps then it must be re-filtered before $\mathrm{BaSO}_{4}$ is precipitated. Precipitates may form because salts become supersaturated during the heating step as some of the water is driven off or silica or iron hydroxide precipitates after the sample is acidified. Salts may redissolve if high quality deionized water is added to the sample, but insoluble material must be removed by filtering the sample through a membrane filter before adding $\mathrm{BaCl}_{2}$ solution in order to avoid contamination of the $\mathrm{BaSO}_{4}$. When re-filtering is completed, 5 to $10 \mathrm{~mL}$ of 10 weight percent $\mathrm{BaCl}_{2}$ solution is added and thoroughly mixed with the sample. The sample may be heated before adding the $\mathrm{BaCl}_{2}$ but heating is not essential 6 . $\mathrm{BaSO}_{4}$ can be precipitated quantitatively at room temperature.

$\mathrm{BaSO}_{4}$ produced by either method above is filtered on a pre-weighed membrane filter, rinsed thoroughly with deionized (DI) water, stored in a preweighed plastic petri dish and dried in a desiccator (using sulfate-free desiccant). A few milliliters of $\mathrm{BaCl}_{2}$ solution are added to the filtrate to assure that all the sulfate has precipitated. When dry, the $\mathrm{BaSO}_{4}$ is weighed and the fraction recovered is calculated based on the amount expected from the reported dissolved sulfate concentration of the sample.

\footnotetext{
${ }^{5}$ An alternative method is to use 10 to $20 \mathrm{~mL}$ of saturated $\mathrm{Br}$ solution to oxidize dissolved organic material (Bates, written comm., 1993). After adding the Br solution the sample is boiled until the yellow color fades. Peroxide treatment is adequate for samples with relatively low DOC (less than about $10 \mathrm{mg} / \mathrm{L}$ ). Saturated $\mathrm{Br}$ solution is used for samples with high DOC (10's of $\mathrm{mg} / \mathrm{L})$. Samples are routinely oxidized by one of these two methods in our laboratory.

6 If a sample with less than $20 \mathrm{mg} / \mathrm{L}$ sulfate is prepared by this method, heating the sample to $90^{\circ} \mathrm{C}$ before precipitating the $\mathrm{BaSO}_{4}$ is recommended. When a small amount of $\mathrm{BaSO}_{4}$ is produced (less than $20 \mathrm{mg}$ ) it should be filtered onto a smaller-diameter filter $(25 \mathrm{~mm}$ diameter polycarbonate membrane). A small amount of $\mathrm{BaSO}_{4}$ is more readily removed if it is deposited on a small diameter filter.
} 


\subsection{Elution and precipitation of sulfate samples collected on anion exchange resin}

The sulfate collected on anion exchange resin in the field is eluted in the laboratory using a concentrated chloride solution and precipitated as $\mathrm{BaSO}_{4}$.

Procedure -- When collecting the sulfate in the field, the following equation proceeds in the forward direction:

$$
\begin{aligned}
& \mathrm{SO}_{4}^{2-}(\mathrm{aq})+\mathrm{X}-2 \mathrm{Cl}^{-} \leftrightarrow 2 \mathrm{Cl}^{-}(\mathrm{aq})+\mathrm{X}-\mathrm{SO}_{4}{ }^{2-} \\
& \text { in solution on resin in solution on resin }
\end{aligned}
$$

To elute the sulfate, the exchange in the above equation is forced in the opposite direction by passing a highly concentrated chloride solution through the resin.

Carefully open one end of the drying tube containing the sulfate sample, discard the glass wool and rinse the resin into a $100-\mathrm{mL}$ chromatography column (see definitions). Discard all water used to rinse the resin into the column (deionized water will not remove the sulfate from the resin). Each resin is eluted twice to provide assurance that all sulfate has been removed from the resin in the first elution. Place a clean 400-mL beaker beneath the column and close the stopcock. Measure $100 \mathrm{~mL}$ of $3 \mathrm{M} \mathrm{KCl}$ solution and pour about one-third of this into the column. Allow the resin to remain in contact with the $\mathrm{KCl}$ solution for 4 minutes. Then open the stopcock and allow the $\mathrm{KCl}$ solution to drain from the column. Repeat with the other two-thirds of the $\mathrm{KCl}$ solution. Follow the $\mathrm{KCl}$ with $100 \mathrm{~mL}$ of deionized water. The water is poured through in thirds; the 4 minute wait before opening the stopcock is not needed. Then, using a second $400 \mathrm{~mL}$ beaker, repeat the entire elution process ( $\mathrm{KCl}$ solution and $\mathrm{Dl}$ water). When the water from the second elution has drained from the resin, close the stopcock and add about 30 to $40 \mathrm{~mL}$ of deionized water to the resin in the column and set aside. If the resin is still light-golden in color it can be reused. Rinse the resin with deionized water, following the instructions in section 2.1.5, before using the resin to collect another sample. If the resin becomes dark brown in color after contact with a sample rich in dissolved organic material, it must be discarded.

The sulfate from the original water sample is now concentrated in approximately $200 \mathrm{~mL}$ of $\mathrm{KCl}$ solution in the first $400 \mathrm{~mL}$ beaker. The $\mathrm{KCl}$ solutions in both beakers are acidified to $\mathrm{pH}$ between 3 and 4 with $\mathrm{HCl}$. If the sample was organic-rich (i.e., the resin is dark brown in color), the solutions from both the first and second elution should next be treated with $10 \mathrm{~mL}$ of 6 weight percent $\mathrm{H}_{2} \mathrm{O}_{2}$ solution or saturated bromine-water to oxidize dissolved organic material. This step may be skipped if the sample was not organic-rich, however, virtually all samples prepared in our lab are routinely oxidized as a precaution. The first and second elution beakers are heated, the oxidizing agent added and mixed with the $\mathrm{KCl}$ solutions and heating is continued at $90^{\circ} \mathrm{C}$ (boiling for $\mathrm{Br}$ - 
water) for at least 2 to 3 hours or until the solutions are colorless (more discussion in section 3.1). Add deionized water if the solutions are in danger of evaporating away and crystallization of the $\mathrm{KCl}$ occurs. If the solutions are clear and free of precipitates after the acidification and oxidation steps are complete, five milliliters of 10 weight percent $\mathrm{BaCl}_{2}$ solution are then added to each beaker to precipitate $\mathrm{BaSO}_{4}$. After stirring and heating for at least 10 minutes, the solutions are allowed to cool slowly overnight.

If any insoluble precipitate formed during the heating or acidification steps, it should be removed by filtering the solution through a membrane filter (the solutions are cooled before filtering). Five to ten milliliters of 10 weight percent $\mathrm{BaCl}_{2}$ solution is then added to the acidified, filtered solution in each beaker. The solutions need not be reheated before precipitating the $\mathrm{BaSO}_{4}$ unless the sulfate concentration is thought to be very low (only a few $\mathrm{mg} \mathrm{BaSO}_{4}$ expected). The solutions are allowed to stand, with stirring, for at least 10 minutes while the $\mathrm{BaSO}_{4}$ precipitate forms.

After the $\mathrm{BaSO}_{4}$ has formed and the solution cooled, if necessary, the solution is filtered to collect the precipitate. Ideally, $\mathrm{BaSO}_{4}$ should form only in the first beaker while the solution in the second beaker should remain clear. The $\mathrm{BaSO}_{4}$ from the first beaker is filtered on a pre-weighed membrane filter, rinsed thoroughly with deionized water to remove all the chloride, stored in a preweighed plastic petri dish and dried in a dessicator (with sulfate-free desiccant). $\mathrm{BaCl}_{2}$ is added to the filtrate to assure that precipitation of the $\mathrm{BaSO}_{4}$ was complete. Occasionally, a small amount of $\mathrm{BaSO}_{4}$ may form in the second beaker. This $\mathrm{BaSO}_{4}$ should be filtered, combined and homogenized with the $\mathrm{BaSO}_{4}$ from the first beaker. And in this case, the resin should be eluted a third time to assure that all sulfate had been removed.

\subsection{Laboratory preparation of dissolved sulfide collected as $\mathrm{Ag}_{2} \mathrm{~S}$}

Silver sulfide collected by nitrogen-stripping in a $\mathrm{AgNO}_{3}$ trap needs no preparation other than drying and weighing the precipitate obtained so that the fraction of the dissolved sulfide recovered can be calculated 7 . In addition, $\mathrm{Ag}_{2} \mathrm{~S}$ collected by nitrogen stripping should be completely removed from the filter and ground with an agate mortar and pestle to homogenize it before weighing an aliquot for sulfur isotopic analysis (section 3.4). $\mathrm{Ag}_{2} \mathrm{~S}$ collected by nitrogen

${ }^{7}$ Fraction of sulfide recovered may be calculated using the following formula:

Fraction of sulfide recovered $=1-f=\left[C_{\text {coll }} / C_{\text {meas }}\right]$ where:

$f=$ fraction of sulfide remaining in carboy

$\mathrm{C}_{\text {coll }}=$ concentration of sulfide based on amount of $\mathrm{Ag}_{2} \mathrm{~S}$ collected

$=\left[w t . \mathrm{Ag}_{2} \mathrm{~S}(\mathrm{mg})^{\star}(0.12938)\right] \mathrm{L}$ of sample processed by nitrogen-stripping 0.12938 is the weight fraction of $\mathrm{S}$ in $\mathrm{Ag}_{2} \mathrm{~S}$.

$\mathrm{C}_{\text {meas }}=$ concentration of sulfide measured using spectrophotometer.

For an example of calculating fraction of sulfide recovered, see table 4.5.4. 
stripping will be isotopically inhomogeneous, with coarse-grained, early-formed $\mathrm{Ag}_{2} \mathrm{~S}$ being enriched in ${ }^{32} \mathrm{~S}$ relative to later-formed, fine-grained $\mathrm{Ag}_{2} \mathrm{~S}$ (see also section 4.5.3). If the $\mathrm{Ag}_{2} \mathrm{~S}$ was collected by direct precipitation, it should be purified using 3 percent $\mathrm{NH}_{4} \mathrm{OH}$ solution, following the procedure discussed in section 4.4.2. The purified $\mathrm{Ag}_{2} \mathrm{~S}$ should also be weighed, and the fraction of the dissolved sulfide recovered should be calculated?

\subsection{Preparation of $\mathrm{SO}_{2}$ from $\mathrm{BaSO}_{4}$ and $\mathrm{Ag}_{2} \mathrm{~S}$ for isotopic analysis}

The ratio ${ }^{34} \mathrm{~S} / 32 \mathrm{~S}$ is most commonly measured on $\mathrm{SO}_{2}$. Originally, $\mathrm{SO}_{2}$ was produced from sulfide minerals and native sulfur by combustion in a stream of oxygen gas (Thode and others, 1949). Methods for preparation of $\mathrm{SO}_{2}$ from sulfide minerals using copper oxide reagents have been published by Fritz and others (1974) and Robinson and Kusakabe (1975). The method utilizing cuprous oxide $\left(\mathrm{Cu}_{2} \mathrm{O}\right)$, developed by Robinson and Kusakabe (1975), minimizes the production of $\mathrm{SO}_{3}$ by controlling the ambient oxygen fugacity more effectively than the earlier methods.

The first methods for preparation of $\mathrm{SO}_{2}$ from sulfate minerals and dissolved sulfate precipitated as $\mathrm{BaSO}_{4}$ involved reduction of the sulfate by various techniques and conversion of the $\mathrm{BaS}$ to $\mathrm{Ag}_{2} \mathrm{~S}$ or $\mathrm{CdS}$ for combustion and isotopic analysis (Thode and others, 1949, 1961, Gavelin and others, 1960). Searching for a less labor-intensive method for preparation of $\mathrm{SO}_{2}$ from sulfates, Holt and Engelkemeir (1970) described a technique for direct decomposition of $\mathrm{BaSO}_{4}$ to $\mathrm{SO}_{2}$ by heating the sulfate under vacuum. Bailey and Smith (1972) modified their technique to include a furnace with hot copper turnings to reduce $\mathrm{SO}_{3}$. Coleman and Moore (1978) introduced a method in which $\mathrm{BaSO}_{4}$ is combined with $\mathrm{Cu}_{2} \mathrm{O}$ and $\mathrm{SiO}_{2} . \mathrm{SO}_{2}$ is produced by heating the mixture in a furnace at $1120^{\circ} \mathrm{C}$ in a vacuum system.

Other reagents that have been used to produce $\mathrm{SO}_{2}$ from $\mathrm{BaSO}_{4}$ include reaction with $\mathrm{NaPO}_{3}$ (Halas and Wolacewicz, 1981) and reaction with a mixture of $\mathrm{V}_{2} \mathrm{O}_{5}$ and $\mathrm{SiO}_{2}$ (Yanagisawa and Sakai, 1983). Gavelin and others (1960) combusted sulfides with $\mathrm{V}_{2} \mathrm{O}_{5}$ to produce $\mathrm{SO}_{2}$ and Ueda and Krouse (1986) used a mixture of $\mathrm{V}_{2} \mathrm{O}_{5}$ and $\mathrm{SiO}_{2}$ to prepare $\mathrm{SO}_{2}$ from both sulfide and sulfate minerals.

The reagents and extraction techniques used in this study are based on the methods of Robinson and Kusakabe (1975) for sulfides and Coleman and Moore (1978) for sulfates, i.e. using $\mathrm{Cu}_{2} \mathrm{O}$ reagent for sulfides and $\mathrm{Cu}_{2} \mathrm{O}$ plus $\mathrm{SiO}_{2}$ for $\mathrm{BaSO}_{4}$. The vacuum system and extraction technique are modified somewhat from the methods discussed by these workers, as described below. 


\subsubsection{Combining $\mathrm{Ag}_{2} \mathrm{~S}$ and $\mathrm{BaSO}_{4}$ samples with reagents in preparation for vacuum extraction}

$\mathrm{Ag}_{2} \mathrm{~S}$ is combined with $\mathrm{Cu}_{2} \mathrm{O}$ and heated in a vacuum system to produce $\mathrm{SO}_{2}$. When $\mathrm{Cu}_{2} \mathrm{O}$ reacts with $\mathrm{Ag}_{2} \mathrm{~S}$ to make $\mathrm{SO}_{2}$, Cu metal is produced. The $\mathrm{Cu}_{2} \mathrm{O}-\mathrm{Cu}$ pair constrains the oxygen fugacity to a curve in log $\mathrm{fO}_{2}$-temperature space. At the low $\mathrm{fO}_{2}$ prevailing under these conditions, production of $\mathrm{SO}_{3}$ will not be significant (Robinson and Kusakabe, 1975). This is illustrated in figure 6. At the reaction temperatures $\left(1050\right.$ and $\left.1150^{\circ} \mathrm{C}\right)$ and in the presence of both $\mathrm{Cu}$ and $\mathrm{Cu}_{2} \mathrm{O}$, the ratio of $\mathrm{SO}_{2}: \mathrm{SO}_{3}$ will be between 10,000:1 and 1000:1.

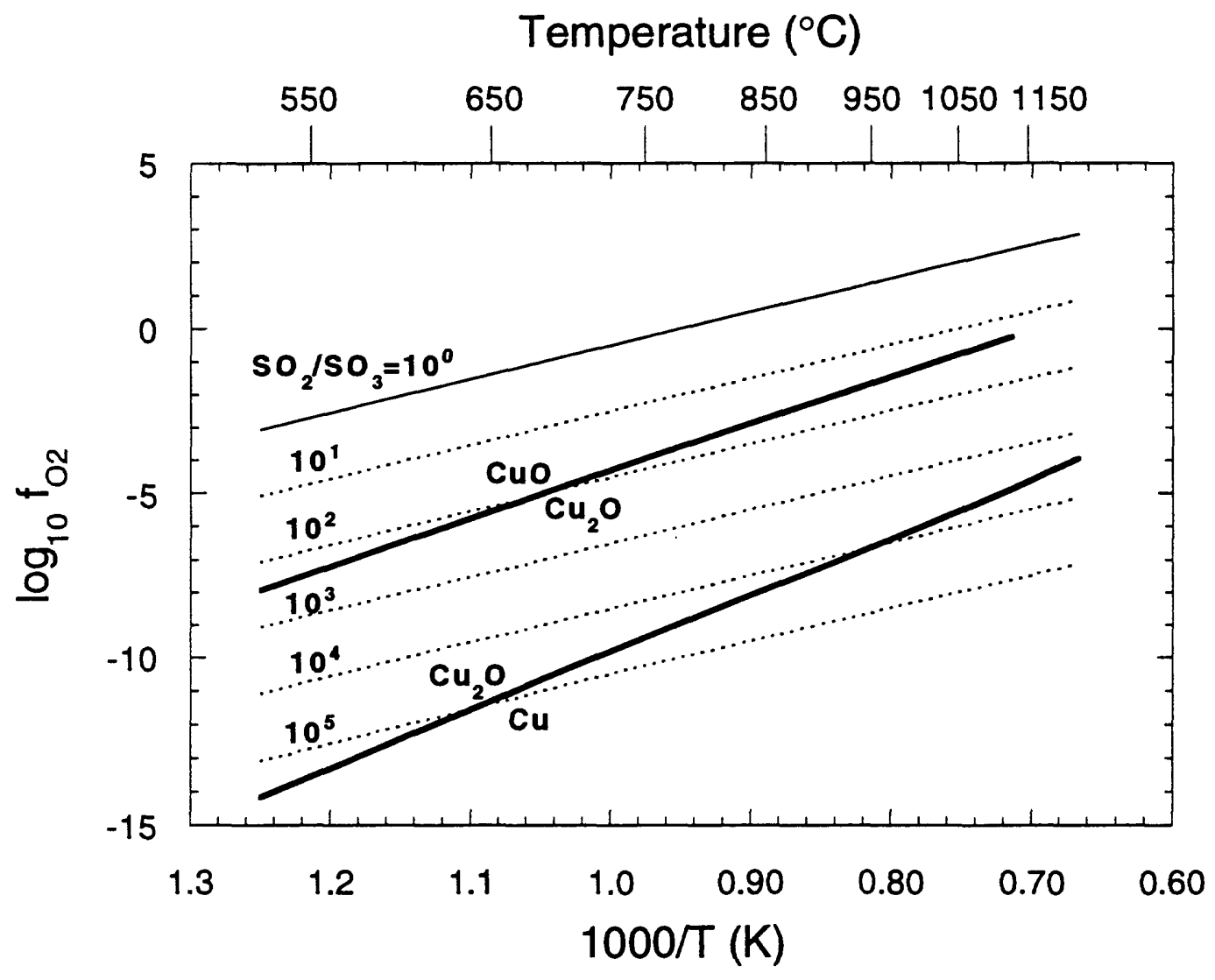

Figure 6. Plot showing the change of log foyith inverse temperature for the equations $2 \mathrm{Cu}+0.5$ $\mathrm{O}_{2} \leftrightarrow \mathrm{Cu}_{2} \mathrm{O}, \mathrm{Cu}_{2} \mathrm{O}+0.5 \mathrm{O}_{2} \leftrightarrow 2 \mathrm{CuO}$ and $\mathrm{SO}_{2}+0.5 \mathrm{O}_{2} \leftrightarrow \mathrm{SO}_{3}$. Curves for the third equation are plotted for various ratios between $\mathrm{SO}_{2}$ and $\mathrm{SO}_{3}$. For the curve with $\mathrm{SO}_{2} / \mathrm{SO}_{3}=10^{\circ}=1$, the number of $\mathrm{SO}_{2}$ molecules equals the number of $\mathrm{SO}_{3}$ molecules. Note that under the conditions of the Cu- $\mathrm{Cu}_{2} \mathrm{O}$ oxygen fugacity buffer at $1050^{\circ} \mathrm{C}(1000 / \mathrm{T}$ (in $\left.\mathrm{K})=0.756\right)$ to $1150^{\circ} \mathrm{C}(1000 / \mathrm{T}$ (in $\mathrm{K}$ ) $=0.703)$, the ratio of $\mathrm{SO}_{2} / \mathrm{SO}_{3}$ varies between $10^{3}$ to $10^{4}$. In other words, there are 1000 to $10,000 \mathrm{SO}_{2}$ molecules for every $\mathrm{SO}_{3}$ molecule present, favorable T-f $\mathrm{O}_{2}$ conditions under which to produce $\mathrm{SO}_{2}$ while minimizing formation of $\mathrm{SO}_{3}$. 
$\mathrm{BaSO}_{4}$ is combined with $\mathrm{Cu}_{2} \mathrm{O}$ and $\mathrm{SiO}_{2}$ glass and heated in a vacuum system to produce a mixture of $\mathrm{SO}_{2}$ and $\mathrm{SO}_{3}$ which is reduced over hot copper wire to $\mathrm{SO}_{2}$. This situation is different from that for $\mathrm{Ag}_{2} \mathrm{~S}$ because $\mathrm{SO}_{3}$ in the evolved gas from $\mathrm{BaSO}_{4}$ must ultimately be reduced to $\mathrm{SO}_{2}$. The $\mathrm{SiO}_{2}$ glass is added to buffer the isotopic effect of the oxygen present in the $\mathrm{BaSO}_{4}$. Because of the excess oxygen that is present in the $\mathrm{BaSO}_{4}-\mathrm{Cu}_{2} \mathrm{O}-\mathrm{SiO}_{2}$ mixture, this material is not constrained to the $\mathrm{Cu}-\mathrm{Cu}_{2} \mathrm{O}$ oxygen fugacity buffer curve. Hot copper wire is needed to convert $\mathrm{SO}_{3}$ to $\mathrm{SO}_{2}$.

Preparation of the reagents -- Cuprous oxide $\left(\mathrm{Cu}_{2} \mathrm{O}\right)$ is prepared from reagent grade CuO (preparation method first described by Kaplan and others, 1970). A few grams of $\mathrm{CuO}$ are placed in a quartz tube $(13 \mathrm{~mm}$ od, $11 \mathrm{~mm}$ id) and connected by a Cajon Ultra-torr union to the extraction line shown in figure 7 . After evacuating the system, the $\mathrm{CuO}$ is heated to $950^{\circ} \mathrm{C}$ and evolved oxygen is pumped away. When oxygen evolution has ceased, the $\mathrm{Cu}_{2} \mathrm{O}$ is cooled in the vacuum system. When the $\mathrm{Cu}_{2} \mathrm{O}$ reaches room temperature, it is removed from the quartz tube and ground to a fine, even grain size in an agate or alumina mortar. The $\mathrm{SiO}_{2}$ used for $\mathrm{BaSO}_{4}$ extraction is prepared from quartz glass tubing. The glass is crushed, ground in an agate mortar and sieved until it passes 200-mesh.

Silver Sulfide $\left(\mathrm{Ag}_{2} \mathrm{~S}\right)$-- Silver sulfide that was collected by nitrogen stripping should be homogenized (see discussion in section 3.3). Twenty milligrams of silver sulfide sample are weighed on an analytical balance and combined with 80 $\mathrm{mg} \mathrm{Cu}_{2} \mathrm{O}$. Weights of samples and reagents are measured and recorded to 0.1 $\mathrm{mg}$. If the sample is smaller than $20 \mathrm{mg}$, then the available sample is combined with 4 times the sample weight of $\mathrm{Cu}_{2} \mathrm{O}$. $\mathrm{Ag}_{2} \mathrm{~S}$ samples as small as $5 \mathrm{mg}$ have been analyzed successfully. The $\mathrm{Ag}_{2} \mathrm{~S}$ and $\mathrm{Cu}_{2} \mathrm{O}$ are thoroughly mixed by grinding in a small agate mortar and loaded into a piece of quartz glass tubing ( $25 \mathrm{~mm}$ long, $6 \mathrm{~mm}$ od, $4 \mathrm{~mm}$ id). The $\mathrm{Ag}_{2} \mathrm{~S}-\mathrm{Cu}_{2} \mathrm{O}$ mixture is held in the tube by plugs of quartz-glass wool.

Barium Sulfate $\left(\mathrm{BaSO}_{4}\right)$-- Eighteen milligrams of $\mathrm{BaSO}_{4}$ are weighed on an analytical balance along with $90 \mathrm{mg}$ of $\mathrm{Cu}_{2} \mathrm{O}$ and $95 \mathrm{mg}$ of $\mathrm{SiO}_{2}$ glass. If less than $18 \mathrm{mg}$ of $\mathrm{BaSO}_{4}$ are available, then the $\mathrm{BaSO}_{4}$ is combined with 5 times the sample weight of $\mathrm{Cu}_{2} \mathrm{O}$ and 5 times the sample weight plus $5 \mathrm{mg}$ of $\mathrm{SiO}_{2}$ glass. $\mathrm{BaSO}_{4}$ samples as small as $1.7 \mathrm{mg}$ have been analyzed successfully. The $\mathrm{BaSO}_{4}$ plus reagents are homogenized by grinding in a small agate mortar and loaded into a quartz glass tube as described for $\mathrm{Ag}_{2} \mathrm{~S}$. 


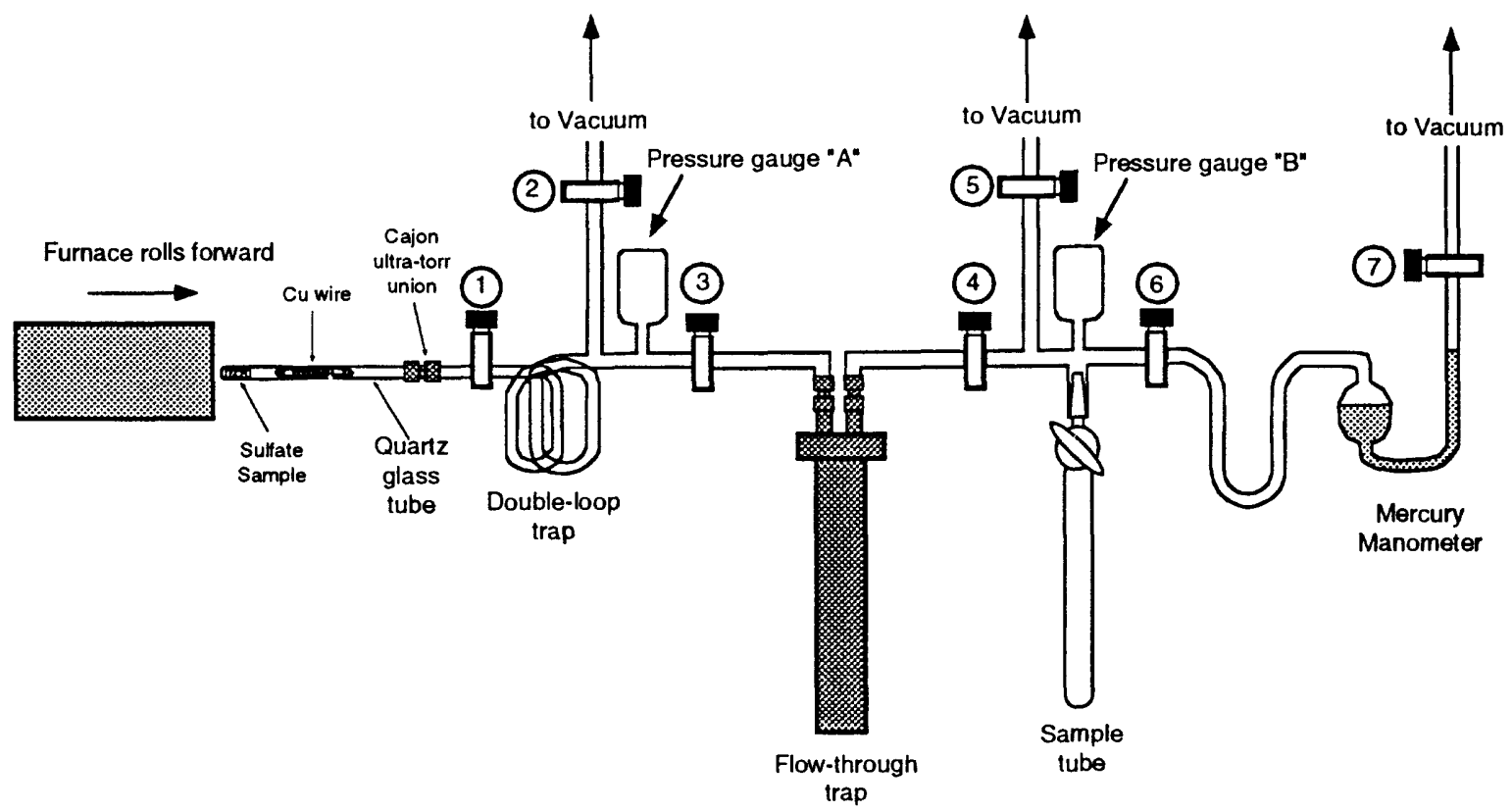

Figure 7. Schematic diagram of the vacuum extraction system used in this study for the preparation of $\mathrm{SO}_{2}$ from $\mathrm{BaSO}_{4}$ and $\mathrm{Ag}_{2} \mathrm{~S}$ samples. Details of the extraction technique are discussed in section 3.4.2.

\subsubsection{Conversion of $\mathrm{Ag}_{2} \mathrm{~S}$ and $\mathrm{BaSO}_{4}$ to $\mathrm{SO}_{2}$ in vacuum extraction line}

The design of the vacuum extraction line used in this study is shown in figure 7. The $\mathrm{SO}_{2}$ gas produced from the sample proceeds generally from left to right. The sample, mixed with reagents and packed into a quartz tube as described in section 3.4.1, is loaded into a 13-mm-od (11-mm-id) quartz-glass tube and connected by a Cajon Ultra-torr union to the extraction line. If the material to be analyzed is $\mathrm{BaSO}_{4}$, a coil of copper wire is placed in the quartz glass tube along with the sample. The copper wire is placed about $1.5 \mathrm{~cm}$ from the end of the quartz tube containing the sample. If the material to be analyzed is $\mathrm{Ag}_{2} \mathrm{~S}$, 'the copper wire is omitted. The large quartz tube is evacuated. The furnace is heated to $1050^{\circ} \mathrm{C}$ for $\mathrm{Ag}_{2} \mathrm{~S}$ or $1150^{\circ} \mathrm{C}$ for $\mathrm{BaSO}_{4}$. Temperature is measured with a chromel-alumel (Type K) thermocouple. When evacuation of the quartz tube and sample is complete and the furnace reaches the desired temperature, the double-loop trap is immersed (half-way) in liquid nitrogen. Valves 2 and 3 are closed and the furnace is rolled forward until the sample is in the hottest part of the furnace and the copper wire is partially inside the furnace. In this way, the copper is heated to the 600 to $800^{\circ} \mathrm{C}$ range recommended by Bailey and Smith (1972) and Coleman and Moore (1978). $\mathrm{Ag}_{2} \mathrm{~S}$ samples are heated for 10 
minutes; $\mathrm{BaSO}_{4}$ samples are heated for 15 minutes. During this time, the pressure on gauge $\mathrm{A}$ goes up as $\mathrm{SO}_{2}$ is evolved from the sample and then goes down as gas evolution ceases and the $\mathrm{SO}_{2}$ freezes into the trap (figure 7).

When the reaction time is complete, the furnace is rolled back and valve 1 closed. The liquid nitrogen dewar flask on the double-loop trap is filled and any non-condensible gas is pumped away through valve 2 . Then, with valves 1,2 , and 4 closed and valve 3 opened, the double-loop trap is warmed to room temperature and $\mathrm{SO}_{2}$ and other condensible gases transferred to the flowthrough trap which has been cooled to liquid-nitrogen temperature. After at least 2 minutes, valves 4 and 5 are opened to transfer the last of the gas from the double-loop trap into the flow-through trap. When the gases have been transferred, valves 3 and 5 are closed, the next sample is loaded into the quartz tube and air in the tube is pumped away through valve 2. The flow-through trap is allowed to warm slowly in room-temperature air. When the trap has warmed to about $-150^{\circ} \mathrm{C}, \mathrm{CO}_{2}$ sublimates and is pumped away through valve 5 . Valve 5 is then closed and valve 6 opened, the $U$-shaped trap is cooled with liquid nitrogen and $\mathrm{SO}_{2}$ is collected in that trap between -135 and $-80^{\circ} \mathrm{C}$. With valve 6 closed, the U-shaped trap is warmed to room temperature and the manometer reading is recorded. The volume of the line between valves 6 and 7 has been calibrated so that the amount of $\mathrm{SO}_{2}$ (in $\mu \mathrm{mol}$ ) can be calculated from the manometer reading. Finally, the $\mathrm{SO}_{2}$ is frozen into the sample tube for analysis on the mass spectrometer by cooling the bottom of the sample tube to liquid nitrogen temperature, opening valve 6 with valves 5 and 4 closed, and opening the sample tube stopcock.

\subsection{Analysis of $\mathrm{SO}_{2}$ on an isotope-ratio mass spectrometer}

The primary mass spectrometer used in this study is a Finnigan MAT 251. The inlet system is described in figure 8. Samples are analyzed using an ion acceleration voltage of $10 \mathrm{kV}$. For $\mathrm{SO}_{2}$, the source window is in the open position. The instrument is automated; samples can be run automatically using an "ISODAT" software package.

Raw data from the mass spectrometer are corrected as discussed in the Appendix. Repeated analyses of the reference material NBS 127 indicate an uncertainty of \pm 0.15 per mill $(1 \sigma)$ associated with the weighing, extraction and mass spectrometric methods. 


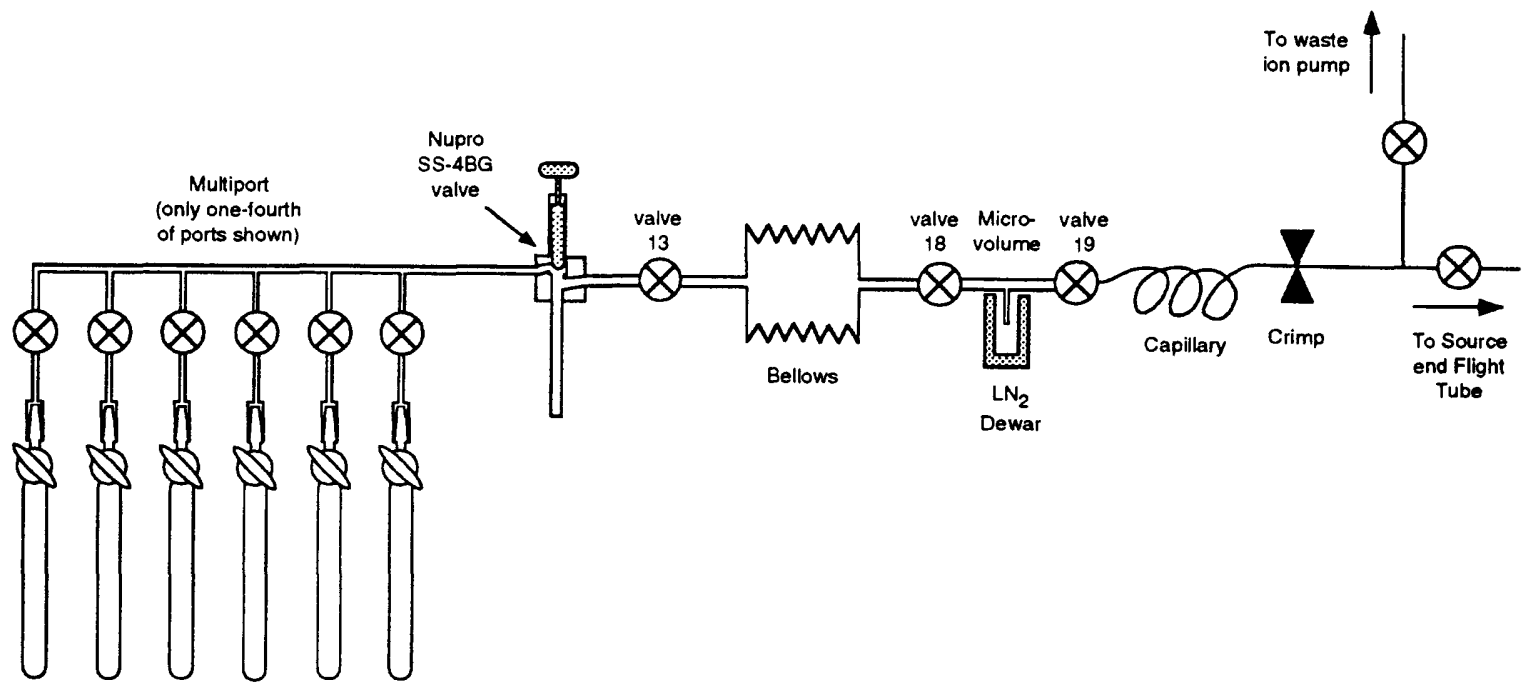

Figure 8. Schematic diagram of the inlet system of the Finnigan MAT 251 mass spectrometer used in this study. The three options described below allow the inlet system of this instrument to accommodate any sample between $0.25 \mu \mathrm{mol}$ to over $200 \mu \mathrm{mol}$. These options are (from left to right): (1) a multiport from which up to 24 samples can be analyzed automatically; (2) a cold finger made from a Nupro bellows valve. A trap was created by drilling into the bottom of the valve, intersecting the location of the valve seat, inserting a partially drilled-out stainless steel rod (about $13 \mathrm{~cm}$ long and $6 \mathrm{~mm}$ od) into the hole, and welding the rod to the valve. This addition to the inlet system of this instrument was made by $W$. C. Shanks, III. The valve is shown in the open position. A sample from the multiport of between 5 and $35 \mu \mathrm{mol}$ is frozen into this cold finger with liquid nitrogen (valve 13 closed). When the Nupro valve is closed, the $\mathrm{SO}_{2}$ can no longer expand back into the multiport. The cold finger is warmed to room temperature, valve 13 opened, and the gas is analyzed. Elimination of the volume of the multiport into which larger samples are expanded facilitates analysis of these moderately small ( 5 to $35 \mu \mathrm{mol}$ ) samples; (3) The microvolume is used for samples of $5 \mu \mathrm{mol}$ or less. In this case, the sample is frozen into a $200-\mu \mathrm{L}$ volume cold finger. The bellows are avoided entirely as such small samples will be "lost" in this large volume. After the sample is frozen in, valve 18 is closed, the microvolume is warmed, valve 19 is opened and the gas analyzed. 


\section{TESTING OF FIELD COLLECTION PROCEDURES}

The methods recommended in this report for collecting sulfate from water with high- and low-sulfate concentration and for collecting dissolved sulfide from samples of ground water were tested in both the laboratory and the field. The primary goal was to determine if these procedures consistently produce $\mathrm{BaSO}_{4}$ or $\mathrm{Ag}_{2} \mathrm{~S}$ precipitates that are unfractionated in sulfur isotopes: In addition, the procedures must not be overly complicated, use transportable equipment, and be capable of producing clean samples or precipitates under field conditions.

\subsection{High-concentration sulfate collection experiments in the laboratory}

Synthetic ground-water samples were produced in the laboratory to test the high-concentration sulfate collection and laboratory preparation methods. From stock solutions with $10,000 \mathrm{mg} / \mathrm{L} \mathrm{SO}{ }^{2-}\left(0.104 \mathrm{M} \mathrm{Na}_{2} \mathrm{SO}_{4}\right.$ solution), $10,000 \mathrm{mg} / \mathrm{L}$ $\mathrm{Cl}^{-}\left(0.282 \mathrm{M} \mathrm{NaCl}\right.$ solution) and $1000 \mathrm{mg} / \mathrm{L} \mathrm{HCO}_{3}{ }^{-}\left(0.0164 \mathrm{M} \mathrm{KHCO}_{3}\right.$ solution) synthetic ground water samples were made with 2000,200 and $20 \mathrm{mg} / \mathrm{L} \mathrm{SO}_{4}{ }^{2-}$ and with concentrations of $\mathrm{Cl}^{-}$and $\mathrm{HCO}_{3}{ }^{\circ}$ as follows:

Table 11. Compositions of synthetic water samples for high-concentration sulfate collection experiments [mg/L, milligrams per liter]

\begin{tabular}{ccc}
$\mathrm{SO}_{4}{ }^{2-}$ - oncentration & $\mathrm{Cl}^{-}$Concentration & $\mathrm{HCO}_{3}{ }^{-}$Concentration \\
\hline 2000,200 and $20 \mathrm{mg} / \mathrm{L}$ & 0 & 0 \\
2000,200 and $20 \mathrm{mg} / \mathrm{L}$ & $2000 \mathrm{mg} / \mathrm{L}$ & 0 \\
2000,200 and $20 \mathrm{mg} / \mathrm{L}$ & 0 & $40 \mathrm{mg} / \mathrm{L}$ \\
2000,200 , and $20 \mathrm{mg} / \mathrm{L}$ & $2000 \mathrm{mg} / \mathrm{L}$ & $40 \mathrm{mg} / \mathrm{L}$ \\
\hline
\end{tabular}

Two solutions with each of the concentrations listed in table 4.1.1 were prepared and the sulfate precipitated using a simplified version of the technique outlined in section 3.1 .

Procedure -- After mixing a solution of the desired concentration in an appropriately-sized beaker (volumes of synthetic ground-water samples were 100 $\mathrm{mL}, 154 \mathrm{~mL}$ and $1543 \mathrm{~mL}$ for sulfate concentrations of 2000,200 and $20 \mathrm{mg} / \mathrm{L}$ respectively), $\mathrm{pH}$ was measured using a $\mathrm{pH}$ meter (calibrated using $\mathrm{pH}=6.86$ and 4.01 buffers) and adjusted to between pH of 3 and 4 using $0.25 \mathrm{M} \mathrm{HCl}$. The speciation of dissolved carbonate must be considered in order to avoid coprecipitation of $\mathrm{BaCO}_{3}$ with the $\mathrm{BaSO}_{4}$. In alkaline solutions, carbonate will be present as $\mathrm{CO}_{3}{ }^{2-}$ and adding $\mathrm{Ba}^{2+}$ will produce $\mathrm{BaCO}_{3} . \mathrm{HCO}_{3}{ }^{-}$is predominant in 
neutral solutions. In acid solutions, carbonate is present as $\mathrm{CO}_{2}(\mathrm{aq})$ or $\mathrm{H}_{2} \mathrm{CO}_{3}(\mathrm{aq})$ which will not form $\mathrm{BaCO}_{3}$ if $\mathrm{Ba}^{2+}$ is added. After acidification, a few milliliters of saturated $\mathrm{BaCl}_{2}$ solution were added to precipitate $\mathrm{BaSO}_{4}$. The sample was stirred constantly using a magnetic stir-bar during acidification and $\mathrm{BaSO}_{4}$ precipitation. After waiting about 5 minutes to allow $\mathrm{BaSO}_{4}$ to precipitate completely, the synthetic sample was filtered through a membrane filter.

Additional $\mathrm{BaCl}_{2}$ solution was added to the filtered solution to assure that all $\mathrm{BaSO}_{4}$ precipitated. The filter was transferred to a small plastic petri dish. The $\mathrm{BaSO}_{4}$ was dried, weighed, and combined with reagents as discussed in section 3.4.1. The $\mathrm{BaSO}_{4}$ was converted to $\mathrm{SO}_{2}$ in a vacuum extraction system as discussed in section 3.4.2. The isotopic composition of the sulfur in the $\mathrm{SO}_{2}$ from these experiments was analyzed on a 6 -inch, $60^{\circ}$-sector Nuclide Corp. isotoperatio mass spectrometer. The analyses are considered to be directly comparable to those made on the Finnigan 251 mass spectrometer discussed in section 3.5 and the appendix. The same standard gases were used on both instruments.

Results -- The data from these 25 experiments are listed in table 12. Recovery of sulfate in the experiments ranged from 73.3 to 104.4 percent, but the majority (17) of the experiments had sulfate recoveries of 94 to 101 percent. The sulfur isotopic composition (relative to VCDT) of the sulfate collected in these experiments ranged from +4.2 to +4.8 per mill with an average of $+4.47 \pm 0.19$ per mill. This is similar to the analytical uncertainty associated with the vacuum extraction and mass spectrometric methods (see appendix). Because of the high recovery of sulfate in these experiments and the reproduciblity of the data within expected limits, the $\delta^{34} S$ value of 4.5 per mill is taken to be the actual sulfur isotopic compositon of the sulfate used in all the laboratory sulfate collection experiments. The Spearman rank-order correlation was calculated for the fraction of sulfate recovered versus $\delta^{34}$ SVCDT data in table 12. The results $(r=$ -0.071 and $p=0.72$ ) indicate that the null hypothesis of zero correlation between fraction of sulfate collected and $\delta^{34} S$ cannot be rejected. Therefore, the methods described here for collection and precipitation of high-concentration sulfate samples do not appear to produce any measurable fractionation of the sulfur isotopes. 
Table 12. High-sulfate (equal to or greater than $20 \mathrm{mg} / \mathrm{L}$ ) direct precipitation experiments in the laboratory [mg/L, milligrams per liter]

\begin{tabular}{|c|c|c|c|c|c|}
\hline Experiment \# & $\begin{array}{c}\mathrm{SO}_{4}^{2-} \text { conc. } \\
(\mathrm{mg} / \mathrm{L})\end{array}$ & $\begin{array}{c}\mathrm{Cl}^{-} \text {conc. } \\
\text { (mg/L) }\end{array}$ & $\begin{array}{c}\mathrm{HCO}_{3}^{-} \text {conc. } \\
(\mathrm{mg} / \mathrm{L})\end{array}$ & $\begin{array}{c}\text { Fraction of } \\
\text { sulfate } \\
\text { recovered (in } \\
\% \text { ) } \\
\end{array}$ & $\begin{array}{c}\delta^{34} S \text { relative } \\
\text { to VCDT (in } \\
\% \text { ) }\end{array}$ \\
\hline 2 & 2000 & 2000 & 0 & 99.2 & +4.8 \\
\hline 3 & 2000 & 2000 & 0 & 99.4 & +4.5 \\
\hline 4 & 2000 & 2000 & 0 & 104.4 & +4.8 \\
\hline 5 & 2000 & 2000 & 40 & 102.1 & +4.4 \\
\hline 6 & 2000 & 2000 & 40 & 84.1 & +4.6 \\
\hline 7 & 2000 & 0 & 0 & 73.3 & +4.7 \\
\hline 8 & 2000 & 0 & 0 & 76.2 & +4.8 \\
\hline 9 & 2000 & 0 & 40 & 97.2 & +4.7 \\
\hline 10 & 2000 & 0 & 40 & 101.3 & +4.6 \\
\hline 11 & 200 & 0 & 0 & 98.3 & +4.3 \\
\hline 12 & 200 & 0 & 0 & 98.0 & +4.4 \\
\hline 13 & 200 & 0 & 40 & 98.2 & +4.2 \\
\hline 14 & 200 & 0 & 40 & 97.2 & +4.2 \\
\hline 15 & 200 & 2000 & 0 & 99.5 & +4.5 \\
\hline 16 & 200 & 2000 & 0 & 99.1 & +4.5 \\
\hline 17 & 200 & 2000 & 40 & 99.4 & +4.4 \\
\hline 18 & 200 & 2000 & 40 & 99.2 & +4.3 \\
\hline 19 & 20 & 0 & 0 & 95.2 & +4.4 \\
\hline 20 & 20 & 0 & 0 & 97.1 & +4.4 \\
\hline 21 & 20 & 0 & 40 & 97.1 & +4.5 \\
\hline 22 & 20 & 0 & 40 & 100.3 & +4.2 \\
\hline 23 & 20 & 2000 & 0 & 91.7 & +4.5 \\
\hline 24 & 20 & 2000 & 0 & 85.2 & +4.3 \\
\hline 26 & 20 & 2000 & 40 & 94.8 & +4.4 \\
\hline 27 & 20 & 2000 & 40 & 94.1 & +4.4 \\
\hline
\end{tabular}




\subsection{Low-concentration sulfate collection experiments in the laboratory}

Many water samples contain low concentrations of sulfate (less than $20 \mathrm{mg} / \mathrm{L}$ ) such that the sulfate must be concentrated in a smaller volume of solution in order to effectively precipitate and filter the $\mathrm{BaSO}_{4}$. Experiments were conducted in the laboratory to test whether sulfate can be collected on anion exchange resin quantitatively and without fractionation of the sulfur isotopes.

The anion exchange resin used in this study has exchange sites that, initially, are occupied by $\mathrm{Cl}^{-}$. The resin, however, has a greater affinity for divalent rather than monovalent anions. When a sulfate-bearing water sample is pumped through the resin, each $\mathrm{SO}_{4}{ }^{2-}$ ion displaces two $\mathrm{Cl}^{-}$ions on the resin as follows:

$$
\mathrm{SO}_{4}{ }^{2-}(\mathrm{aq})+\mathrm{X}-2 \mathrm{Cl}^{-} \leftrightarrow 2 \mathrm{Cl}-(\mathrm{aq})+\mathrm{X}-\mathrm{SO}_{4}{ }^{2-}
$$

in solution

on resin in solution

on resin

In order to remove the sulfate from the resin in the laboratory, a small volume of concentrated chloride solution is passed through the resin. Despite the resin's higher affinity for divalent anions, the overwhelmingly large amount of chloride forces equation 2 in the opposite direction (right to left). As a result, the sulfate from several liters of a dilute water sample is concentrated in a few hundred milliliters of solution and precipitation and filtering of the sulfate are very much simplified.

Procedure -- A clean plastic bucket with a capacity of greater than 10 liters was used to mix the solutions for these experiments. A large plastic "paddle" $(50 \mathrm{~cm}$ $X 5.8 \mathrm{~cm} \times 1.3 \mathrm{~cm}$ slab) was used to stir the solutions. After mixing the stock solutions (see section 4.1) with an appropriate amount of deionized water to make a synthetic water sample of the desired concentration ( 3 liters of solution were used for the $10 \mathrm{mg} / \mathrm{L} \mathrm{SO}_{4}{ }^{2-}$ experiments, three 10 -liter buckets of solution were used for the $1 \mathrm{mg} / \mathrm{L} \mathrm{SO}_{4}{ }^{2-}$ experiments) the $\mathrm{pH}$ of the sample was measured with the $\mathrm{pH}$ meter and $1 \mathrm{M} \mathrm{HCl}$ added to adjust the $\mathrm{pH}$ to between 3 and 4 . This $\mathrm{pH}$ adjustment is necessary so that dissolved carbonate will be present as $\mathrm{CO}_{2}(\mathrm{aq})$ or $\mathrm{H}_{2} \mathrm{CO}_{3}(\mathrm{aq})$ and not as $\mathrm{CO}_{3}{ }^{2-}$ which would be collected with $\mathrm{SO}_{4}{ }^{2-}$ on the anion exchange resin. The acidified sample was then pumped through a plastic drying tube half-filled with the anion exchange resin using the set-up shown in figure 3 . The peristaltic pump was set on its lowest speed (about 0.4 liters per minute).

Next the sulfate was eluted from the anion exchange resin. The resin was transferred to a chromatography column and $100 \mathrm{~mL}$ of $3 \mathrm{M} \mathrm{KCl}$ solution was passed through the resin, driving sulfate off the resin and into solution (equation 2 proceeding right to left). The $\mathrm{KCl}$ solution was passed through the resin in three approximately equal aliquots. Each aliquot was allowed to remain in contact with the resin for at least 2 minutes before the stopcock was opened and 
the solution was allowed to pass through the column. The $\mathrm{KCl}$ is followed by 100 $\mathrm{mL}$ of deionized water which is also flushed through the resin one-third at a time. In this way, sulfate from several liters of a dilute water sample was concentrated in $200 \mathrm{~mL}$ of solution. After adjusting the $\mathrm{pH}$ to the 3 to 4 range using $0.25 \mathrm{M}$ $\mathrm{HCl}$, a few milliliters of saturated $\mathrm{BaCl}_{2}$ solution were added to the solution to precipitate $\mathrm{BaSO}_{4}$. The $\mathrm{BaSO}_{4}$ was filtered, dried, weighed and combined with reagents, combusted and the isotopic composition of the resulting $\mathrm{SO}_{2}$ was analyzed as described above (sections 3.4 and 3.5, the Nuclide mass spectrometer was used to analyze these samples).

\subsubsection{Low-SO ${ }_{4}^{2-}, \mathrm{Cl}^{-}-$free experiments}

Nine experiments were performed in which sulfate was collected on anion exchange resin from synthetic water samples with 10 and $1 \mathrm{mg} / \mathrm{L} \mathrm{SO}_{4}{ }^{2-}$, with and without bicarbonate. The solutions were initially free of $\mathrm{Cl}^{-}$. The results of these experiments are summarized in table 13. Recovery of sulfate in these experiments ranged from 81.4 to 98.0 percent. Sulfur isotope values range from +4.1 to +4.5 per mill with an average value of $+4.31 \pm 0.11$ per mill. The Spearman rank-order correlation was calculated for the fraction of sulfate recovered versus $\delta^{34}$ SVCDT data in table 13. The results $(r=0.101$ and $p=0.80)$ indicate that the null hypothesis of zero correlation between fraction of sulfate collected and $\delta^{34} S$ cannot be rejected. Anion exchange resin is effective for collecting sulfate from dilute water samples with bicarbonate but without chloride in solution. The mean $\delta^{34} S$ values for these sulfate analyses is about 0.2 per mill less than that observed for high-sulfate samples (in table 13; the same starting material was used for all sulfate experiments in the laboratory). A similar-sized shift in $\delta^{34} S$ values for sulfate collected by direct precipitation and on anion exchange resin is observed in data from the field experiments (section 4.3.2). Additional experiments conducted in 1996, which assist in determining the likely source of this 0.2 per mill shift, are summarized in section 4.2.3.

\subsubsection{Low-SO ${ }_{4}{ }^{2-}$, high-Cl- experiments}

Nine experiments were performed in which sulfate was collected on anion exchange resin from synthetic water samples with 10 and $1 \mathrm{mg} / \mathrm{L} \mathrm{SO}_{4}{ }^{2-}$, containing between 500 and $3000 \mathrm{mg} / \mathrm{L} \mathrm{Cl}^{-}$, with and without $\mathrm{HCO}_{3}{ }^{-}$. Results for these experiments are shown in table 14.

In contrast to the high-concentration $\mathrm{SO}_{4}{ }^{2-}$ and low- $\mathrm{SO}_{4}{ }^{2-}, \mathrm{Cl}^{-}$-free experiments, many of these low- $\mathrm{SO}_{4}{ }^{2-}$, high- $\mathrm{Cl}^{-}$experiments have low recovery of sulfate. In addition, for those experiments which produced enough $\mathrm{BaSO}_{4}$ for isotopic analysis, $\delta^{34} S$ values have greater variability. Average $\delta^{34} S$ for these five experiments is 4.92 with a standard deviation of 0.65 per mill. 
Table 13. Results from low-SO ${ }_{4}^{2-}, \mathrm{Cl}^{-}$-free experiments in $1993\left(\mathrm{SO}_{4}{ }^{2-}\right.$ collected on anion exchange resin)

[mg/L, milligrams per liter, conc., concentration; frac., fraction]

\begin{tabular}{ccccc}
\hline Experiment \# & $\begin{array}{c}\text { Conc. } \mathrm{SO}_{4}{ }^{2-} \\
\text { (in } \mathrm{mg} / \mathrm{L} \text { ) }\end{array}$ & $\begin{array}{c}\mathrm{Conc.} \mathrm{HCO}_{3}{ }^{-} \\
\text {(in } \mathrm{mg} / \mathrm{L} \text { ) }\end{array}$ & $\begin{array}{c}\text { Frac. sulfate } \\
\text { recovered } \\
\text { (in \%) }\end{array}$ & $\begin{array}{c}\delta^{34} \mathrm{~S}_{\text {relative }} \\
\text { to VCDT } \\
\text { (in \%o) }\end{array}$ \\
\hline 32 & 10 & 0 & 82.5 & +4.3 \\
33 & 10 & 0 & 81.4 & +4.4 \\
35 & 10 & 40 & 92.5 & +4.2 \\
25 & 10 & 40 & 98.0 & +4.3 \\
28 & 1 & 0 & 81.7 & +4.3 \\
30 & 1 & 0 & 92.5 & +4.4 \\
31 & 1 & 0 & 86.5 & +4.3 \\
34 & 1 & 40 & 83.3 & +4.1 \\
\hline
\end{tabular}

Table 14. Results of (1993) experiments on low-SO ${ }_{4}^{2-}$ high-Cl synthetic samples [mg/L, milligrams per liter; conc., concentration; insuff. spl., insufficient sample]

\begin{tabular}{cccccc}
$\begin{array}{c}\text { Experiment } \\
\#\end{array}$ & $\begin{array}{c}\text { conc. } \mathrm{SO}_{4}^{2-} \\
\text { (in } \mathrm{mg} / \mathrm{L} \text { ) }\end{array}$ & $\begin{array}{c}\text { conc. } \mathrm{Cl}^{-} \\
\text {(in } \mathrm{mg} / \mathrm{L} \text { ) }\end{array}$ & $\begin{array}{c}\text { conc. } \mathrm{HCO}_{3}^{-} \\
\text {(in } \mathrm{mg} / \mathrm{L} \text { ) }\end{array}$ & $\begin{array}{c}\text { Fraction } \\
\text { sulfate } \\
\text { recovered (in } \\
\% \text { ) }\end{array}$ & $\begin{array}{c}\delta^{34} \mathrm{~S} \text { relative } \\
\text { to VCDT } \\
\text { (in \%o) }\end{array}$ \\
36 & 10 & 3000 & 0 & $\geq 8.0$ & insuff. spl. \\
37 & 10 & 3000 & 0 & 11.5 & insuff. spl. \\
38 & 10 & 3000 & 0 & 12.5 & insuff. spl. \\
39 & 10 & 3000 & 0 & 18.6 & insuff. spl. \\
40 & 10 & 3000 & 40 & 13.5 & +3.9 \\
41 & 10 & 3000 & 40 & 25.3 & +4.6 \\
42 & 10 & 1000 & 0 & 99.2 & +5.5 \\
43 & 10 & 1000 & 0 & 66.9 & +5.3 \\
44 & 1.05 & 526.32 & 0 & 52.6 & +5.4 \\
\hline
\end{tabular}


The reason for the low recovery of $\mathrm{SO}_{4}{ }^{2-}$ is that the high- $\mathrm{Cl}^{-}$solutions are selfeluting. When a sample with $10 \mathrm{mg} / \mathrm{L} \mathrm{SO}_{4}{ }^{2-}$ and $3000 \mathrm{mg} / \mathrm{L} \mathrm{Cl}^{-}$is pumped through the anion exchange resin, a steady state is reached regarding the amount of sulfate collected on the resin (see equation 2). Sulfate is displacing the original chloride on the resin while, at the same time, chloride in the sample is displacing sulfate that has occupied the exchange sites. As the experiments summarized in table 14 were being performed, several modifications to the experimental procedure were investigated to determine if increased recovery of sulfate could be obtained. One approach was to double the volume of sample passed through the resin (experiments 40 and 41 ). This did not result in a corresponding increase in the recovery of sulfate suggesting that, after a few liters of this type of solution has passed through the resin cartridge, a steady state is reached between $\mathrm{SO}_{4}{ }^{2-}$ and $\mathrm{Cl}^{-}$displacing one another on the resin.

Another modification to the experimental procedure was to increase the volume of resin used to collect the sulfate. Experiment 40 utilized a full drying tube of resin and for experiments 41 to 44 two full drying tubes of resin were used. Increasing the amount of resin did result in an increase in the number of milligrams of sulfate recovered. The increase in the number of exchange sites available allowed more $\mathrm{SO}_{4}{ }^{2-}$ to be retained, even though only a fraction of the sites were occupied by $\mathrm{SO}_{4}{ }^{2-}$.

Even with the increase in recovery of sulfate, the isotopic composition of the sulfate collected in these experiments is more variable, and four of the five sulfur isotopic analyses are more positive than the averages obtained for the highconcentration $\mathrm{SO}_{4}{ }^{2-}$ experiments ( +4.5 per mill) and in the low-SO ${ }_{4}{ }^{2-}, \mathrm{Cl}^{-}$-free experiments ( +4.3 per mill). This suggests that there may be preferential removal of $32 S$ from the resin during the self-elution process. An alternative method (e.g., Fritz and others, 1957) should be considered if it is necessary to collect sulfate from samples with sulfate present at low concentration and chloride present at high concentration. Additional discussion on collection of sulfate from chloridebearing water samples on anion exchange resin is included in section 4.3.2.

\subsubsection{Sulfate collection on anion exchange resin (with low $\mathrm{Cl}^{-}$) revisited}

A group of sulfate collection experiments using anion exchange resin were carried out in the Fall of 1996 to (1) compare the process of pumping a sulfate solution through a resin cartridge (flow-through method, as in figure 3 ) with simply placing the resin in a beaker of solution (batch method) to collect the sulfate, (2) better track sulfate not collected by the resin by analyzing sulfate concentration in solutions after contact with resin and (3) determine the origin of the 0.2 per mill isotopic shift between samples collected by direct precipitation and on anion exchange resin.

Procedure -- For all the experiments summarized in table 15, the starting solution was $2 \mathrm{~L}$ of solution containing $500 \mathrm{mg}$ of sulfate (about $740 \mathrm{mg}$ of $\mathrm{Na}_{2} \mathrm{SO}_{4}$ ). This amount of sulfate represents about 35 percent of the total capacity of the $25 \mathrm{~mL}$ 
of anion exchange resin used in these experiments.. Experiments 1 and 3 were performed on chloride-free solutions; experiments 5 and 7 were performed on solutions containing about $1 \mathrm{~mL}$ of $1 \mathrm{M} \mathrm{HCl}$ which was used to adjust the $\mathrm{pH}$ to between 3 and 4 . The designation " $A$ " following the experiment number indicates a duplicate experiment, for example, experiments 1 and $1 A$ are two experiments performed with identical starting materials and under identical conditions. Duplicate experiments were performed to test the reproducibility of the method.

Sulfate collection by batch method -- After the starting solution was prepared, a 58-mL subsample was pipetted out and saved in a separate bottle for ion chromatographic analysis. Twenty-five milliiters of the Amberlite IRA-400 anion exchange resin (pretreated to remove sulfate and rinsed to remove excess chloride, as discussed in section 2.1.5) was added to the beaker containing the starting sulfate solution and stirred for 10 minutes. The solution was allowed to remain in contact with the resin overnight. The next day, another sub-sample of the solution was pipetted out, and the solution plus resin was poured through a chromatography column in preparation for elution of the sulfate.

Sulfate collection by flow-through method -- This is essentially the same procedure as discussed in section 2.1.5 and the beginning of section 4.2. After the starting solution was prepared, a 58-mL sub-sample was pipetted out and saved in a separate bottle for ion chromatographic analysis. Twenty-five milliliters of prepared anion exchange resin was loaded into a clean "drying" tube and the equipment set up as shown in figure 3 . The solution was pumped through the resin at a rate of $0.2 \mathrm{~L}$ minute and collected in a beaker. The solution that had been pumped through the resin was stored in bottles and saved for ion chromatographic analysis.

Elution of the sulfate -- Resins from all experiments were eluted by essentially the same method described in section 3.2. After transferring the resin to a chromatography column, the sulfate was eluted by passing $100 \mathrm{~mL}$ of $3 \mathrm{M} \mathrm{KCl}$ through the column about $33 \mathrm{~mL}$ at a time. Each addition of $\mathrm{KCl}$ was allowed to remain in contact with the resin for 4 minutes before it was drained into a beaker. The $\mathrm{KCl}$ was followed by $100 \mathrm{~mL}$ of deionized water, also passed through the resin in three approximately $33 \mathrm{~mL}$ portions but were allowed to drain immediately into the beaker. A second elution was performed for all these experiments, and a small amount of $\mathrm{BaSO}_{4}$ was obtained in the second elution for all experiments except 7 and $7 A$. The resins from these experiments $(1,1 A$, $3,3 A, 5$, and $5 A$ ) were eluted a third time to assure that all sulfate had been removed. For experiments 7 and $7 A$, the elution procedure was modified such that $120 \mathrm{~mL}$ of $\mathrm{KCl}$ solution was passed through the resin in four $30 \mathrm{~mL}$ portions that were allowed to remain in contact with the resin for 5 minutes before the $\mathrm{KCl}$ was drained. By utilizing this modification, all the sulfate was removed from the resin in the first elution and no $\mathrm{BaSO}_{4}$ precipitated from the second elution.

The $\mathrm{KCl}$ solutions used to elute the resins were acidified and the sulfate precipitated and filtered as described in section 3.2 (the oxidation step was not 
necessary for these laboratory solutions). The $\mathrm{BaSO}_{4}$ was precipitated at room temperature. Sulfate in the start and end solutions was prepared for sulfur isotopic analysis by precipitating $\mathrm{BaSO}_{4}$ directly from these solutions following the procedure in section 4.1. $\mathrm{BaSO}_{4}$ was weighed, combined with reagents and converted to $\mathrm{SO}_{2}$ as described in sections 3.4.1 and 3.4.2. The Finnigan MAT 251 mass spectrometer was used to analyze the sulfur isotopic composition of $\mathrm{SO}_{2}$ produced from these experimental products. The sulfur isotopic composition $\left(\delta^{34} \mathrm{~S}\right)$ of the $\mathrm{Na}_{2} \mathrm{SO}_{4}$ starting material for experiments 1 and 3 is 4.24 per mill $( \pm$ $0.05, n=4$ ) and the $\mathrm{Na}_{2} \mathrm{SO}_{4}$ starting material for experiments 5 and 7 has $\delta^{34} S$ of 6.65 per mill $( \pm 0.07, n=5)$.

Table 15. Results of experiments (1996) in which sulfate was collected on anion exchange resin by both batch and flow-through methods [ppm, parts per million; sol'n, solution; conc., concentration; n. a., not analyzed]

\begin{tabular}{|c|c|c|c|c|c|c|c|c|}
\hline $\begin{array}{c}\text { Exp } \\
\#\end{array}$ & $\begin{array}{c}\text { Batch or } \\
\text { Flow- } \\
\text { through }\end{array}$ & $\begin{array}{c}\text { Pre- } \\
\text { acidi- } \\
\text { fied } \mathrm{Wl} \\
\mathrm{HCl} \text { ? }\end{array}$ & $\begin{array}{l}\mathrm{SO}_{4}^{2-} \\
\text { conc. of } \\
\text { start sol'n } \\
(\mathrm{ppm})^{1}\end{array}$ & $\begin{array}{l}\mathrm{SO}_{4}^{2-} \\
\text { conc. of } \\
\text { end sol'n } \\
(\mathrm{ppm})^{1}\end{array}$ & $\begin{array}{l}\text { Elu- } \\
\text { tion } \\
\#\end{array}$ & $\begin{array}{c}\text { Fraction of } \\
\text { sulfate } \\
\text { recovered (in } \\
\% \text { ) } \\
\end{array}$ & $\begin{array}{l}\delta^{34} S \\
\text { relative } \\
\text { to VCDT } \\
\text { (in \%o) }\end{array}$ & $\begin{array}{c}\text { Bulk } \\
\delta^{34 S} \\
(\text { in } \% \circ)^{2}\end{array}$ \\
\hline 1 & Batch & no & 247 & 6.8 & $\begin{array}{l}1 \\
2\end{array}$ & $\begin{array}{c}97.38 \\
1.58\end{array}$ & $\begin{array}{l}4.3 \\
5.1\end{array}$ & 4,3 \\
\hline $1 \mathrm{~A}$ & Batch & no & 249 & 11.9 & $\begin{array}{l}1 \\
2\end{array}$ & $\begin{array}{c}95.81 \\
1.11\end{array}$ & $\begin{array}{l}4.2 \\
5.8\end{array}$ & 4.2 \\
\hline 3 & $\begin{array}{l}\text { Flow- } \\
\text { through }\end{array}$ & no & 250 & 2.2 & $\begin{array}{l}1 \\
2\end{array}$ & $\begin{array}{c}100.13 \\
0.72\end{array}$ & $\begin{array}{l}4.1 \\
5.5\end{array}$ & 4.2 \\
\hline $3 A$ & $\begin{array}{l}\text { Flow- } \\
\text { through }\end{array}$ & no & 244 & 1.0 & $\begin{array}{l}1 \\
2\end{array}$ & $\begin{array}{c}101.00 \\
0.45\end{array}$ & $\begin{array}{l}\text { n. a. } \\
\text { n. a. }\end{array}$ & \\
\hline 5 & Batch & yes & 244 & 31 & $\begin{array}{l}1 \\
2\end{array}$ & $\begin{array}{c}89.34 \\
0.41\end{array}$ & $\begin{array}{l}6.6 \\
7.5\end{array}$ & 6.6 \\
\hline $5 \mathrm{~A}$ & Batch & yes & 244 & 28 & $\begin{array}{l}1 \\
2\end{array}$ & $\begin{array}{l}92.3 \\
0.28\end{array}$ & $\begin{array}{l}\text { n. a. } \\
\text { n. a. }\end{array}$ & \\
\hline 7 & $\begin{array}{l}\text { Flow- } \\
\text { through }\end{array}$ & yes & 238 & 2.0 & 1 & 99.8 & 6.6 & 6.6 \\
\hline $7 A$ & $\begin{array}{l}\text { Flow- } \\
\text { through }\end{array}$ & yes & 246 & 1.5 & 1 & 102.87 & n. a. & \\
\hline
\end{tabular}

1 concentrations measured by ion chromatograph.

2 Sum of sulfur isotopic composition of sulfate from first and second elutions multiplied by the weighted fraction of sulfate recovered from the resin in each elution.

Results -- Results of these experiments are summarized in table 15. These experiments illustrate several important points. First, sulfate can be collected on and eluted from anion exchange resin without imparting significant sulfur isotopic fractionation. The sulfur isotopic composition of bulk sulfate collected in the elutions is identical to the sulfur isotopic composition of the starting materials for 
these experiments to within analytical uncertainty. Second, sulfate remaining in solution after it has passed through the anion exchange resin and the sulfate remaining on the resin after the first elution both have more positive $\delta^{34} S$ values than the starting material by 0.5 to 1.5 per mill. (Sulfur isotopic composition of sulfate in the end solution was 5.5 per mill for experiment 3 and 7.1 per mill for experiment 5). Third, the flow-through method is more efficient for collecting the sulfate than the batch method, although both methods produce acceptable results in terms of the sulfur isotopic composition of the sulfate collected.

The results of these experiments assist in the interpretation of the 0.2 per mill isotopic shift noted for the low-SO ${ }_{4}^{2-}$, low- $\mathrm{Cl}^{-}$experiments from 1993 (section 4.2.1). The mean fraction of sulfate recovered in the 1993 experiments (table 13) was 88.04 percent, so that, on average, 11.96 percent of the sulfate either remained in solution or was not removed from the anion exchange resin (only one elution was done on each resin for the 1993 experiments ${ }^{8}$ ). The 1996 experiments suggest that in either case the result, isotopically, would be the same -- sulfate remaining in solution after contact with the resin ${ }^{9}$ and sulfate remaining on the anion exchange resin after the first elution would both be enriched in ${ }^{34} \mathrm{~S}$ relative to the starting material, and hence, sulfate from the first elution would be slightly depleted in $34 \mathrm{~S}$. Using 4.47 per mill as the accepted sulfur isotopic composition of the starting material (section 4.1) and using the weight fraction and isotopic composition of the sulfate collected in the 1993 experiments ( 0.8804 and 4.31 per mill, respectively), $\delta^{34} S$ of the 0.1196 weight fraction of sulfate not collected is 5.64 per mill. The difference between this value and $\delta^{34} S$ of the starting material (1.17 per mill) is within the range measured in the 1996 experiments.

\subsection{Field testing of sulfate collection techniques}

Sulfate was collected by both direct precipitation and on anion exchange resin at two wells east of Sarasota, Florida. The locations and compositional characteristics of the wells are summarized in table 16. For brevity, the wells will be referred to as the Upper Intermediate well and the Suwannee well.

Three important questions concerning the sulfate collection procedures were addressed by the experiments conducted at these wells. (1) How much time is required to remove (strip) hydrogen sulfide by bubbling nitrogen gas through an acidified ground-water sample from which sulfate will be collected? (2) Which sulfate collection technique produces the most quantitative and isotopically

\footnotetext{
8 Routine second elutions were begun in November 1994. The time for each $33 \mathrm{~mL}$ portion of the $\mathrm{KCl}$ solution to be in contact with the resin was increased from 2 to 4 minutes in February 1995. 9 The amount of sulfate ion that may have passed through the resin in the 1993 experiments is not known. Since the sulfate concentration in the 1993 experiments was much lower $(10 \mathrm{mg} / \mathrm{L}$ or $1 \mathrm{mg} / \mathrm{L})$ than the sulfate concentration of the 1996 experiments $(250 \mathrm{mg} / \mathrm{L})$, if even a few tenths of a $\mathrm{mg} / \mathrm{L}$ of sulfate ion remained in solution after passing through the resin, this would represent a much larger fraction of the sulfate than that remaining in solution in the 1996 experiments, and would help explain why lower fractions of the original sulfate were collected in the 1993 experiments.
} 
consistent results? (3) Will oxidized sulfide contaminate the sulfate if sulfate is collected on anion exchange resin or by direct precipitation in the field without first stripping dissolved sulfide? The sulfate versus sulfide concentrations of the water from these wells is not ideally suited to answering the third question (see table 16). A ground water with $\mathrm{S}^{2-}$ concentration greater than or equal to $\mathrm{SO}_{4}{ }^{2-}$ would potentially give more conclusive results. At the time that this field work was conducted (March 1994), however, the location of such an ideal well was not known, and so these experiments were carried out at the Upper Intermediate and Suwannee wells. Extent of oxidation of sulfide to sulfate was also evaluated in laboratory experiments which are discussed in sections 4.3.1 and 4.5.4.

\subsubsection{Stripping of $\mathrm{H}_{2} \mathrm{~S}$ prior to collection of sulfate}

Six experiments, one at each well site and four in the laboratory, were performed in order to (1) determine how long to bubble nitrogen through a 10-liter bucket of ground water to remove $\mathrm{H}_{2} \mathrm{~S}$ prior to collection of sulfate and (2) evaluate two methods for diluting water samples with dissolved sulfide concentrations greater than $0.6 \mathrm{mg} / \mathrm{L}$ prior to $\mathrm{S}^{2-}$ analysis using a Hach spectrophotometer. In the first three experiments (one in the laboratory and one at each well site, all in 1994) water samples with greater than $0.6 \mathrm{mg} / \mathrm{L} \mathrm{S}^{2-}$ were diluted with deionized water prior to the addition of the Hach reagents and nitrogen gas flow rates were not measured. Three laboratory experiments (performed in March 1995) differed in the following ways: (1) samples with greater than $0.6 \mathrm{mg} / \mathrm{L} \mathrm{S}^{2-}$ were analyzed by adding the reagents to a small amount $(5 \mathrm{~mL})$ of the sample and diluting after the reaction time was complete, (2) nitrogen flow rate was measured with a flowmeter and the effect of varying the nitrogen flow rate was quantified and (3) after sulfide stripping was complete, the solution was passed through anion exchange resin to collect dissolved sulfate. The amount of sulfide oxidized to sulfate and the isotopic composition of this sulfate was determined.

Procedure -- Equipment was set up as shown in figure 2 (in the 1994 experiments, the flowmeter was not used). A clean, plastic bucket was filled to the 10-liter mark with a natural ground water or deionized water. Synthetic sulfide-bearing ground water was created by adding a measured amount of sodium sulfide to deionized water that had been bubbled with $\mathrm{N}_{2}$ gas for over three hours to reduce its dissolved oxygen content. The dissolved oxygen content of the water decreased from $8.7 \mathrm{mg} / \mathrm{L}$ before bubbling to $1.1 \mathrm{mg} / \mathrm{L}$ after three hours of bubbling. The $\mathrm{pH}$ of the sample was measured with a $\mathrm{pH}$ meter (calibrated with $\mathrm{pH}=7.00$ and 4.00 buffers) and the sample was immediately acidified with $\mathrm{HCl}$ to $\mathrm{pH}$ between 3 and 4 . A sample of the water was collected at this point (in the 1995 experiments, a sample was also collected before acidification). Immediately thereafter, $\mathrm{N}_{2}$ gas was bubbled through the bucket using a pair of gas-dispersion tubes. In the 1995 experiments, a selected 
Table 16. Information on Florida' well sites

[l.s., land surface; $\mathrm{m}$, meters; $\mathrm{cm}$, centimeters; $\mathrm{mg} / \mathrm{L}$, milligrams per liter]

\begin{tabular}{|c|c|c|}
\hline Well Site & Romp 22 & Romp 17 \\
\hline Latitude & $27^{\circ} 18^{\prime} 13^{\prime \prime} N$ & $27^{\circ} 10^{\prime} 26^{\prime \prime} \mathrm{N}$ \\
\hline Longitude & $82^{\circ} 20^{\prime} 13^{\prime \prime} \mathrm{W}$ & $81^{\circ} 58^{\prime} 36^{\prime \prime} W$ \\
\hline Well Name & Upper Intermediate & Suwannee (Flowing) \\
\hline Site I.D. \# & 1271813082201394 & ${ }^{1} 271026081583602$ \\
\hline Depth (m) & 138.1 & 1204.2 \\
\hline Diameter & $\begin{array}{c}5.0 \mathrm{~cm} \text { to } 9.1 \mathrm{~m} \\
3.2 \mathrm{~cm} \text { from } 9.1 \\
\text { to } 38.1 \mathrm{~m}\end{array}$ & $15.2 \mathrm{~cm}$ \\
\hline Open or screened interval (m) & screened 27.4 to $38.1 \mathrm{~m}^{1}$ & open 189.0 to $204.2 \mathrm{~m}^{1}$ \\
\hline Casing type & $\begin{array}{c}5.0 \mathrm{~cm} \text { PVC I.s. to } 9.1 \mathrm{~m} \\
3.2 \mathrm{~cm} \text { PVC } 9.1 \text { to } 27.4 \mathrm{~m} \\
3.2 \mathrm{~cm} \text { PVC screen }(0.05 \mathrm{~cm} \\
\text { slot) } 27.4 \text { to } 38.1 \mathrm{~m} \\
\text { silica sand pack } 24.3 \text { to } 40.2 \mathrm{~m} \\
3.2 \mathrm{~cm} \text { PVC } 38.1 \text { to } \\
40.2 \mathrm{~m}\end{array}$ & $\begin{array}{c}15.2 \mathrm{~cm} \text { PVC from l.s. to } \\
189.0 \mathrm{~m}\end{array}$ \\
\hline $\mathrm{SO}_{4}{ }^{2-}$ concentration & $48 \mathrm{mg} / \mathrm{L}$ & $380 \mathrm{mg} / \mathrm{L}$ \\
\hline $\mathrm{S}^{2-}$ concentration & $0.20 \mathrm{mg} / \mathrm{L}$ & $2.95 \mathrm{mg} / \mathrm{L}^{2}$ \\
\hline $\mathrm{Cl}^{-}$concentration ${ }^{3}$ & $73 \mathrm{mg} / \mathrm{L}$ & $64 \mathrm{mg} / \mathrm{L}$ \\
\hline $\mathrm{HCO}_{3}^{-}$concentration 3 & $298 \mathrm{mg} / \mathrm{L}$ & $191 \mathrm{mg} / \mathrm{L}$ \\
\hline
\end{tabular}

1 Information given in Sacks and Tihansky (1996, table 4, p. 16).

2 This $S^{2-}$ concentration was calculated by adding sulfide collected as $\mathrm{Ag}_{2} \mathrm{~S}$ plus $\mathrm{S}^{2-}$ remaining in solution in carboy after collecting sulfide by nitrogen stripping. Measurements of $S^{2-}$ greater than $0.6 \mathrm{mg} / \mathrm{L}$ were lowered by oxidation of $\mathrm{S}^{2-}$ during dilution. For details see sections 4.3 .1 and 4.5 , table 27.

3 Analyses from Laura Sacks (oral comm., 1994).

$\mathrm{N}_{2}$ flow rate was maintained using a flowmeter. The dispersion tubes were swirled in the bucket in order to achieve thorough mixing of the water. A timer was started as soon as the $\mathrm{N}_{2}$ flow began and water samples were collected at intervals in order to track the loss of $\mathrm{H}_{2} \mathrm{~S}$ with time. Samples for $\mathrm{S}^{2-}$ analysis were collected by dipping $60-\mathrm{mL}$ glass bottles into the bucket, filling them completely and closing the bottles tightly with polyseal caps. When sulfide stripping was complete, the solution was pumped slowly through an anion 
exchange resin cartridge and the sulfate was subsequently eluted from the resin as described in section 4.2.3.

The dissolved sulfide concentration of the water samples was measured using a Hach spectrophotometer. It was necessary to dilute synthetic and Suwannee well water samples because their $\mathrm{S}^{2-}$ concentrations were greater than $0.6 \mathrm{mg} / \mathrm{L}$, the upper limit of measurement with the spectrophotometer. The two methods used are described below.

"DI water first" -- In the 1994 experiments, dilutions were performed by measuring an appropriate amount of the water sample and adding deionized (DI) water to create a 5:1 or 10:1 dilution (e.g., $20 \mathrm{~mL}$ water sample diluted to $100 \mathrm{~mL}$ for a $5: 1$ dilution or $25 \mathrm{~mL}$ water sample diluted to $250 \mathrm{~mL}$ for a 10:1 dilution). The water sample was measured in a $10 \mathrm{~mL}$ graduated cylinder or 25 or $50 \mathrm{~mL}$ pipet and the dilutions made in 100 or $250 \mathrm{~mL}$ volumetric flasks. After mixing by inverting and shaking the flask, $25 \mathrm{~mL}$ of the diluted sample was poured into the sample cell for the spectrophotometer, the reagents added, and the procedure for analysis described in the Hach handbook (Hach Co., 1988) was followed.

"Reagents first" -- This method was suggested to the authors by D. Kirk Nordstrom (oral comm., 1994). A small amount of water sample $(5 \mathrm{~mL}$ in these experiments) is pipetted into a clean, dry $25 \mathrm{~mL}$ volumetric flask, the Hach reagents are added and the color is allowed to develop for 5 minutes. Then deionized water is added to bring the volume of the solution up to $25 \mathrm{~mL}$. The flask was closed with a polyseal cap and shaken to mix. The solution is poured into the cell and analyzed with the spectrophotometer. Results obtained with these two dilution methods are discussed below.

Results -- Selected data from the three 1994 experiments are listed in table 17 and the data are plotted in figure 9. Selected data from the 1995 experiments are listed in table 18 and plotted in figures 10 and 11.

Stripping rate and effect of nitrogen flow rate -- The 1994 experiments illustrated qualitatively the relationship between nitrogen flow rate and sulfide stripping rate. About 45 minutes were required to strip $\mathrm{H}_{2} \mathrm{~S}$ from the 1994 laboratory sample which started with an $\mathrm{S}^{2-}$ concentration estimated to have been about $2.2 \mathrm{mg} / \mathrm{L}$ (if uncertainty caused by the dilution technique is accounted for, see figure $9 \mathrm{a}$ ) to the recommended $\mathrm{S}^{2-}$ concentration of $0.01 \mathrm{mg} / \mathrm{L}$ (figure $1 \mathrm{a}$ and section 2.1.3). In contrast, the ground water from the Suwannee well (figure 9b), which had a comparable initial $\mathrm{S}^{2-}$ concentration of $2.95 \mathrm{mg} / \mathrm{L}$, required only about 15 minutes to remove the $\mathrm{H}_{2} \mathrm{~S}$ to the same level $(0.01 \mathrm{mg} / \mathrm{L})$. Likewise, the Upper Intermediate well, which contained less dissolved sulfide to begin with $(0.20$ $\mathrm{mg} / \mathrm{L}$ ), required only eight minutes to strip the $\mathrm{H}_{2} \mathrm{~S}$ to below $0.01 \mathrm{mg} / \mathrm{L}$. The difference in the stripping rates between the laboratory and field experiments is illustrated by the slopes of the exponential curves fit to the data in figure $9 \mathrm{c}$. 
Table 17. $\mathrm{H}_{2} \mathrm{~S}$ stripping experiments in laboratory and field (1994). "DI water first" dilution method was used; $\mathrm{N}_{2}$ flow rate was not measured ${ }^{1}$

[min., minutes; L, liters; $\mathrm{mg} / \mathrm{L}$, milligrams per liter]

\begin{tabular}{|c|c|c|c|c|c|c|}
\hline & \multicolumn{2}{|c|}{ Laboratory exp. } & \multicolumn{2}{|c|}{ Upper Intermediate } & \multicolumn{2}{|c|}{ Suwannee Well } \\
\hline Time (min.) & Dilution & $\begin{array}{c}\mathrm{S}^{2-} \\
(\mathrm{mg} / \mathrm{L})\end{array}$ & Dilution & $\begin{array}{c}\mathrm{S}^{2-} \\
(\mathrm{mg} / \mathrm{L})\end{array}$ & Dilution & $\begin{array}{c}\mathrm{S}^{2-} \\
(\mathrm{mg} / \mathrm{L})\end{array}$ \\
\hline $0: 00$ & $10: 1$ & 1.63 & none & 0.128 & $10: 1$ & 2.18 \\
\hline $0: 30$ & $10: 1$ & 1.38 & & & & \\
\hline $1: 00$ & $10: 1$ & 1.30 & none & 0.070 & $10: 1$ & 1.70 \\
\hline $1: 30$ & $10: 1$ & 1.16 & & & & \\
\hline $2: 00$ & $10: 1$ & 1.15 & none & 0.046 & $10: 1$ & 1.08 \\
\hline 3:00 & $10: 1$ & 1.08 & & & & \\
\hline 4:00 & $10: 1$ & 0.97 & & & & \\
\hline $5: 00$ & $10: 1$ & 0.87 & none & 0.021 & $10: 1$ & 0.44 \\
\hline $6: 00$ & $10: 1$ & 0.73 & & & & \\
\hline 7:00 & $10: 1$ & 0.59 & & & & \\
\hline 8:00 & $10: 1$ & 0.58 & none & 0.004 & none & 0.132 \\
\hline $9: 00$ & $10: 1$ & 0.46 & & & & \\
\hline 10:00 & none & 0.577 & & & & \\
\hline $11: 00$ & & & none & 0.004 & none & 0.034 \\
\hline $12: 00$ & none & 0.396 & & & & \\
\hline $15: 00$ & none & 0.337 & none & 0.000 & none & 0.006 \\
\hline $20: 00$ & none & 0.157 & none & 0.001 & none & 0.001 \\
\hline $30: 00$ & none & 0.053 & & & & \\
\hline $45: 00$ & none & 0.009 & & & & \\
\hline $60: 00$ & none & 0.002 & & & & \\
\hline
\end{tabular}

1 Constraints on the likely flow rates in these experiments: Data plotted in figure 9 indicate that the nitrogen flow rate in the laboratory experiment was significantly lower than the flow rate in the field experiments. Flow rate in the field experiment at the Suwannee well is known to have been greater than $3 \mathrm{~L}$ minute (see text). Comparison with the data from the 1995 experiments (figure 10) suggests that the nitrogen flow rate for the 1994 laboratory experiment less than or equal to 4 Lminute and the flow rate for the experiment at the Suwannee well was greater than or equal to 7.7 Lminute. Nitrogen flow rate for the experiment at the Upper Intermediate well was probably between 6-8 L/minute. 
Table 18. $\mathrm{H}_{2} \mathrm{~S}$ stripping experiments in the laboratory (1995). "Reagents first" dilution method was used. $\mathrm{N}_{2}$ flow rate measured with flow meter

[min., minutes; L/min., liters per minute; $\mathrm{mg} / \mathrm{L}$, milligrams per liter, $\mathrm{n}$. d., not determined]

\begin{tabular}{|c|c|c|c|c|c|c|}
\hline \multirow{3}{*}{$\frac{\text { Date }}{\frac{\mathrm{N}_{2} \text { flow }}{\text { Time (min.) }}}$} & \multirow{2}{*}{\multicolumn{2}{|c|}{$\frac{3 / 8 / 95}{4 \mathrm{~L} / \mathrm{min} .}$}} & \multirow{2}{*}{\multicolumn{2}{|c|}{$\frac{3 / 15 / 95}{6 \mathrm{~L} \text { min. }}$}} & \multirow{2}{*}{\multicolumn{2}{|c|}{$\frac{3 / 22 / 95}{7.7 \mathrm{~L} / \mathrm{min} .}$}} \\
\hline & & & & & & \\
\hline & Dilution & $\begin{array}{c}\mathrm{S}^{2-} \\
(\mathrm{mg} / \mathrm{L})\end{array}$ & Dilution & $\begin{array}{c}\mathrm{S}^{2-} \\
(\mathrm{mg} / \mathrm{L})\end{array}$ & Dilution & $\begin{array}{c}\mathrm{S}^{2-} \\
(\mathrm{mg} / \mathrm{L})\end{array}$ \\
\hline pre-acid & $5: 1$ & 2.420 & $5: 1$ & 2.030 & $5: 1$ & 2.535 \\
\hline 0:00 & $5: 1$ & 2.045 & $5: 1$ & 1.860 & $5: 1$ & 2.030 \\
\hline $1: 00$ & $5: 1$ & 1.715 & $5: 1$ & 1.505 & $5: 1$ & 1.545 \\
\hline 2:00 & $5: 1$ & 1.490 & $5: 1$ & 1.275 & $5: 1$ & 1.190 \\
\hline $3: 30$ & $5: 1$ & 1.225 & $5: 1$ & 0.980 & $5: 1$ & 0.820 \\
\hline 5:00 & $5: 1$ & 0.980 & $5: 1$ & 0.695 & $5: 1$ & 0.520 \\
\hline 7:00 & $5: 1$ & 0.645 & $5: 1$ & 0.480 & $5: 1$ & 0.335 \\
\hline $10: 00$ & $5: 1$ & 0.500 & $5: 1$ & 0.260 & $5: 1$ & 0.160 \\
\hline $10: 00$ & none & 0.394 & none & 0.211 & none & 0.131 \\
\hline $12: 30$ & none & 0.277 & none & 0.135 & none & 0.072 \\
\hline $15: 00$ & none & 0.204 & none & 0.078 & none & 0.042 \\
\hline $20: 00$ & none & 0.087 & none & 0.025 & none & 0.013 \\
\hline $30: 00$ & none & 0.028 & none & 0.005 & none & 0.014 \\
\hline 40:00 & none & 0.007 & none & 0.001 & none & n. d. \\
\hline
\end{tabular}

An attempt was made to measure the flow rate of $\mathrm{N}_{2}$ gas during the experiment at the Suwannee well, but the desired flow rate was off scale on the flowmeter available, hence flow rate during this experiment was greater than 3 $\mathrm{L}$ minute $\mathrm{N}_{2}$. The $\mathrm{N}_{2}$ flow rate for the other two experiments was not measured.

A quantitative assessment of the influence of nitrogen flow rate on stripping rate is obtained from the results of the three 1995 experiments. Data from table 18 , plotted in Figure 10b, show that stripping rate was fastest at the highest $\mathrm{N}_{2}$ flow rate $\left(7.7 \mathrm{~L} /\right.$ minute) and slowest at the lowest $\mathrm{N}_{2}$ flow rate used $(4 \mathrm{~L} /$ minute). This is also illustrated in figure 11 where time to strip to $S^{2-} \leq 0.01 \mathrm{mg} / \mathrm{L}$ is plotted against $\mathrm{N}_{2}$ flow rate. In the experiment with $\mathrm{N}_{2}$ flow rate of $7.7 \mathrm{~L}$ minute, about 20 minutes were required to strip dissolved sulfide to the $0.01 \mathrm{mg} / \mathrm{L}$ level. This is similar to the length of time required to strip the sulfide at the Suwannee well. 

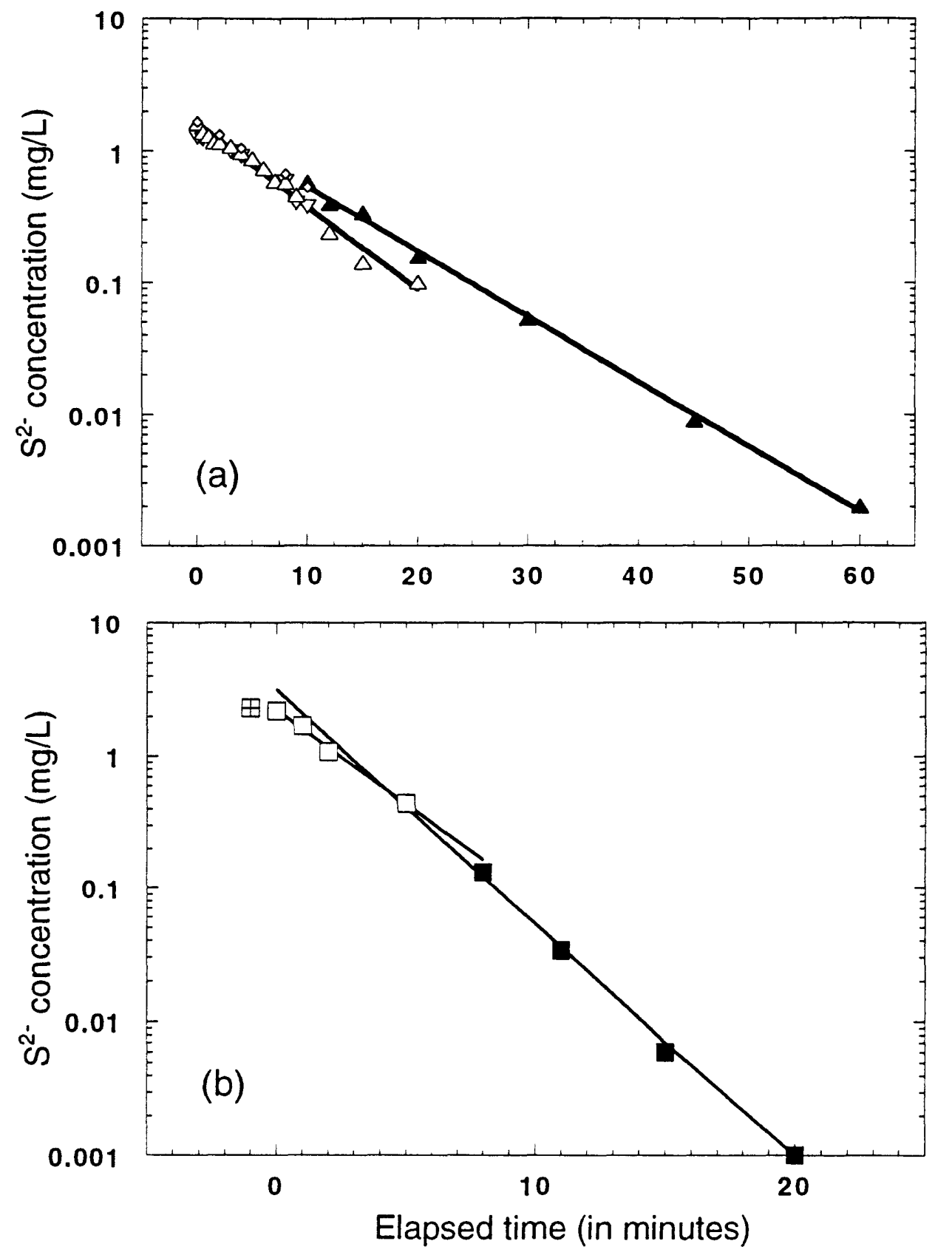

Figure 9. (a) Results of a 1994 laboratory test of sulfide removal by the nitrogen stripping technique. Open triangles indicate measurements made on samples diluted with oxygenated deionized water (normal-orientation triangles indicate 10:1 dilution, inverted triangles indicate 5:1 dilutions) and solid triangles indicate undiluted analyses. Samples from between 10 and 20 minutes after the start of the experiment were analyzed both with and without dilution and there is a clear shift to lower apparent dissolved sulfide concentration for the diluted analyses. About 45 minutes were required to remove the sulfide down to the $0.01 \mathrm{mg} / \mathrm{L}$ level recommended. (b) Results of $\mathrm{H}_{2} \mathrm{~S}$ stripping experiments on a ground-water sample from the Suwannee well. Open squares indicate samples measured by the DI water first dilution method; solid squares indicate samples measured without dilution. The square with a cross indicates the concentration of dissolved sulfide before acidification of the sample $(2.32 \mathrm{mg} / \mathrm{L}$, measured with the spectrophotometer). This data point is plotted at time $=-1$ minute to indicate sulfide concentration before acidification and the start of the experiment. Dissolved sulfide concentration was below $0.01 \mathrm{mg} / \mathrm{L}$ after 15 minutes of nitrogen stripping. 


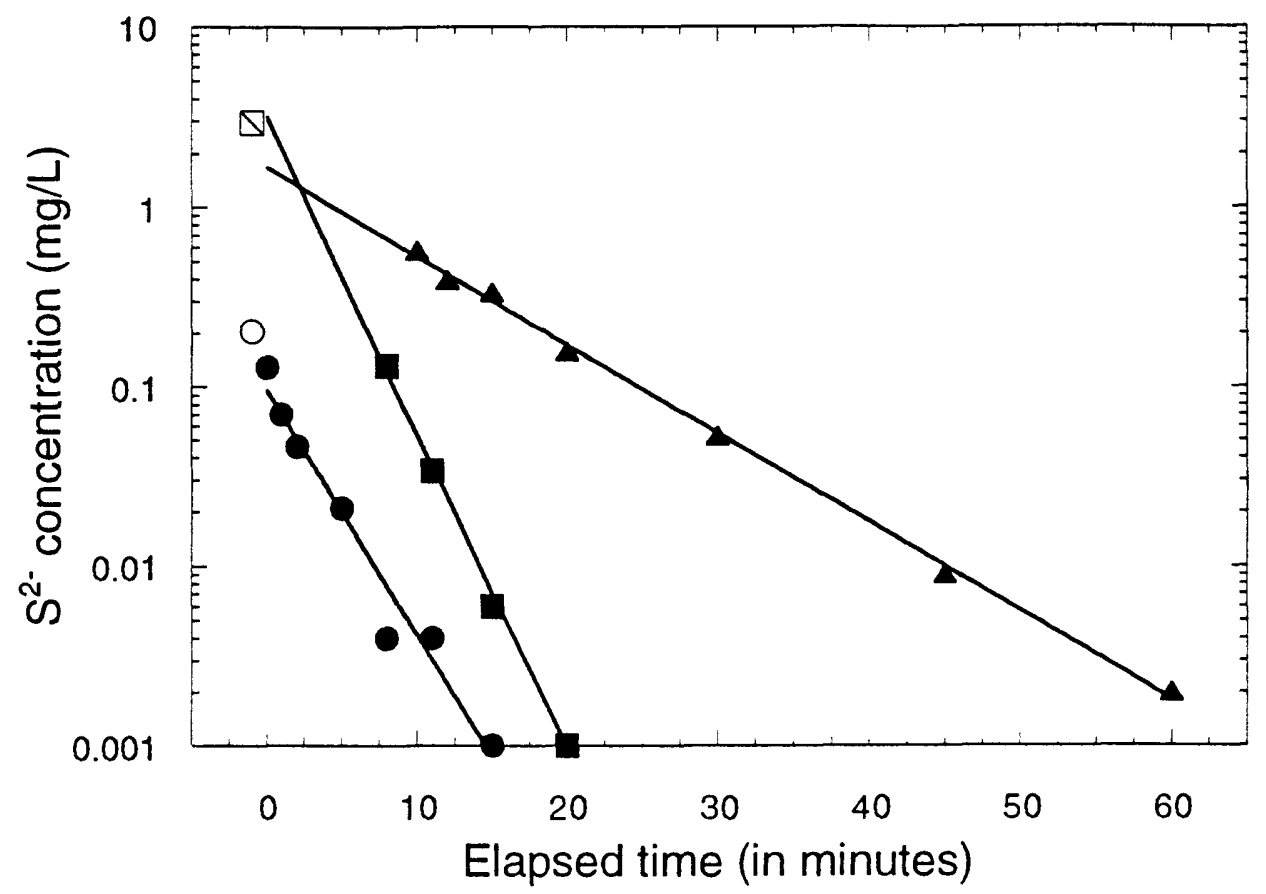

Figure 9. (c) Comparison of all three 1994 sulfide stripping experiments. Only undiluted data and exponential fits to these data are plotted. Triangles = laboratory experiment, squares = ground water from the Suwannee well, and circles = data from a stripping experiment at the Upper Intermediate well. The square with a slash is the inferred dissolved sulfide concentration for the Suwannee well $(2.95 \mathrm{mg} / \mathrm{L}$, see section 4.5 .3$)$. The open circle is the concentration of dissolved sulfide in ground water from the Upper Intermediate well before acidification $(0.200$ $\mathrm{mg} / \mathrm{L}$ ). These data points are plotted at time $=-1$ minute to indicate sulfide concentration before acidification and the start of the experiment. Sulfide concentrations of all samples from the experiment at the Upper Intermediate well were measured without dilution. Although the starting concentrations were similar, 45 minutes were required to strip sulfide (to the $0.01 \mathrm{mg} / \mathrm{L}$ ) in the laboratory experiment whereas only 15 minutes was required in the field experiment at the Suwannee well.

Recommendations -- The following recommendations apply when removing $\mathrm{H}_{2} \mathrm{~S}$ from an acidified water sample before collecting samples for sulfur isotopic analysis of sulfate: (1) use a flowmeter so that $\mathrm{N}_{2}$ flow rate can be measured accurately; (2) use an $\mathrm{N}_{2}$ flow rate of $8 \mathrm{~L}$ minute or more to hasten stripping of $\mathrm{H}_{2} \mathrm{~S}$. Stir water in bucket to assure thorough mixing; (3) cover the bucket with a plastic sheet (see section 2.1.3) to reduce oxidation of sulfide by keeping the sample in contact with $\mathrm{N}_{2}$ gas rather than atmospheric oxygen; (4) after about 10 to 15 minutes, use the spectrophotometer to measure the $\mathrm{S}^{2-}$ content of the water in the bucket (continue bubbling $\mathrm{N}_{2}$ while the sample is being analyzed). If the $\mathrm{S}^{2-}$ concentration is below $0.01 \mathrm{mg} / \mathrm{L}$, stripping is completed. If not, continue stripping and measuring $S^{2-}$ concentration at intervals until the desired concentration is achieved. A practical consideration is that stripping water samples with such a high flow rate of nitrogen will use up a significant amount of the nitrogen in a tank. For example, the pressure in the C-sized nitrogen tank used in the stripping experiment at the Suwannee well was reduced by about 400 p.s.i. after about 30 minutes of bubbling at about $8 \mathrm{~L} /$ minute. Taking an ample supply of nitrogen in the field is recommended. 

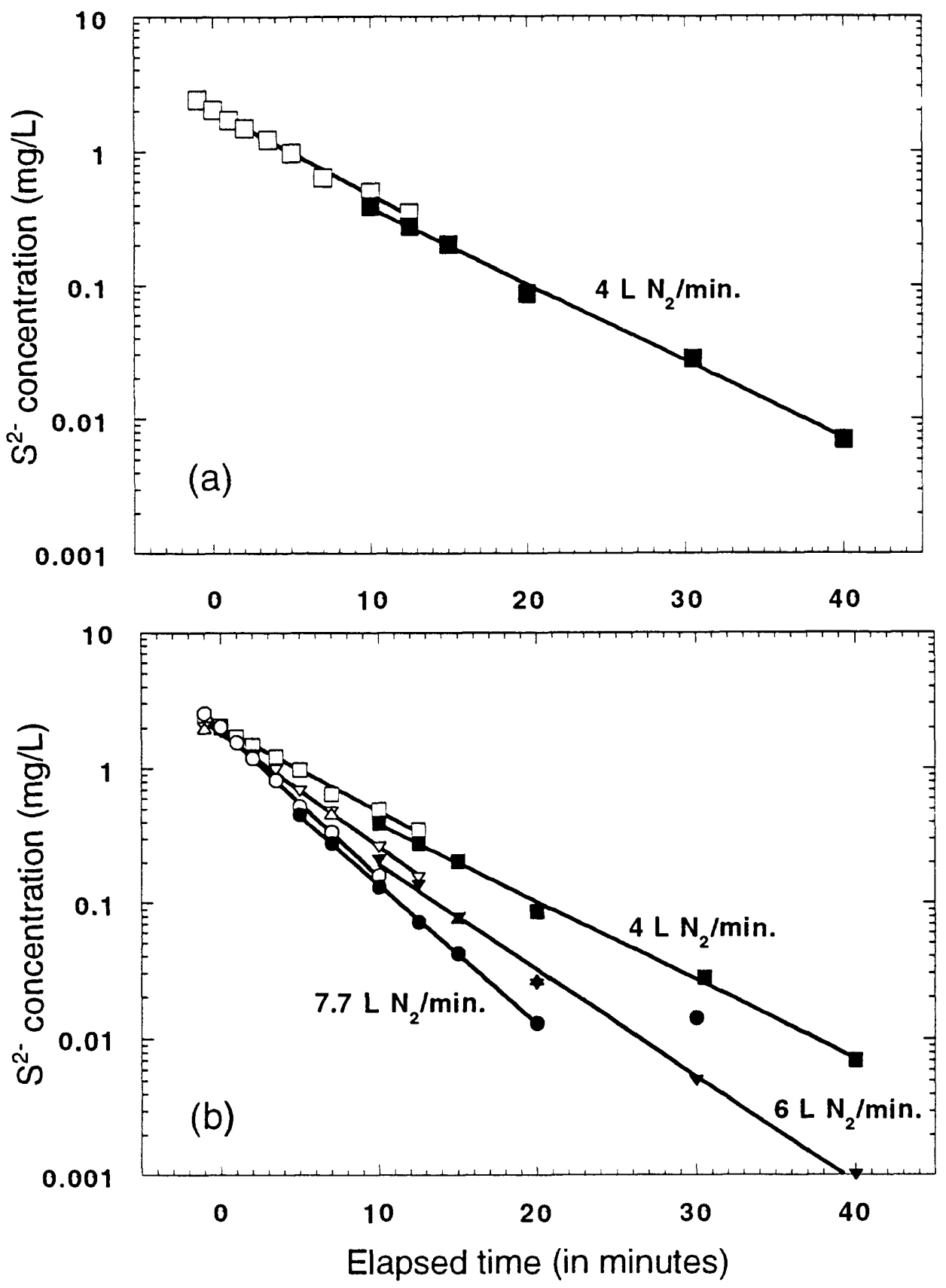

Figure 10. Results of 1995 sulfide stripping experiments with controlled nitrogen flow rates. Data points plotted at one minute before the start of the experiment indicate sulfide concentration before acidification and beginning of nitrogen flow. (a) Stripping experiment with nitrogen flow rate of $4 \mathrm{~L}$ minute. Open squares indicate measurements made by the reagents-first dilution technique (explained in text) and closed squares indicate undiluted measurements. Notice that diluted measurements give higher apparent sulfide concentrations than undiluted measurements on the same samples. This is opposite to the situation observed for the DI water first dilution technique (compare figure with 9a). (b) Comparison of all three 1995 sulfide stripping experiments with controlled nitrogen flow rates. Open symbols indicate diluted measurements made by the reagents-first dilution technique. Closed symbols indicate undiluted measurements. Most of the data from the $6 \mathrm{~L}$ minute experiment are plotted with downward-pointing triangles. Several $\mathrm{S}^{2-}$ analyses of solutions from this experiment were duplicated to test the reproducibility of analyses from the field spectrophotometer -- the duplicate analyses are plotted with upwardpointing triangles. These results show that as flow rate increases, time required to strip sulfide from the sample (until the sulfide concentration is $0.01 \mathrm{mg} / \mathrm{L}$ or less) decreases. 


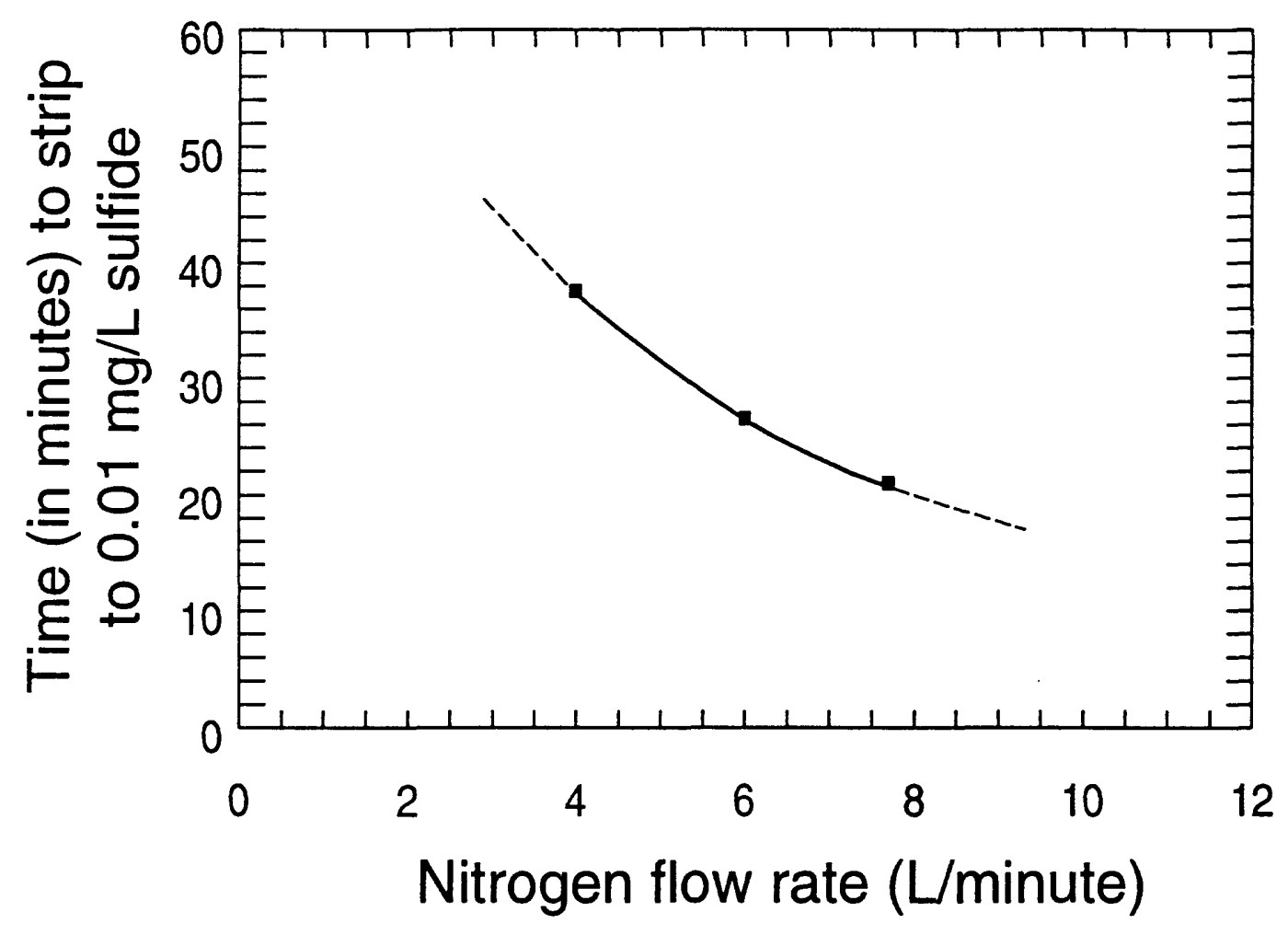

Figure 11. This graph shows another way to illustrate the relationship seen in figure $10 \mathrm{~b}$. Time to reach the recommended sulfide concentration of $0.01 \mathrm{mg} / \mathrm{L}$ for the three 1995 stripping experiments is plotted against nitrogen flow rate, showing that required stripping time decreases as flow rate increases.

Evaluation of the "Dl water first" dilution technique -- The data plotted in figure 9a illustrate the effect of diluting the high-concentration sulfide samples with oxygenated deionized water. The diluted analyses are consistently shifted to lower apparent $\mathrm{S}^{2-}$ concentrations relative to the undiluted samples. Note in figure 9a that samples collected between 10 and 20 minutes after the start of the experiment were analyzed both with and without dilution. The diluted analyses indicated consistently lower $\mathrm{S}^{2-}$ concentrations than the undiluted analyses. Projecting the exponential fit to the undiluted data into elapsed time range from 0 to 10 minutes suggests that measured $\mathrm{S}^{2-}$ concentrations were lowered by the dilution process. Dissolved sulfide analyses made with dilution at the Suwannee well were also lower than expected due to oxidation of sulfide by the deionized water (see section 4.5.2 and table 27)

This method of dilution adds an additional degree of uncertainty because adding oxygenated deionized water to a reduced, sulfide-bearing water sample will immediately oxidize a fraction of the sulfide. The calculations in table 19 illustrate that the oxygen present in air-saturated deionized water at $25^{\circ} \mathrm{C}$ is more than sufficient to oxidize all the sulfide present in a typical diluted sample. The percentage of sulfide that could be oxidized to $\mathrm{SO}_{4}{ }^{2-}$ by the oxygen present in the deionized water is given by:

$$
\text { percent sulfide oxidized }=\frac{(\text { moles } \mathrm{O} / 4)}{\text { moles S }} \times 100
$$


The dilutions shown in table 19 are "minimal dilutions", that is, they would yield solutions with dissolved sulfide concentrations of $0.6 \mathrm{mg} / \mathrm{L}$, the maximum concentration that can be analyzed with the Hach spectrophotometer. Typical dilutions are intended to produce dissolved sulfide concentrations of less than 0.6 $\mathrm{mg} / \mathrm{L}$, hence the percentage of sulfide oxidized would be higher.

Table 19. Percentage of dissolved sulfide which could be oxidized by dilution of samples with airsaturated deionized water $\left(\mathrm{DO}=8.26 \mathrm{mg} / \mathrm{L}\right.$ at $\left.25^{\circ} \mathrm{C}\right)$

[vol., volume; sol'n, solution; DI, deionized; DO, dissolved oxygen; mol, moles; mg/L, milligrams per liter]

\begin{tabular}{cccc}
$\begin{array}{c}\text { Dilution (Final vol. } \\
\text { sol'n : sample) }\end{array}$ & $\begin{array}{c}\text { Concentration of S2- } \\
\text { (mg/L) }\end{array}$ & $\begin{array}{c}\text { vol. DI water / volume } \\
\text { sample }\end{array}$ & $\begin{array}{c}((\mathrm{mol} \mathrm{O/4)/mol} \mathrm{S)} \\
\text { (in \%) }\end{array}$ \\
\hline $2: 1$ & 1.2 & 1 & $345 \%$ \\
$5: 1$ & 3.0 & 4 & $552 \%$ \\
$10: 1$ & 6.0 & 9 & $621 \%$ \\
$20: 1$ & 12.0 & 19 & $655 \%$ \\
\hline
\end{tabular}

The oxidation of the sulfide does not, however, go to completion immediately. Estimations of percent of sulfide lost due to oxidation resulting from dilution with air-saturated water just prior to spectrophotometric analysis range from 8.5 percent to 36.9 percent (for the 1994 laboratory experiment and the experiment at the Suwannee well). The extent of oxidation seems to depend on the dissolved sulfide concentration of the sample and on time required for the analyst to carry out the dilution and analysis on the spectrophotometer. If a diluted sulfide sample is allowed to stand and is reanalyzed at intervals, its sulfide concentration decreases with time. This is illustrated by the data shown in table 20. The dissolved oxygen in the water continues to oxidize the dissolved sulfide so that, after several hours, the sulfide will be completely oxidized.

Evaluation of the "Reagents first" dilution technique -- The idea behind this dilution method is to fix the concentration of dissolved sulfide in the sample by adding the reagents before diluting with oxygenated deionized water. This method again produces a mismatch (see figure 10) between the samples that were diluted and those that were not, with the diluted samples having higher apparent dissolved sulfide concentrations than the undiluted samples. (Note that this is opposite to the situation observed in the 1994 experiments where diluted samples had lower apparent dissolved sulfide concentrations. Compare figures $9 \mathrm{a}$ and 10a.) Sulfide concentrations were measured on nine aliquots using both the "Reagents first" dilution and undiluted methods; sulfide concentrations measured by "Reagents first" dilution exceeded undiluted measurements by 14 to 35 percent.

These higher-than-expected sulfide concentrations measured by the "reagents first" dilution technique are apparently erroneous. Gustafsson (1960) found that yield of methylene blue increases with increasing acidity. By adding 
the volumes of Hach reagents normally used for $25 \mathrm{~mL}$ samples to a $5 \mathrm{~mL}$ sample, the acidity of the solution is increased. Evidently, it is important to maintain the recommended $\mathrm{pH}$ and reagent concentrations inherent in the Hach method in order to obtain accurate sulfide concentration results because a specific methylene blue calibration is built into the Hach instrument.

Table 20. Decrease in sulfide concentration of diluted samples with time ${ }^{1}$ [mgl, milligrams per liter]

\begin{tabular}{cccc}
\hline Sample \# & Dilution & $\begin{array}{c}\text { Time since dilution } \\
\text { (in minutes) }\end{array}$ & $\begin{array}{c}\mathrm{S}^{2-} \text { concentration } \\
\text { (in mg/L) }\end{array}$ \\
\hline 1 & $10: 1$ & 9 & 1.58 \\
1 & $10: 1$ & 28 & 1.12 \\
1 & $10: 1$ & 76 & 0.93 \\
\hline 2 & $10: 1$ & 9 & 0.85 \\
2 & $10: 1$ & 26 & 0.64 \\
\hline
\end{tabular}

TBefore first dilution, samples were in glass bottles with tightly-closed polyseal caps and no head space. The caps were replaced between analyses but after the first dilution there was head space in the bottle.

Conclusions regarding dilution techniques -- The results of these experiments indicate that neither of the two dilution methods tested produce dissolved sulfide concentration measurements consistent with undiluted measurements. When measurement of dissolved sulfide concentration greater than $0.6 \mathrm{mg} / \mathrm{L}$ is necessary, there are several options to consider. First, how accurately must the dissolved sulfide concentration be measured? Is an uncertainty on the order of 20 percent acceptable or not? If so, one of the dilution methods above could be used, bearing in mind the typical uncertainty associated with each method. If dissolved sulfide needs to be measured more accurately (1) for samples with $\mathrm{S}^{2-}$ concentrations $\leq 1.8 \mathrm{mg} / \mathrm{L}$, a special adapter for the spectrophotometer will extend the measurable range by a factor of 3 ; (2) use both dilution methods above to bracket the actual dissolved sulfide concentration; (3) dilute the sample with oxygen-free deionized water (use "DI water first" method above) to avoid oxidizing the sulfide. A method for preparing oxygen-free deionized water is given in Lindsay and Baedecker (1988); or (4) measure dissolved sulfide with a laboratory spectrophotometer rather than a field instrument. For more information on this method see Lindsay and Baedecker (1988). Although this method produces more accurate results over a much wider sulfide concentration range, samples must be brought back to the laboratory to be analyzed. The field spectrophotometer allows on-the-spot analyses in just a few minutes time.

Dissolved sulfate in stripping experiments -- In the three 1995 experiments, the amount of dissolved sulfate that was collected on anion exchange resin was low 
$(0.31 \mathrm{mg} / \mathrm{L}$ sulfate produced in the $4 \mathrm{~L} /$ minute experiment, $0.5 \mathrm{mg} / \mathrm{L}$ sulfate produced in the $6 \mathrm{~L} /$ minute experiment and $0.08 \mathrm{mg} / \mathrm{L}$ sulfate produced in the 7.7 $\mathrm{L}$ /minute experiment). The isotopic composition of this sulfate is only slightly enriched in ${ }^{34} \mathrm{~S}$ relative to the sodium sulfide starting material (1.6 per mill for the sulfate versus 1.35 per mill for the starting material, see section 4.4.1).

Therefore, contamination of the dissolved sulfate sample with oxidized sulfide will be minimal if the sample is stripped quickly by this technique. But any oxidized sulfide added to the dissolved sulfate in the sample will be isotopically similar to the sulfide, so the potential for isotopic contamination of the sulfate exists, particularly for very low sulfate concentration samples.

\subsubsection{Testing sulfate collection techniques in the field}

It was suggested to the authors by Laura Sacks (oral comm., 1993) that the $\mathrm{H}_{2} \mathrm{~S}$ stripping technique discussed above might be avoided if the sulfate were collected quickly in the field before significant oxidation of the sulfide could occur. In order to test this idea, sulfate was collected by both direct precipitation of $\mathrm{BaSO}_{4}$ (filtered in the field) and on anion exchange resin from ground-water samples that had been stripped of $\mathrm{H}_{2} \mathrm{~S}$ (as described above) and from ground water that had not been stripped of $\mathrm{H}_{2} \mathrm{~S}$.

Procedure for direct precipitation -- An appropriate volume of ground water either stripped of $\mathrm{H}_{2} \mathrm{~S}$ or not stripped was measured into a glass beaker. The $\mathrm{pH}$ of the sample was determined using a $\mathrm{pH}$ meter and $\mathrm{HCl}$ was added to lower the $\mathrm{pH}$ to between 3 and 4 . Six to ten milliliters of 10 weight percent $\mathrm{BaCl}_{2}$ solution was added to the ground water sample and, after thorough mixing, was allowed to stand for 5 minutes to complete precipitation. The resulting $\mathrm{BaSO}_{4}$ was filtered on a membrane filter. The 5 minute interval between adding $\mathrm{BaCl}_{2}$ to the sample and filtering was consistently followed in order to allow enough time for the precipitate to form but also to minimize the time interval in which oxidized sulfide might be precipitated as sulfate for those samples not stripped of $\mathrm{H}_{2} \mathrm{~S}$. In the laboratory, the $\mathrm{BaSO}_{4}$ was dried, weighed, combined with reagents, combusted and the isotopic composition of the resulting $\mathrm{SO}_{2}$ analyzed as described in sections 3.4 and 3.5 (the Finnigan 251 mass spectrometer was used to analyze these samples).

Procedure for sulfate collection on anion exchange resin -- The procedure for collecting these samples on anion exchange resin is similar to the technique used for the laboratory samples, discussed in section 4.2 , except that the Finnigan 251 mass spectrometer was used to analyze these samples. Volumes of ground water pumped through the resin are included in table 21. The appropriate volume of each ground water used for these experiments was determined so that the capacity of the anion exchange resin would not be exceeded (see section 2.1.5). The resins were rinsed with 1 liter of deionized water in the field immediately before the sample was collected. 
Results -- The data from these experiments are listed in table 21 and plotted in figure 12. Each type of experiment was performed in duplicate for a total of eight experiments at each well.

Table 21. Sulfur isotopic analyses of sulfate collected in the field [frac., fraction; $\mathrm{mL}$, milliliters; D. P., direct precipitation; int., intermediate; $y$, yes; $n, n$ o]

\begin{tabular}{cccccc}
\hline Well Name & $\begin{array}{c}\text { Direct Precip- } \\
\text { itation or } \\
\text { on Resin }\end{array}$ & $\begin{array}{c}\text { Stripped of } \\
\mathrm{H}_{2} \mathrm{~S} ?\end{array}$ & $\begin{array}{c}\text { Volume of } \\
\text { sample }(\mathrm{mL})\end{array}$ & $\begin{array}{c}\text { Frac. sulfate } \\
\text { recovered } \\
\text { (in \%) }\end{array}$ & $\begin{array}{c}\delta^{34} \text { S relative } \\
\text { to VCDT } \\
\text { (in \%o) }\end{array}$ \\
\hline Suwannee & D.P. & $\mathrm{Y}$ & 400 & 98.97 & +24.9 \\
Suwannee & D.P. & $\mathrm{Y}$ & 400 & 97.97 & +25.0 \\
Suwannee & Resin & $\mathrm{Y}$ & 1000 & 76.66 & +25.0 \\
Suwannee & Resin & $\mathrm{Y}$ & 1000 & 86.59 & +24.7 \\
Suwannee & D.P. & $\mathrm{N}$ & 400 & 103.95 & +24.8 \\
Suwannee & D.P. & $\mathrm{N}$ & 400 & 101.97 & +25.0 \\
Suwannee & Resin & $\mathrm{N}$ & 1000 & 83.66 & +24.6 \\
Suwannee & Resin & $\mathrm{N}$ & 1000 & 77.66 & +24.7 \\
\hline Upper Int. & D.P. & $\mathrm{Y}$ & 800 & 87.14 & +13.1 \\
Upper Int. & D.P. & $\mathrm{Y}$ & 800 & 96.57 & +13.4 \\
Upper Int. & Resin & $\mathrm{Y}$ & 3000 & 81.32 & +12.9 \\
Upper Int. & Resin & $\mathrm{Y}$ & 3000 & 66.82 & +13.1 \\
Upper Int. & D.P. & $\mathrm{N}$ & 800 & 96.89 & +13.3 \\
Upper Int. & D.P. & $\mathrm{N}$ & 800 & 95.07 & +13.4 \\
Upper Int. & Resin & $\mathrm{N}$ & 3000 & 85.09 & +13.2 \\
Upper Int. & Resin & $\mathrm{N}$ & 3000 & 75.34 & +13.2 \\
\hline
\end{tabular}

The sulfur isotopic compositions of sulfate collected in these experiments showed very limited variation at each well site. Sulfur isotopic analyses of sulfate collected at the Suwannee well vary from +24.6 to +25.0 per mill and sulfur isotopic analyses of sulfate from the Upper Intermediate well range from +12.9 to +13.4 per mill (figure 12). There is no consistent isotopic effect seen between those samples collected from ground water stripped of $\mathrm{H}_{2} \mathrm{~S}$ versus those collected from ground water not stripped of $\mathrm{H}_{2} \mathrm{~S}$. The isotopic composition of the sulfide from both of these wells has more negative $\delta^{34} \mathrm{~S}$ values (see sections 4.4.2, 4.5.2 and 4.5.3) compared to the coexisting sulfate, as observed previously for Floridan aquifer ground-water samples by Rye and others (1981), Sacks 


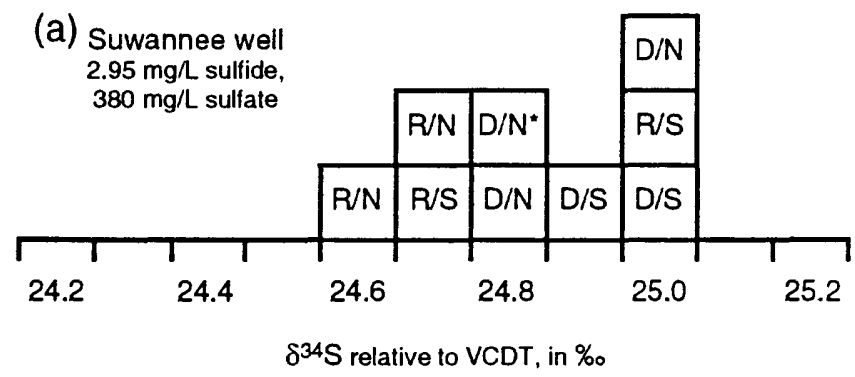

(b) Upper Intermediate well

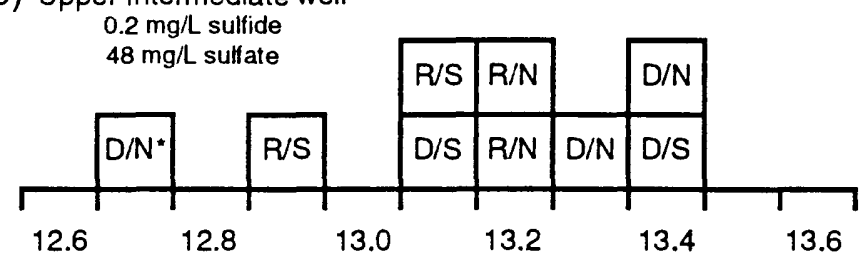

$\delta^{34} S$ relative to VCDT, in \%。

Figure 12. Sulfur isotopic compositions of sulfate collected at the Suwannee (a) and Upper Intermediate (b) wells. Notation in diagram is as follows: "R" indicates sulfate collected on anion exchange resin, " $\mathrm{D}$ " indicates sulfate collected by direct precipitation in the field as $\mathrm{BaSO}_{4}$. "S" indicates that the sample was stripped of $\mathrm{H}_{2} \mathrm{~S}$ before sulfate was collected and " $\mathrm{N}$ " indicates that the sample was not stripped of $\mathrm{H}_{2} \mathrm{~S}$ before sulfate was collected. Samples noted with a * were collected by Laura Sacks at these same wells and analyzed by Robert Seal for the study by Sacks and Tihansky (1996). There is more discussion of collection techniques in section 4.3.2. The data are listed in table 21. Interval on these plots is 0.1 per mill. Note that $\delta^{34} S$ values for sulfate collected by direct precipitation (D/S and D/N) from both wells is generally more positive than sulfate collected on anion exchange resin (R/S and $R / N)$.

(1996), and Sacks and Tihansky (1996). Therefore, if oxidized sulfide were contributing a significant amount of sulfate, the $\delta^{34} S$ of sulfate from the unstripped experiments should be more negative than $\delta^{34} S$ of sulfate from the stripped experiments. The sulfate collected on anion exchange resin from the Suwannee well appears to show this effect, where the stripped experiments have higher $\delta^{34} S$ values $(+25.0,+24.7$ per mill) than in the unstripped experiments $(+24.6,+24.7$ per mill). However, sulfate collected on anion exchange resin at the Upper Intermediate well does not show the expected isotopic effect; in this case, $\delta^{34}$ S values for the stripped experiments $(+12.9,+13.1$ per mill) are lower than $\delta^{34} S$ values for the unstripped experiments (both +13.2 per mill). These slight compositional differences are similar in magnitude to the analytical uncertainty associated with the extraction and mass spectrometry of the $\mathrm{SO}_{2}$ gas (see appendix) and may not be significant. No consistent isotopic effect is seen among the direct precipitation experiments.

Figure 12 shows that the sulfur isotopic composition of sulfate collected by direct precipitation tends to be slightly enriched in ${ }^{34} \mathrm{~S}$ (Suwannee average $=$ +24.9 per mill, Upper Intermediate average $=+13.3$ per mill) relative to sulfate 
collected on anion exchange resin (Suwannee average $=+24.75$ per mill, Upper Intermediate average $=+13.1$ per mill). A similar observation was made in section 4.2.1 where sulfate collected in laboratory direct precipitation experiments was, on average, enriched in ${ }^{34} S$ by about 0.2 per mill relative to sulfate from $\mathrm{Cl}^{-}$free, low- $\mathrm{SO}_{4}{ }^{2-}$ experiments collected on anion exchange resin. A related observation, based on the data in table 21, is that all the anion exchange resin experiments have lower fractions of recovered sulfate than the direct precipitation experiments. In fact, except for one experiment, the fraction of sulfate recovered for the direct precipitation experiments is greater than 95 percent whereas the fraction of sulfate recovered for the anion exchange resin experiments does not exceed 87 percent.

Results of the Fall 1996 laboratory experiments, discussed in section 4.2.3, also aid in interpreting of the data from the anion exchange resin experiments in the field. The starting composition of the pre-acidified laboratory solution (238 $\mathrm{mg} / \mathrm{L} \mathrm{SO}_{4}{ }^{2-}, 26 \mathrm{mg} / \mathrm{L} \mathrm{Cl}^{-}$, experiment 7 ) is somewhat similar to the acidified Suwannee ground water $\left(380 \mathrm{mg} / \mathrm{L} \mathrm{SO}_{4}{ }^{2-}\right.$, about $\left.188 \mathrm{mg} / \mathrm{L} \mathrm{Cl}^{-}\right)$, yet sulfate collection in the laboratory experiment was more complete. In experiment 7, 99.8 percent of the sulfate in the starting solution was precipitated and collected as $\mathrm{BaSO}_{4}$ and its sulfur isotopic composition was indistinguishable from the sulfur isotopic composition of the starting material (table 15). The differences in percent of sulfate collected, and the isotopic composition of the sulfate collected versus the isotopic composition of the starting material between experiment 7 and the experiments at the Suwannee well are likely due to either (1) increased elution of sulfate by chloride in the acidified Suwannee ground water resulting in more sulfate passing through the resin or (2) improved elution methods in later experiments (footnote 8 ) resulting in more complete elution of sulfate from the resin. As discussed in section 4.2.3, sulfate that passes through the resin during sulfate collection and sulfate remaining on the anion exchange resin after one elution will both have more positive $\delta^{34} S$ values than sulfate in the starting solution (or ground water). One or both of these processes likely produced both lower sulfate recovery and the slight isotopic fractionation (-0.2 per mill) observed for the sulfate collection on anion exchange resin experiments in the field.

Suggestions for sulfate collection in the field -- Based on sulfate collection experiments at the Suwannee and Upper Intermediate wells, the following recommendations are made regarding the collection of dissolved sulfate for isotopic analysis. (1) For ground waters with dissolved sulfate to dissolved sulfide ratios in the range of these wells or higher (43.0 for the Suwannee well and 80.1 for the Upper Intermediate well, ratios calculated on a molar basis), sulfate may be collected without first stripping $\mathrm{H}_{2} \mathrm{~S}$ if the sulfate is precipitated in the field or collected on anion exchange resin. Water samples collected in bottles for sulfur isotopic analysis of sulfate in the laboratory should always be stripped of $\mathrm{H}_{2} \mathrm{~S} .{ }^{10}$ (2) Sulfate and chloride concentrations should be measured

10 Sulfide-bearing water collected for analysis of sulfate concentration should also be stripped by the same method. 
and the fraction of sulfate recovered should be calculated. The extent to which sulfate recovery is low may allow a rough estimate of the uncertainty associated with the sulfur isotopic analysis of a particular sample (uncertainty may be on the order of \pm 0.2 to 1.0 per mill based on the data presented here and in section 4.2.2).

\subsection{Sulfide collection by direct precipitation}

The goal of the laboratory and field experiments on sulfide collection techniques was to establish whether the recommended method was causing any fractionation of the sulfur isotopes. The recommended method involves bubbling $\mathrm{N}_{2}$ through a large volume of acidified ground water in order to strip $\mathrm{H}_{2} \mathrm{~S}$ from solution and collect it as $\mathrm{Ag}_{2} \mathrm{~S}$ precipitated in a $\mathrm{AgNO}_{3}$ trap (discussed in section 2.2 and 4.5). The $\delta^{34} S$ of the dissolved sulfide needed to be determined in order to have a value to compare to the $\delta^{34} S$ values from the nitrogen-stripping experiments. This was done by direct precipitation of $\mathrm{Ag}_{2} \mathrm{~S}$ by adding $\mathrm{AgNO}_{3}$ solution directly to synthetic or natural ground-water samples.

\subsubsection{Sulfide collection by direct precipitation in the laboratory}

Procedure -- The amount of 10 weight percent $\mathrm{AgNO}_{3}$ solution needed to precipitate all the $\mathrm{S}^{2-}$ as $\mathrm{Ag}_{2} \mathrm{~S}$ was determined prior to the start of a direct precipitation experiment. About 150 to $200 \mathrm{mg}$ of $\mathrm{Na}_{2} \mathrm{~S}$ (technical, 60 percent) were added to a small volume of (preferably deoxygenated) deionized water, stirring until $\mathrm{Na}_{2} \mathrm{~S}$ dissolved. This was the same starting material used for the nitrogen-stripping sulfide collection experiments (sections 4.5.1 and 4.5.4). $\mathrm{Na}_{2} \mathrm{~S}$ solution is quite basic, and this is desirable because in a basic solution dissolved sulfide will be present as $\mathrm{S}^{2-}$ which precipitates readily with addition of $\mathrm{Ag}^{+}$. Therefore, the $\mathrm{Na}_{2} \mathrm{~S}$ solution was not acidified. Four to ten milliliters of 10 weight percent $\mathrm{AgNO}_{3}$ solution were added to the $\mathrm{Na}_{2} \mathrm{~S}$ solution to precipitate $\mathrm{Ag}_{2} \mathrm{~S}$. After waiting several minutes to allow complete precipitation, the $\mathrm{Ag}_{2} \mathrm{~S}$ was filtered on a membrane filter, rinsed, and dried. Additional $\mathrm{AgNO}_{3}$ solution was added to the filtrate to assure that all the sulfide in solution had precipitated. The $\mathrm{Ag}_{2} \mathrm{~S}$ was dried, weighed, combined with $\mathrm{Cu}_{2} \mathrm{O}$, combusted to $\mathrm{SO}_{2}$, and analyzed for isotopic composition as described in sections 3.4 and 3.5 (both the Finnigan and Nuclide mass spectrometers were used to analyze these samples).

Results -- Direct precipitation experiments were attempted on four different occasions and only two of these provided the "correct" $\delta^{34} S$ of the dissolved sulfide. The other experiments were faulty because insufficient $\mathrm{AgNO}_{3}$ was added and some of the sulfide was left in solution. Direct precipitation experiments that were considered acceptable were characterized by sulfide recovery of greater than 95 percent whereas unacceptable experiments had yields in the range 66 to 84 percent (see table 22). The $\delta^{34} S$ values from the 
unacceptable experiments were, for the most part, enriched in ${ }^{34} \mathrm{~S}$ relative to the higher-yield experiments.

Table 22. Direct precipitation experiments in the laboratory. Experiments with acceptable results are listed first

[exp., experiment; frac., fraction]

\begin{tabular}{ccccc}
\hline $\begin{array}{c}\text { Experiment or } \\
\text { Fraction }\end{array}$ & $\begin{array}{c}\text { Frac. sulfide } \\
\text { recovered } \\
\text { (in \%) }\end{array}$ & $\begin{array}{c}\text { Number of } \\
\text { analyses }\end{array}$ & $\begin{array}{c}\text { Average } \text { 8 }^{34} \mathrm{~S} \\
\text { relative to VCDT } \\
\text { (in \%) }\end{array}$ & $\begin{array}{c}\text { Standard } \\
\text { deviation (in \%) }\end{array}$ \\
\hline Exp. A & $95.9 \%$ & 4 & +1.36 & 0.03 \\
Exp. B & $95.1 \%$ & 3 & +1.34 & 0.05 \\
\hline Exp. C & $84.1 \%$ & 2 & +1.54 & 0.01 \\
Exp. D & $66.3 \%$ & 2 & +1.55 & 0.01 \\
Exp. E, frac. 1 & total & 1 & +1.71 & \\
Exp. E, frac. 2 & recovered & 1 & +1.61 & \\
Exp. E, frac. 3 & $=72.2 \%$ & 1 & +0.68 & \\
\hline
\end{tabular}

The $\delta^{34} \mathrm{~S}$ value for the $\mathrm{Na}_{2} \mathrm{~S}$ used in the laboratory experiments is taken to be the average of the values from the two acceptable experiments, i.e., +1.35 per mill.

Data on the unacceptable experiments are included in table 22 to illustrate the importance of adding sufficient $\mathrm{AgNO}_{3}$ to precipitate all the sulfide. In experiments $\mathrm{C}$ and $\mathrm{D}$, addition of insufficient $\mathrm{Ag}^{+}$resulted in precipitation of $\mathrm{Ag}_{2} \mathrm{~S}$ which was about 0.2 per mill more positive than expected. ${ }^{34} S$ is enriched in the precipitate whereas ${ }^{32} \mathrm{~S}$ was preferentially enriched in solution (see also figure 14). This is seen even more clearly in the results of the unacceptable experiment E. $\mathrm{AgNO}_{3}$ was added to the sulfide solution, $\mathrm{Ag}_{2} \mathrm{~S}$ formed and this was filtered (frac. 1). When additional $\mathrm{AgNO}_{3}$ was added to the sulfide solution, additional $\mathrm{Ag}_{2} \mathrm{~S}$ formed. When this was again filtered (frac. 2) and more $\mathrm{AgNO}_{3}$ added, still more $\mathrm{Ag}_{2} \mathrm{~S}$ formed (frac. 3 , the concentration of the $\mathrm{AgNO}_{3}$ solution was lower than expected). As shown in Table 22, the $\delta^{34} S$ value of each successive fraction became more negative.

\subsubsection{Sulfide collected by direct precipitation in the field}

Procedure -- Water from the Suwannee well was collected in a clean 1 liter beaker from an overflowing 10-liter bucket and 1 to $2 \mathrm{~mL}$ of approximately 10 weight percent $\mathrm{AgNO}_{3}$ solution was added immediately to precipitate $\mathrm{Ag}_{2} \mathrm{~S}$. Because the natural ground water also contains $\mathrm{Cl}^{-}, \mathrm{AgCl}$ co-precipitated with $\mathrm{Ag}_{2} \mathrm{~S}$. The mixed precipitate was filtered on membrane filter(s) and dried. 
These samples required additional processing in the laboratory to remove $\mathrm{AgCl}$ precipitated with $\mathrm{Ag}_{2} \mathrm{~S}$ because sulfur isotopic analysis could not be performed on a mixed precipitate. A 3 weight percent solution of $\mathrm{NH}_{4} \mathrm{OH}^{11}$ can be used to remove the $\mathrm{AgCl}$ and leave pure $\mathrm{Ag}_{2} \mathrm{~S}$ precipitate. The $\mathrm{CRC}$ handbook (Lide and Frederikse, 1994, p. 4-95 to 4-96) indicates that $\mathrm{NH}_{4} \mathrm{OH}$ dissolves many other silver compounds that might precipitate with $\mathrm{AgCl}$, but does not dissolve $\mathrm{Ag}_{2} \mathrm{~S}$. The following sequence of steps gave good results. The mixed precipitate was scraped off the membrane filter and ground to a fine, even grain size using a small agate mortar and pestle. The mixed precipitate was then weighed on an analytical balance to $0.0001 \mathrm{~g}$ and transferred to a $50-\mathrm{mL}$ beaker. About $20 \mathrm{~mL}$ of 3 weight percent $\mathrm{NH}_{4} \mathrm{OH}$ solution was added to the beaker along with a small magnetic stir bar. The beaker was covered with a small watch glass and the precipitate was stirred in the $\mathrm{NH}_{4} \mathrm{OH}$ solution for 30 minutes. The mixture was then allowed to stand for 2 to 3 hours after which the precipitate was filtered on a pre-weighed membrane filter, rinsed thoroughly with deionized water and allowed to dry. The precipitate was again weighed to $0.0001 \mathrm{~g}$. The results are shown in table 23. Because the amount of precipitate after the $\mathrm{NH}_{4} \mathrm{OH}$ procedure closely matches the amount of $\mathrm{Ag}_{2} \mathrm{~S}$ expected (table 23), it appears that this treatment was successful in removing the $\mathrm{AgCl}$. Therefore, the $\mathrm{Ag}_{2} \mathrm{~S}$ was weighed, combined with $\mathrm{Cu}_{2} \mathrm{O}$, combusted and the isotopic composition of the resulting $\mathrm{SO}_{2}$ analyzed as described in sections 3.4 and 3.5.

Table 23. Direct precipitation experiments at Suwannee well [wt., weight; mg, milligrams; n.a., not applicable]

\begin{tabular}{ccccccc}
\hline Experiment \# & Fraction & $\begin{array}{c}\text { wt. mixed } \\
\text { precipitate } \\
\text { treated } \\
\text { (in mg) }\end{array}$ & $\begin{array}{c}\text { wt. precip. } \\
\text { after } \mathrm{NH}_{4} \mathrm{OH} \\
\text { treatment } \\
\text { (in } \mathrm{mg})\end{array}$ & $\begin{array}{c}\text { wt. } \mathrm{Ag}_{2} \mathrm{~S} \\
\text { expected } \\
\text { (in } \mathrm{mg})\end{array}$ & $\begin{array}{c}\text { yield on } \\
\text { extraction } \\
\text { line } \\
\text { (in \%) }\end{array}$ & $\begin{array}{c}\delta^{34} \mathrm{~S} \\
\text { relative to } \\
\text { VCDT } \\
\text { (in \% })\end{array}$ \\
\hline 18 & n. a. & 80.5 & 22.5 & 23.5 & 85.0 & -33.9 \\
28 & 1 & 63.7 & 9.4 & 10.0 & 90.4 & -33.7 \\
28 & 2 & 72.9 & 23.2 & 22.8 & 94.9 & -33.8 \\
\hline
\end{tabular}

Results of these experiments also constrain the amount of $\mathrm{Ag}^{+}$that should be added to the sample. Consider the example of Experiment 28, fraction 2, which was the most successful direct precipitation experiment. The amount of 10 weight percent $\mathrm{AgNO}_{3}$ solution added to this sample ( $1 \mathrm{~mL}$ per liter of sample) was more than enough to precipitate the sulfide $(0.64$ mmoles $\mathrm{Ag}$ added compared to 0.184 mmoles $\mathrm{Ag}$ required to precipitate sulfide as $\mathrm{Ag}_{2} \mathrm{~S}$ ) but not sufficient $\mathrm{Ag}$ to precipitate the sulfide plus the chloride, or just the chloride (there are 1.805 mmoles $/ \mathrm{L} \mathrm{Cl}^{-}$in the Suwannee ground water). Because the precipitation of $\mathrm{Ag}_{2} \mathrm{~S}$ appears to have been complete (yield by direct

11 To make an approximately 3 weight percent solution, pour $11 \mathrm{~mL}$ of 29.3 percent commercial $\mathrm{NH}_{4} \mathrm{OH}$ solution into a $100 \mathrm{~mL}$ volumetric flask and add deionized water to make $100 \mathrm{~mL}$ of solution. 
precipitation, given in table 23 , is close to the expected amount based on a sulfide concentration of this water of $2.95 \mathrm{mg} / \mathrm{L}$ ), yet precipitation of $\mathrm{AgCl}$ was incomplete (if all $\mathrm{S}^{2-}$ plus $\mathrm{Cl}^{-}$had precipitated as $\mathrm{Ag}_{2} \mathrm{~S}$ and $\mathrm{AgCl}$, respectively, the total weight of the mixed precipitate would have been $281.5 \mathrm{mg}$; this was not observed) we infer that $\mathrm{Ag}_{2} \mathrm{~S}$ forms much faster than $\mathrm{AgCl}$. It is possible, therefore, to minimize the amount of $\mathrm{AgCl}$ co-precipitated with the $\mathrm{Ag}_{2} \mathrm{~S}$, and achieve complete precipitation of the sulfide, by adding only a 3-times excess of $\mathrm{AgNO}_{3}$ to the sample (see table 4). Adding more than about a three-fold excess of $\mathrm{AgNO}_{3}$ is undesirable because the large amount of $\mathrm{AgCl}$ produced will greatly slow the filtering process in the field and may complicate the laboratory clean-up procedure.

\subsubsection{Results and implications from direct precipitation experiments}

The average $\delta^{34} S$ values from these direct precipitation experiments are $+1.35 \pm 0.04$ per mill $(n=7)$ for the sodium sulfide used in the laboratory and $-33.81 \pm 0.11$ per mill $(n=4)$ for sulfide from the Suwannee well. These will be the accepted $\delta^{34} S$ values for these dissolved sulfides. In the next section (4.5), the $\delta^{34} S$ values for $\mathrm{Ag}_{2} \mathrm{~S}$ collected by nitrogen stripping will be compared to these $\delta^{34} S$ values obtained by direct precipitation.

Under some circumstances, it may be preferable to collect sulfide in the field by direct precipitation (detailed discussion of these circumstances in section 2.2). Based on the results of these direct precipitation experiments, the following recommendations will help obtain the best results. (1) Dissolved sulfide concentration of the ground water must be known with reasonable accuracy (measured with spectrophotometer in the field) so that the amount of $\mathrm{AgNO}_{3}$ needed to precipitate the $\mathrm{S}^{2-}$ as $\mathrm{Ag}_{2} \mathrm{~S}$ can be closely approximated. Addition of insufficient $\mathrm{AgNO}_{3}$ will result in an isotopically fractionated (enriched in ${ }^{34} \mathrm{~S}$ ) sulfur isotope sample. (2) The concentration of the $\mathrm{AgNO}_{3}$ solution must also be known accurately. Using fresh 10 weight percent $\mathrm{AgNO}_{3}$ solution, not $\mathrm{AgNO}_{3}$ solution recycled from nitrogen stripping experiments, is recommended. (3) Precipitation of $\mathrm{AgCl}$ should be minimized by adding no more than a three-fold excess of $\mathrm{AgNO}_{3}$ to the sample (examples of amounts of $\mathrm{AgNO}_{3}$ needed are given in table 9). If care is taken to remove $\mathrm{AgCl}$ from the $\mathrm{Ag}_{2} \mathrm{~S}$ using $\mathrm{NH}_{4} \mathrm{OH}$ solution, very satisfactory sulfur isotope analyses can be obtained on sulfide collected by direct precipitation from ground water with moderate chloride concentrations.

\subsection{Experiments on the nitrogen stripping-method for collection of dissolved sulfide}

A nitrogen-stripping technique for collection of dissolved sulfide in ground water has been tested and the results are summarized in this section. Note that this is a separate technique for collection of dissolved sulfide for isotopic analysis 
and is not the same as the stripping method in section 4.3.1, which is used to remove dissolved sulfide before collecting sulfate for isotopic analysis.

\subsubsection{One-trap sulfide-collection-by-nitrogen-stripping experiments in the laboratory}

These experiments were carried out on four different dissolved sulfide concentrations $(3,0.5,0.1$ and $0.03 \mathrm{mg} / \mathrm{L})$ using the same technical (60 percent) $\mathrm{Na}_{2} \mathrm{~S}$ starting material that was used in the laboratory direct precipitation experiments.

Procedure -- The equipment was set up as shown in figure 4 using one 50-L carboy for experiments with solutions containing $3 \mathrm{mg} / \mathrm{L}$ and $0.5 \mathrm{mg} / \mathrm{L}$ dissolved sulfide, two $50-\mathrm{L}$ carboys for experiments with solutions containing $0.1 \mathrm{mg} / \mathrm{L}$ dissolved sulfide and three 50-L carboys for experiments with solutions containing $0.03 \mathrm{mg} / \mathrm{L}$ dissolved sulfide. A bubbler was included in the setup instead of a gas flowmeter. The day before the collection experiment was performed, the carboy(s) and $\mathrm{AgNO}_{3}$ trap were filled with deionized water, the carboys and trap were tightly capped. $\mathrm{N}_{2}$ was bubbled through the water overnight in order to remove the oxygen dissolved in the deionized water. Measurements with a dissolved oxygen (DO) meter showed that about 0.6 to 0.7 $\mathrm{mg} / \mathrm{L} \mathrm{O}_{2}$ remained in solution in the carboy(s) after bubbling overnight with $\mathrm{N}_{2}$. Because water in equilibrium with the atmosphere at $25^{\circ} \mathrm{C}$ will contain $8.26 \mathrm{mg} / \mathrm{L}$ $\mathrm{DO}$, bubbling $\mathrm{N}_{2}$ overnight was successful in removing over 90 percent of the DO, but a significant fraction (about 8.5 percent) of the DO remained in solution. When ready to begin the sulfide collection, the deionized water in the $\mathrm{AgNO}_{3}$ trap was replaced with 10 weight percent $\mathrm{AgNO}_{3}$ solution. ("One-trap" indicates that the sulfide from the entire experiment was collected in a single $\mathrm{AgNO}_{3}$ trap. This is in contrast to the 6-trap fractional experiments described below.) An appropriate amount of the $\mathrm{Na}_{2} \mathrm{~S}$ was weighed on an analytical balance (if more than one carboy was used, 2 or 3 aliquots of $\mathrm{Na}_{2} \mathrm{~S}$ were weighed out). The carboy was uncapped and the $\mathrm{Na}_{2} \mathrm{~S}$ quickly added along with $50 \mathrm{~mL}$ of $12 \mathrm{~N}$ $\mathrm{H}_{2} \mathrm{SO}_{4}$. Then the carboy was recapped and rocked to thoroughly mix the $\mathrm{Na}_{2} \mathrm{~S}$ and sulfuric acid with the deionized water. The acid lowers the $\mathrm{pH}$ of the solution so that $\mathrm{H}_{2} \mathrm{~S}(\mathrm{aq})$ will be the predominant sulfide species in solution; this dissolved gas is removed ("stripped") from solution by the flux of $\mathrm{N}_{2}$ gas. A timer was started when the carboy was capped to time the length of the experiment. $\mathrm{Ag}_{2} \mathrm{~S}$ began to form in the $\mathrm{AgNO}_{3}$ trap within a few minutes, forming most rapidly in the higher-concentration $(3 \mathrm{mg} / \mathrm{L})$ experiments.

When the experiment had been run for the length of time desired, the $\mathrm{Ag}_{2} \mathrm{~S}$ in the $\mathrm{AgNO}_{3}$ trap was carefully filtered on a membrane filter and the $\mathrm{AgNO}_{3}$ solution saved for use in later experiments. $\mathrm{Ag}_{2} \mathrm{~S}$ was also carefully rinsed out of the glass tube through which the $\mathrm{N}_{2}$ was bubbled into the trap (figure 4). After rinsing the $\mathrm{Ag}_{2} \mathrm{~S}$ with deionized water, it was transferred to a small petri dish and dried in a dessicator. The $\mathrm{Ag}_{2} \mathrm{~S}$ was weighed, combined with $\mathrm{Cu}_{2} \mathrm{O}$, combusted 
to $\mathrm{SO}_{2}$ and analyzed as described in sections 3.4 and 3.5. (these samples were analyzed on the Nuclide mass spectrometer except $2 S$ which was analyzed on the Finnigan).

Results -- The data from these experiments are listed in table 24 and plotted in figures 13 and 14 . Figure 13 shows that with longer stripping time, the fraction of sulfide recovered increases. However, even for the longer ( 6 hour) experiments, $100 \%$ recovery of sulfide was not achieved. From a practical point of view, 6 hours to collect one sulfide sample in the field is rather long. Three hours is the length of time that these sulfide collections have typically been run in the field.

Table 24. Sulfide collected by nitrogen stripping -- laboratory experiments [mg/L, milligrams per liter]

\begin{tabular}{ccccc}
\hline Experiment \# & $\begin{array}{c}\text { Sulfide } \\
\text { concentration } \\
(\mathrm{mg} / \mathrm{L})\end{array}$ & $\begin{array}{c}\text { Length of exp- } \\
\text { eriment (hours) }\end{array}$ & $\begin{array}{c}\text { Fraction of } \\
\text { sulfide recovered } \\
\text { (in \%) }\end{array}$ & $\begin{array}{c}\delta^{34} \text { S relative to } \\
\text { VCDT } \\
\text { (in \%o) }\end{array}$ \\
\hline 15 & 3.09 & 6 & 80.4 & +1.1 \\
$10 \mathrm{~S}$ & 3 & 4 & 69.7 & +0.8 \\
$9 \mathrm{~S}$ & 3 & 3 & 61.3 & +0.9 \\
$2 \mathrm{~S}$ & 3 & 1 & 24.0 & +0.6 \\
\hline $3 \mathrm{~S}$ & 0.51 & 3 & 58.6 & +0.8 \\
$4 \mathrm{~S}$ & 0.53 & 1.5 & 41.3 & +0.7 \\
\hline $5 \mathrm{~S}$ & 0.10 & 4 & 58.2 & +0.9 \\
$6 \mathrm{~S}$ & 0.10 & 4 & 62.9 & +1.0 \\
\hline $7 \mathrm{~S}$ & 0.03 & 6 & 66.5 & +0.8 \\
$8 \mathrm{~S}$ & 0.03 & 3 & 31.6 & +0.8 \\
\hline 1 expected value $=+1.35 \pm 0.04$ per mill. & & &
\end{tabular}

The next question is, how long should a sample be stripped to obtain $\mathrm{Ag}_{2} \mathrm{~S}$ that is isotopically representative of the sulfide dissolved in the ground water? The data in table 24 (plotted in figure 14) illustrate that there is an increase in the $\delta^{34} \mathrm{~S}$ value with increasing fraction of dissolved sulfide recovered, and fraction recovered increases with time. Figure 14 shows, however, that even for the 6 hour experiment at $3 \mathrm{mg} / \mathrm{L} \mathrm{S}^{2-}$ (80.4 percent yield), the $\delta^{34} S$ value for this experiment was about 0.2 per mill more negative than the $\delta^{34} S$ of sulfide collected by direct precipitation. For other experiments with lower percent recovery of sulfide, $\mathrm{Ag}_{2} \mathrm{~S}$ collected was even more depleted in ${ }^{34} \mathrm{~S}$. Although the variability of the data is somewhat high, it appears that $\delta^{34} S$ of the $A_{2} S$ increases toward the direct precipitation value but does not reach it within the 6hour duration of even the longest experiments. Increasing the length of the 
experiments would probably result in a somewhat higher recovery of sulfide, but it is unclear whether close to 100 percent recovery (and a $\delta^{34} \mathrm{~S}$ value equal to the direct precipitation value) would be achieved. A possible reason for incomplete collection and fractionation of sulfide would be that it was oxidized to sulfate by

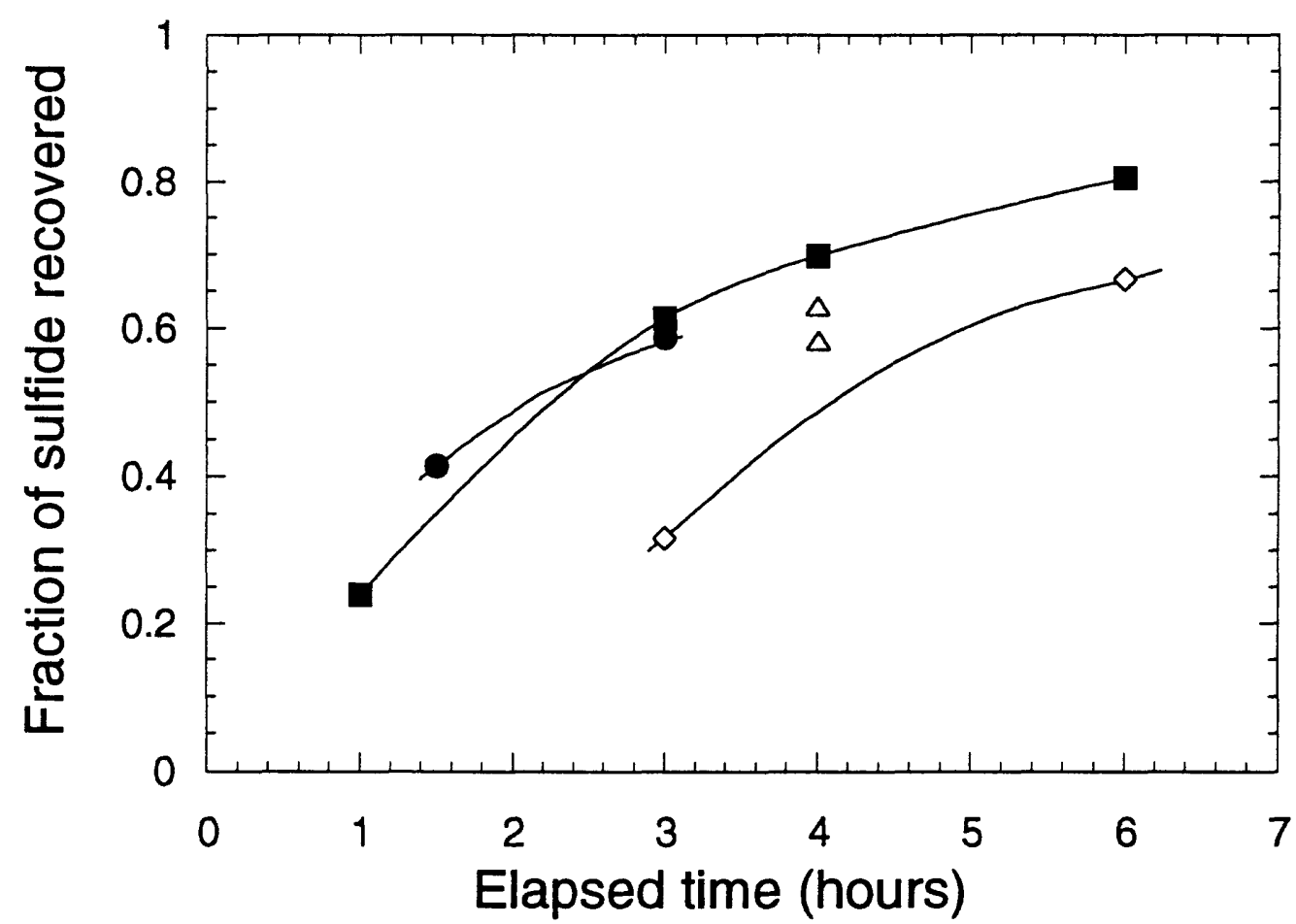

Figure 13. Fraction of sulfide recovered with time from one-trap laboratory experiments with different initial sulfide concentrations. Solid squares are for experiments with $3 \mathrm{mg} / \mathrm{L}$ sulfide solutions, solid circles for $0.5 \mathrm{mg} / \mathrm{L}$ experiments, open triangles for $0.1 \mathrm{mg} / \mathrm{L}$ experiments and opened diamonds for $0.03 \mathrm{mg} / \mathrm{L}$ experiments. Note that "fraction of sulfide recovered" equals (1$f)$ with $f$ defined as discussed in section 4.5.5. Longer collection time results in a larger fraction of the sulfide recovered. At higher initial concentration (i.e. fewer carboys of solution needed), a larger fraction of the sulfide is collected in less time than for lower concentration experiments with more carboys. This may, at least in part, be due to re-solution of $\mathrm{H}_{2} \mathrm{~S}$ stripped from "upstream" carboys in "downstream" carboys when more than one is connected in series.

Table 25. Maximum effect of $0.7 \mathrm{mg} / \mathrm{L}$ of dissolved oxygen on sulfide solutions with concentrations ranging from 3.0 to $0.03 \mathrm{mg} / \mathrm{L}$ [conc., concentration; $L$, liters; $\mathrm{mg} / \mathrm{L}$, milligrams per liter; $\mathrm{mmol}$, millimoles]

\begin{tabular}{ccccc}
$\begin{array}{c}\text { Conc. of } \mathrm{S}^{2-} \\
\text { (in } \mathrm{mg} / \mathrm{L} \text { ) }\end{array}$ & $\begin{array}{c}\text { Volume of } \\
\text { solution (in L) }\end{array}$ & $\begin{array}{c}\mathrm{mmol} \text { O in } 0.7 \\
\mathrm{mg} / \mathrm{L} \text { solution }\end{array}$ & $\begin{array}{c}\text { mmol } \mathrm{S}^{2-} \text { in } \\
\text { solution }\end{array}$ & $\begin{array}{c}(\mathrm{mmol} \mathrm{O/4)/} \\
\mathrm{mmol} \mathrm{S}\end{array}$ \\
\hline 3.0 & 50 & 2.19 & 4.16 & 0.131 \\
0.5 & 50 & 2.19 & 0.69 & 0.788 \\
0.1 & 100 & 4.38 & 0.28 & 3.940 \\
0.03 & 150 & 6.56 & 0.12 & 13.133 \\
\hline
\end{tabular}


the $0.7 \mathrm{mg} / \mathrm{L}$ dissolved oxygen remaining in the carboy at the beginning of the experiment. The theoretical maximum effect of this level of dissolved oxygen on the various experimental solutions is given in table 25. Moles of dissolved oxygen (divided by 4 , the ratio occurring in $\mathrm{SO}_{4}{ }^{2-}$ ) greatly exceeds the moles of dissolved sulfide in the 0.1 and $0.03 \mathrm{mg} / \mathrm{L} \mathrm{S} \mathrm{S}^{2-}$ solutions. Complete reaction of dissolved sulfide with dissolved oxygen apparently takes several hours, as discussed in section 4.3.1. Otherwise it would not have been possible to collect up to 66 percent of the dissolved sulfide from the 0.1 and $0.03 \mathrm{mg} / \mathrm{L} \mathrm{S}^{2-}$ solutions. In addition, some of the sulfide in the carboy may be oxidized by trace amounts of oxygen in the nitrogen gas and leakage of atmospheric oxygen into the apparatus, further decreasing the likelihood of a 100 percent recovery of sulfide under these laboratory conditions. In two fractional sulfide collection experiments conducted in 1995, however, the amount of sulfide oxidized to sulfate was quantified and found to be rather small (less than 2 percent, see section 4.5.4).

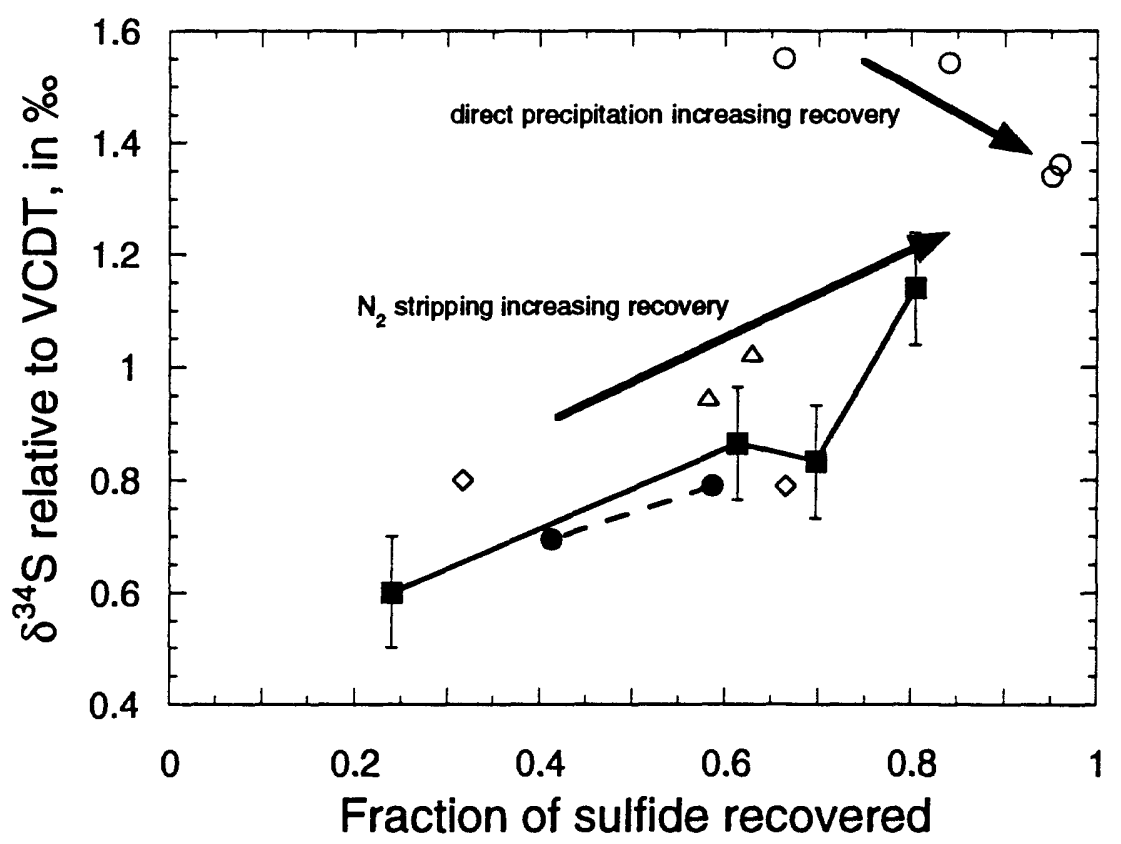

Figure 14. Change in the $\delta^{34} \mathrm{~S}$ of $\mathrm{Ag}_{2} \mathrm{~S}$ collected in one-trap laboratory sulfide collection experiments versus fraction of sulfide recovered (also corresponds to increased collection time). Symbols as in figure 13. Note that "fraction of sulfide recovered" equals $(1-f)$ with $f$ defined as discussed in section 4.5.5. Also plotted are the $\delta^{34} S$ values versus fraction sulfide recovered for laboratory direct precipitation experiments (open circles). Error bars on the data points for the 3 $\mathrm{mg} / \mathrm{L}$ nitrogen stripping experiments show analytical uncertainty associated with $\delta^{34} \mathrm{~S}$ values.

The same error bars could be applied to all data points but are not included to avoid cluttering the diagram. The $8^{34} \mathrm{~S}$ of $\mathrm{Ag}_{2} \mathrm{~S}$ increases with fraction of sulfide recovered, indicating that ${ }^{32} \mathrm{~S}$ is fractionated preferentially into $\mathrm{H}_{2} \mathrm{~S}(\mathrm{~g})$, as also observed by Szaran (1996). On the other hand, for direct precipitation experiments with less than 95 percent sulfide recovery, the $\mathrm{Ag}_{2} \mathrm{~S}$ collected is more positive than expected, indicating that ${ }^{32} \mathrm{~S}$ tends to stay in solution relative to ${ }^{34} \mathrm{~S}$ when $\mathrm{Ag}^{+}$ is added. Only the two direct precipitation experiments with greater than 95 percent recovery of sulfide are considered to have given the correct $\delta^{34} S$ of the sulfide. All the other data approach this value, namely, the value $\delta^{34} \mathrm{~S}=1.35$ per mill. 


\subsubsection{One-trap sulfide-collection-by-nitrogen-stripping experlments in the field}

Sulfide collection experiments were conducted in the field using oxygen-free ground water so that possible complications resulting from the presence of dissolved oxygen in laboratory experimental solutions were avoided. Water from the Suwannee well and Upper Intermediate well had sulfide concentrations that differed by an order of magnitude (table 16). The procedure for these one-trap sulfide-collection-by-nitrogen-stripping experiments differed somewhat from the procedure used in the laboratory.

Procedure -- Equipment was set up as shown in figure 4 (see also figure 15) using one 50-L carboy for experiments at the Suwannee well $\left(2.95 \mathrm{mg} / \mathrm{L} \mathrm{S}^{2-}\right)$ and two 50-L carboys at the Upper Intermediate well $\left(0.20 \mathrm{mg} / \mathrm{L} \mathrm{S}^{2-}\right)$. The carboys were filled as quickly as possible with the ground water and were allowed to overflow for about one carboy volume to eliminate ground water that was in contact with air while the carboy was filling. At the Upper Intermediate well, the first carboy was filled, overflowed and capped with no head space while the second carboy was filled. Flow rates and time required to fill the carboys at each well are listed in table 26.

After the carboys were filled and overflowed, a small amount of the water was poured out to create a small head space, $100 \mathrm{~mL}$ of $6 \mathrm{~N} \mathrm{H}_{2} \mathrm{SO}_{4}$ was added, the carboy was capped with a venting / filling cap with gas dispersion tubes, and the tubing was connected to the nitrogen tank and the traps. A flowmeter was included in experiment 1 (flow rate about $2.1 \mathrm{~L}$ minute), experiment 4 (flow rate about $1.2 \mathrm{~L} /$ minute) and experiment 14 (flow rate about $1.1 \mathrm{~L}$ minute); in the other experiments, the flowmeter was not included. $\mathrm{N}_{2}$ flow was started immediately and a timer was used to time the length of the experiment. The carboy was rocked at the beginning of the experiment to mix the acid with the ground water and rocked at intervals during the experiment to homogenize the ground water sample and assure even stripping. When the experiment was complete (about 3 hours had elapsed or the production of $\mathrm{Ag}_{2} \mathrm{~S}$ had ceased) the tubing was disconnected (downstream traps first), the $\mathrm{N}_{2}$ flow stopped and the contents of the $\mathrm{AgNO}_{3}$ trap were carefully filtered on a membrane filter. A plastic, $250-\mathrm{mL}$ filter flask and hand pump were convenient for filtering $\mathrm{Ag}_{2} \mathrm{~S}$ in the field. The $\mathrm{AgNO}_{3}$ solution was saved for use in additional nitrogen-stripping runs. The $\mathrm{Ag}_{2} \mathrm{~S}$ was rinsed thoroughly with deionized water and transferred to a small, plastic petri dish. In the laboratory, the $\mathrm{Ag}_{2} \mathrm{~S}$ was dried, weighed, homogenized, combined with $\mathrm{Cu}_{2} \mathrm{O}$, combusted to $\mathrm{SO}_{2}$ and analyzed as described in sections 3.4 and 3.5.

These data, along with the direct precipitation data from the Suwannee well (table 23) are plotted in figure 16. Data from a two-trap experiment at the Upper Intermediate well are included in table 26. 
Table 26. Results on one-trap nitrogen-stripping experiments in the field [mg. milligrams: Upp. Int.. Upper Intermediate well]

\begin{tabular}{ccccccc}
\hline $\begin{array}{c}\text { Exp. \# I } \\
\text { fraction }\end{array}$ & Well Name & $\begin{array}{c}\text { Time to } \\
\text { filVoverflow } \\
\text { carboy(s) } \\
\text { (in minutes) }\end{array}$ & $\begin{array}{c}\text { Length of } \\
\text { Experim. (in } \\
\text { hours) }\end{array}$ & $\begin{array}{c}\mathrm{Ag}_{2} \mathrm{~S} \\
\text { obtained (in } \\
\mathrm{mg} \text { ) }\end{array}$ & $\begin{array}{c}\text { Fraction of } \\
\text { sulfide } \\
\text { recovered } \\
\text { (in \%) }\end{array}$ & $\begin{array}{c}\delta^{34} \mathrm{~S} \\
\text { relative to } \\
\text { VCDT } \\
\text { (in \%) }\end{array}$ \\
\hline 1 & Upp. Int. & 55 & 1.83 & 52.0 & 33.8 & -52.3 \\
$3 / 1$ & Upp. Int. & 40 & 2.75 & 43.8 & 28.5 & -51.9 \\
$3 / 2$ & same as & above & $\begin{array}{c}1 \\
92\end{array}$ & 6.9 & 4.5 & -48.8 \\
4 & Upp. Int. & 40 & 5.58 & 102.4 & 66.6 & -51.3 \\
\hline 14 & Suwannee & $<2$ & 3.25 & 953.7 & 83.7 & $1-34.0$ \\
17 & Suwannee & $<2$ & 3.0 & 1042.4 & 91.4 & $1-34.1$ \\
\hline 1
\end{tabular}

1 Expected value $=-33.8 \pm 0.11$ per mill.

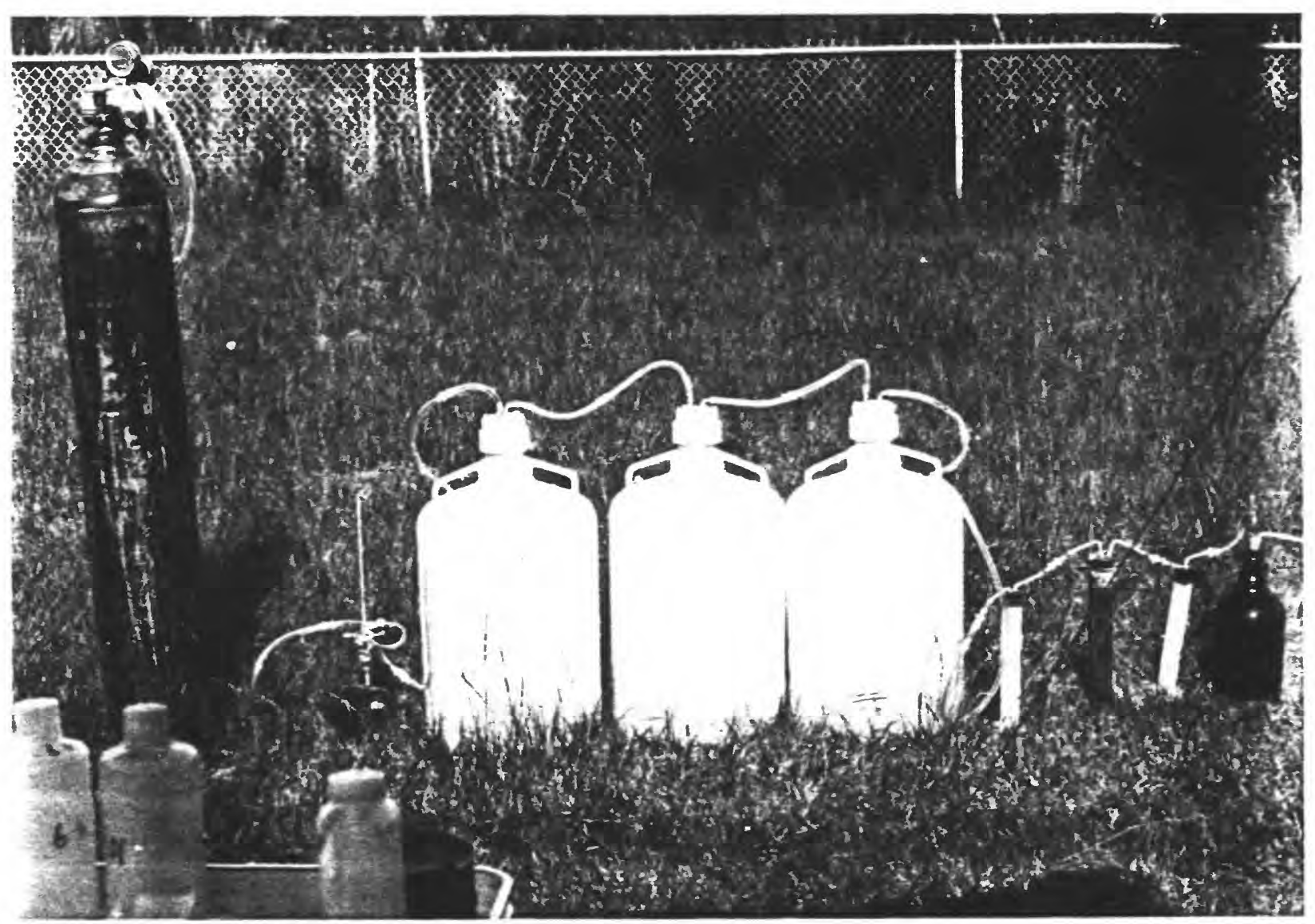

Figure 15. Sulfide-collection-by-nitrogen-stripping apparatus set up in the field. Compare to the diagram in figure 4. In the photograph, three carboys have been set up in series in order to obtain enough $\mathrm{Ag}_{2} \mathrm{~S}$ for analysis from a water sample with low dissolved sulfide concentration. The trap on the downstream end of the apparatus, farthest to the right in the photo, does not corresponding to any trap in figure 4 . This trap was used to collect a sample for ${ }^{14} \mathrm{C}$ analysis; it is not part of the sulfide collection. 
(a) Suwannee well $2.95 \mathrm{mg} / \mathrm{L}$ sulfide, $380 \mathrm{mg} / \mathrm{L}$ sulfate

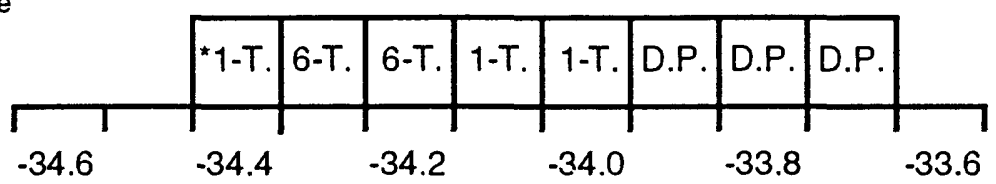

$\delta^{34} \mathrm{~S}$ relative to $\mathrm{VCDT}$, in \%。

(b) Upper Intermediate well $0.2 \mathrm{mg} / \mathrm{L}$ sulfide $48 \mathrm{mg} / \mathrm{L}$ sulfate

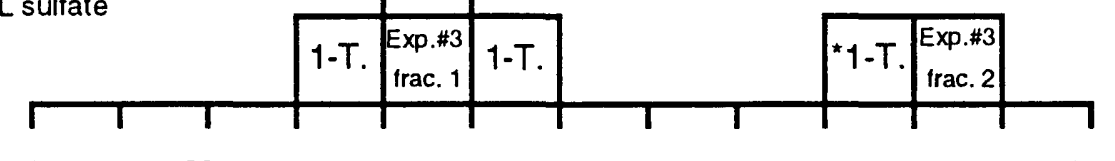

$\begin{array}{lllllll}-54.0 & -53.0 & -52.0 & -51.0 & -50.0 & -49.0 & -48.0\end{array}$

$\delta^{34} \mathrm{~S}$ relative to $\mathrm{VCDT}$, in \%。

Figure 16. Plots illustrating the composition of sulfide collected at the Suwannee (a) and Upper Intermediate wells (b). Note that the interval on the Suwannee plot is 0.1 per mill, whereas the interval on the plot of the Upper Intermediate data is 0.5 per mill. "1-T." indicates a one-trap experiment and "6-T." indicates the weighted average $\delta^{34} S$ value for a six-trap experiment. Samples noted with a * were collected by Laura Sacks at these same wells and analyzed by Robert Seal for the study by Sacks and Tihansky (1996). In (b), the two fractions collected in experiment \#3 at the Upper Intermediate well are plotted separately. The weighted average of these two fractions is plotted as "Exp. \#3 F.I." (fractions integrated). The $\delta^{34} \mathrm{~S}$ values for sulfide collected by direct precipitation (D.P.) at the Suwannee well are consistently less negative (more enriched in ${ }^{34} \mathrm{~S}$ ) than sulfide collected by nitrogen stripping (1-T. and 6-T.) indicating that, although the fraction of sulfide recovered in the nitrogen stripping experiments was high (see table 26 ), the $\delta^{34} S$ of the sulfide collected was more negative than expected.

Figure 16 illustrates that $\mathrm{Ag}_{2} \mathrm{~S}$ collected by direct precipitation is consistently enriched in ${ }^{34} \mathrm{~S}$ relative to $\mathrm{Ag}_{2} \mathrm{~S}$ collected by nitrogen stripping. Note, however, that the range of $\delta^{34} S$ values (figure 16a) for sulfide from the Suwannee well is only 0.8 per mill. Isotopic data for $\mathrm{Ag}_{2} \mathrm{~S}$ collected at the Upper Intermediate well are more scattered, with a range of $\delta^{34} S$ values of about 4 per mill (figure 16b).

The different characteristics of these wells account for much of the difference in the precision of the data. The Upper Intermediate well is a small-diameter well (table 16). At pumping rates greater than 5.0 liters per minute, air bubbles were entrained in the water, indicating that the well was being drawn down faster than it could fill, and so pumping rates were kept below this level. As a result, it took 40 to 55 minutes to fill and overflow two $50-L$ carboys at the Upper Intermediate well. It is noteworthy that, not only was recovery of sulfide low for these experiments (table 26), but measurements with the Hach spectrophotometer indicate that little dissolved sulfide remained in the carboys when the experiments were complete $\left(0.013 \mathrm{mg} / \mathrm{L} \mathrm{S}^{2-}\right.$ for experiment 1 and $0.003 \mathrm{mg} / \mathrm{L} \mathrm{S}^{2-}$ 
for experiment 4). The missing dissolved sulfide probably dissipated into the air while the carboys were being filled. Szaran (1996) measured the equilibrium sulfur isotopic fractionation between dissolved $\mathrm{H}_{2} \mathrm{~S}$ and $\mathrm{H}_{2} \mathrm{~S}$ gas and found that gaseous $\mathrm{H}_{2} \mathrm{~S}$ is depleted in ${ }^{34} \mathrm{~S}$ relative to dissolved $\mathrm{H}_{2} \mathrm{~S}$ at temperatures between 10 and $30^{\circ} \mathrm{C}$. We conclude from this evidence that gaseous $\mathrm{H}_{2} \mathrm{~S}$ dissipated into the air during filling of the carboys would have been isotopically more negative than the dissolved $\mathrm{H}_{2} \mathrm{~S}$ that remains in solution. Different degrees of loss of $\mathrm{H}_{2} \mathrm{~S}$ are most likely responsible for the scatter in the data from the Upper Intermediate well. The relatively low initial concentration of dissolved sulfide at the Upper Intermediate well made these experiments particularly sensitive to the loss of a fraction of the available dissolved sulfide as gaseous $\mathrm{H}_{2} \mathrm{~S}$.

Characteristics of the Suwannee well were ideal for obtaining $\mathrm{Ag}_{2} \mathrm{~S}$ from dissolved sulfide with much more consistent $\delta^{34} S$ values. The Suwannee well is a large-diameter flowing well (table 16) that produced water at a rate of 170 liters per minute. As a result, a 50-L carboy could be filled to overflowing in less than 2 minutes. Furthermore, the sum of sulfide recovered as $\mathrm{Ag}_{2} \mathrm{~S}$ plus the sulfide remaining in solution at the end of each nitrogen-stripping experiment was very consistent for the two one-trap and for the two fractional experiments (table 27). The initial dissolved sulfide concentration of the ground water calculated on this basis was considered more reliable than the measurements with the Hach spectrometer which were diluted with deionized water and suffered from the uncertainty described in section 4.3.1. The average value of the four "recalculated initial dissolved sulfide" concentrations is $2.95 \mathrm{mg} / \mathrm{L}( \pm 0.10)$ and this is taken to be the "actual" dissolved sulfide concentration of the Suwannee ground water in table 16.

Table 27. Sulfide concentration of Suwannee water calculated from results of nitrogen-stripping experiments

[mg, milligrams; $\mathrm{mg} / \mathrm{L}$, milligrams per liter]

\begin{tabular}{cccccc}
\hline Experiment & $\begin{array}{c}\mathrm{S}^{2-} \text { conc. } \\
\text { (diluted) } \\
\text { (in } \mathrm{mg} / \mathrm{L})\end{array}$ & $\begin{array}{c}\mathrm{Ag}_{2} \mathrm{~S} \\
\text { produced } \\
\text { (in } \mathrm{mg})\end{array}$ & $\begin{array}{c}\mathrm{S}^{2-} \text { at end } \\
\text { (undiluted) } \\
\text { (mg/L) }\end{array}$ & $\begin{array}{c}\text { Fraction of } \\
\text { sulfide ac- } \\
\text { counted for } \\
\text { (in \%) }\end{array}$ & $\begin{array}{c}\text { recalculated } \\
\text { initial dissolved } \\
\text { sulfide } \\
\text { (in } \mathrm{mg} / \mathrm{L})^{2}\end{array}$ \\
\hline 13 & 2.28 & 1000.9 & 0.276 & 125.7 & 2.87 \\
14 & 2.28 & 953.7 & 0.414 & 126.4 & 2.88 \\
17 & 2.82 & 1042.4 & 0.384 & 109.3 & 3.08 \\
27 & 2.39 & 1051.9 & 0.248 & 124.3 & 2.97 \\
\hline
\end{tabular}

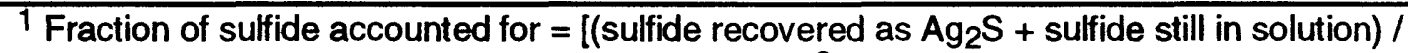
(sulfide present based on diluted measurement of $S^{2-}$ in ground water)].

2 Dissolved sulfide present in Suwannee water based on the sum of the sulfide collected as $\mathrm{Ag}_{2} \mathrm{~S}$ plus the dissolved sulfide (measured without dilution) remaining in the carboy at the end of each experiment. 


\subsubsection{Six-trap (fractional) sulfide-collection-by-nitrogen-stripping experiments in the field}

In two sulfide collection experiments at the Suwannee well, the $\mathrm{AgNO}_{3}$ traps were changed at intervals during the experiment in order to better document the change in the sulfur isotopic composition of the $\mathrm{Ag}_{2} \mathrm{~S}$ collected with time. Other than changing the $\mathrm{AgNO}_{3}$ traps, the experimental procedure was identical to that for the one-trap experiments discussed above. The flowmeter was not included in the setup for these experiments. Nitrogen flow rate is thought to have been about 1.2 L/minute. Data from these six-trap, fractional experiments are given in table 28.

Table 28. Fractional sulfide collection experiments at the Suwannee Well [exp., experiment]

\section{Exp. \# / fraction \# Time $\mathrm{Ag}_{2} \mathrm{~S}$ collected in trap (in minutes)}

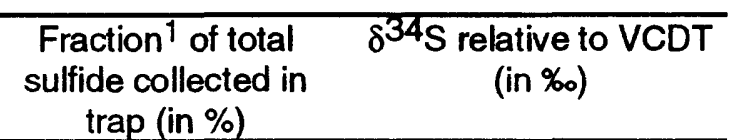

\begin{tabular}{llcl}
\hline $13 / 1$ & 4.5 & 12.3 & -34.77 \\
$13 / 2$ & 14.0 & 11.2 & -34.71 \\
$13 / 3$ & 15.5 & 10.6 & -34.82 \\
$13 / 4$ & 31.0 & 16.8 & -34.44 \\
$13 / 5$ & 33.0 & 14.6 & -34.10 \\
$13 / 6$ & 102.0 & 24.9 & -33.69 \\
\hline $27 / 1$ & 10.0 & 9.5 & -34.87 \\
$27 / 2$ & 15.0 & 13.5 & -34.63 \\
$27 / 3$ & 15.0 & 12.2 & -34.60 \\
$27 / 4$ & 20.0 & 14.2 & -34.36 \\
$27 / 5$ & 30.0 & 20.5 & -34.02 \\
$27 / 6$ & 60.0 & 21.8 & -33.46 \\
\hline
\end{tabular}

1 where 100 percent includes sulfide remaining in the solution at the end of the experiment.

A kinetic fractionation between dissolved and gaseous $\mathrm{H}_{2} \mathrm{~S}$, in the same sense $\left(\delta^{34} \mathrm{~S}\right.$ of $\mathrm{H}_{2} \mathrm{~S}(\mathrm{~g})$ more negative than $\delta^{34} \mathrm{~S}$ of $\mathrm{H}_{2} \mathrm{~S}(\mathrm{aq})$ ) but smaller in magnitude than the equilibrium fractionation described by Szaran (1996), occurs during sulfide collection by nitrogen stripping. $\mathrm{H}_{2} \mathrm{~S}(\mathrm{~g})$ is quantitatively converted 
to $\mathrm{Ag}_{2} \mathrm{~S}$ in the $\mathrm{AgNO}_{3}$ trap.12 Early-formed $\mathrm{Ag}_{2} \mathrm{~S}$ will, therefore, be isotopically more negative than later-forming $\mathrm{Ag}_{2} \mathrm{~S}$. Also, as $\mathrm{Ag}_{2} \mathrm{~S}$ forms in the $\mathrm{AgNO}_{3}$ trap, its grain size increases with time. Fractionation of the sulfur isotopes in $\mathrm{H}_{2} \mathrm{~S}$ stripped from the carboy is strong enough that $\mathrm{Ag}_{2} \mathrm{~S}$ collected in a trap for 10 to 15 minutes may exhibit fractionation between coarse-grained, early-crystallizing and fine-grained, late-crystallizing $\mathrm{Ag}_{2} \mathrm{~S}$. It is imperative, therefore, that $\mathrm{Ag}_{2} \mathrm{~S}$ collected by this nitrogen-stripping method be completely removed from the membrane filter and ground with a mortar and pestle to homogenize it before it is weighed and combined with $\mathrm{Cu}_{2} \mathrm{O}$, as described in section 3.4.

In both of these field experiments more than 90 percent of the dissolved sulfide originally in the ground water was collected as $\mathrm{Ag}_{2} \mathrm{~S}$. Yet, as was the case with the one-trap experiments, $\delta^{34} S$ of dissolved sulfide for these experiments is more negative than that for the direct precipitation experiments (figure 16). This suggests that sulfide remaining in solution in the carboy was enriched in ${ }^{34} \mathrm{~S}$.

\subsubsection{Six-trap (fractional) sulfide-collection-by-nitrogen-stripping experiments in the laboratory}

Two fractional sulfide collection experiments were conducted in the laboratory in 1995 in order to address some questions not answered by the previous experiments including (1) the effect of nitrogen flow rate on the amount and isotopic composition of the $\mathrm{Ag}_{2} \mathrm{~S}$ collected and (2) the extent to which oxygen dissolved in the experimental solutions oxidizes the sulfide to sulfate rendering it unavailable for recovery as $\mathrm{Ag}_{2} \mathrm{~S}$. Changes were made to the experimental procedure to accomplish these goals.

Procedure -- The equipment was set up as shown in figure 4; the flowmeter was included in the setup. An additional trap (for potassium acid phthalate buffer) was included between traps 1 and 2. The carboy was filled with deionized water and nitrogen was bubbled through the carboy overnight before the experiment was started to eliminate most of the dissolved oxygen. The dissolved oxygen content of the deionized water was measured immediately before each experiment was started and in both cases was found to be $0.4 \mathrm{mg} / \mathrm{L}$. At this point, $200 \mathrm{~mL}$ of 10 weight percent $\mathrm{AgNO}_{3}$ solution was poured into Trap 2 and about $150 \mathrm{~mL}$ of potassium acid phthalate buffer was poured into the preceding trap. The nitrogen flow rate was set to the desired experimental value (1.4

\footnotetext{
12 Three experiments were preformed in January 1997 in which a native sulfur reference material was converted to $\mathrm{H}_{2} \mathrm{~S}$ via reduction with acidic chromous chloride solution. The $\mathrm{H}_{2} \mathrm{~S}$ was bubbled with nitrogen gas through two $\mathrm{AgNO}_{3}$ traps in series to determine whether any $\mathrm{H}_{2} \mathrm{~S}$ passed the first $\mathrm{AgNO}_{3}$ trap without precipitating as $\mathrm{Ag}_{2} \mathrm{~S}$. Note that the volume of the $\mathrm{AgNO}_{3}$ traps used for these experiments were much smaller $(50 \mathrm{~mL})$ than the $250 \mathrm{~mL}$ cylinders used in the sulfide collection from ground water apparatus. After bubbling for several hours, no trace of $\mathrm{Ag}_{2} \mathrm{~S}$ formed in the second $\mathrm{AgNO}_{3}$ traps and $\mathrm{Ag}_{2} \mathrm{~S}$ collected in the first traps represented nearly complete conversion (96.2 to $100.7 \%$ ) of the $\mathrm{S}$ to $\mathrm{Ag}_{2} \mathrm{~S}$.
} 
$\mathrm{L} /$ minute or $0.8 \mathrm{~L} /$ minute) using the flowmeter. Technical $\mathrm{Na}_{2} \mathrm{~S}$ (60 percent) to produce an approximately $3 \mathrm{mg} / \mathrm{L}$ sulfide solution was weighed out and quickly added to the carboy along with $100 \mathrm{~mL}$ of $6 \mathrm{~N} \mathrm{HCl}^{13}$. $\mathrm{HCl}$ was used to acidify the solutions in these experiments so that the extent of oxidation of sulfide to sulfate could be evaluated. Because $\mathrm{HCl}$ is a more volatile acid than $\mathrm{H}_{2} \mathrm{SO}_{4}$, the potassium acid phthalate trap was needed to prevent $\mathrm{HCl}$ vapor from reaching the $\mathrm{AgNO}_{3}$ trap and causing the precipitation of $\mathrm{AgCl}$.

A sample of the solution was collected in a $60 \mathrm{~mL}$ glass bottle with a polyseal cap to measure the sulfide concentration of the solution with the Hach spectrophotometer. A timer was started as soon as the carboy was recapped and bubbling began in trap 2. This trap was changed at intervals (see Table 29) and the $\mathrm{Ag}_{2} \mathrm{~S}$ was filtered onto a pre-weighed membrane filter. After pouring the $\mathrm{AgNO}_{3}$ solution out of the filter flask so that it could be saved without dilution, the $\mathrm{Ag}_{2} \mathrm{~S}$ was carefully rinsed with deionized water.

When the three-hour sulfide collection was complete, a sample of the solution was collected in a $60 \mathrm{~mL}$ glass bottle with a polyseal cap for determination of the concentration of sulfide remaining in solution. About $9 \mathrm{~L}$ of the solution was poured into a clean $10 \mathrm{~L}$ plastic bucket and nitrogen was bubbled through the solution for about 30 minutes at a $\mathrm{N}_{2}$ flow rate of $7.7 \mathrm{~L} /$ minute to strip remaining sulfide from the solution. Removal of sulfide to below the $0.01 \mathrm{mg} / \mathrm{L}$ level was confirmed by analyzing the $S^{2-}$ concentration of the solution with the spectrophotometer. The bucket was then covered and the solution saved so that sulfate could be collected on anion exchange resin on the following day. Sulfate was collected on the anion exchange resin as discussed in section 2.1.5 and eluted as described in section 3.2.

Results -- Experiments were performed at nitrogen flow rates of $0.8 \mathrm{~L} /$ minute and $1.4 \mathrm{~L}$ minute, the maximum possible with the equipment shown in figure 4 without transferring solutions from one trap to another. The results of the sulfide collection portion of the experiments is given in table 29. A total of $801.6 \mathrm{mg}$, or 87 percent of the sulfide was collected as $\mathrm{Ag}_{2} \mathrm{~S}$ in the $1.4 \mathrm{~L} \mathrm{~N} /$ /minute experiment (a total of $15.6 \mathrm{mg} \mathrm{S}$ remained in the solution at the end). In contrast, a total of $612.6 \mathrm{mg}$, or 74.0 percent of the sulfide was collected as $\mathrm{Ag}_{2} \mathrm{~S}$ in the $0.8 \mathrm{~L} \mathrm{~N} /$ minute experiment (a total of $25.6 \mathrm{mg} \mathrm{S}$ remained in solution). As expected, the higher nitrogen flow rate allowed recovery of a higher percentage of the dissolved sulfide in a given period of time. The weighted average $\delta^{34} S$ of sulfide collected in the $1.4 \mathrm{~L} \mathrm{~N} /$ minute experiment is 1.10 per mill. This is closer to the $\delta^{34} S$ value from direct precipitation experiments (1.35 per mill) than the weighted average $\delta^{34} S$ value of 0.97 per mill from the $0.8 \mathrm{~L} \mathrm{~N} /$ minute experiment.

13 To make $6 \mathrm{~N} \mathrm{HCl}$, measure $242.2 \mathrm{~mL}$ of 38 percent reagent-grade $\mathrm{HCl}$. Pour about $200 \mathrm{~mL}$ deionized water into $500 \mathrm{~mL}$ volumetric flask. Add $\mathrm{HCl}$ and then add deionized water to make $500 \mathrm{~mL}$ of solution. See also table 2, footnote 2 . 
The extent of sulfide oxidation to sulfate was also evaluated in these two experiments. For the experiment with nitrogen flow rate of $1.4 \mathrm{~L}$ minute, the procedure above was followed but no sulfate was found in this solution. In light

Table 29. Fractional sulfide collection experiments with controlled nitrogen flow rates [L/min., liters per minute]

\begin{tabular}{|c|c|c|c|}
\hline $\begin{array}{l}\mathrm{N}_{2} \text { flow rate (in } \\
\mathrm{L} \text { min.)/ trap \# }\end{array}$ & $\begin{array}{l}\text { Time } \mathrm{Ag}_{2} \mathrm{~S} \text { collected } \\
\text { in trap (in minutes) }\end{array}$ & $\begin{array}{l}\text { Fraction }{ }^{1} \text { of total } \\
\text { sulfide collected in } \\
\text { trap (in \%) }\end{array}$ & $\begin{array}{c}\delta^{34} S \text { relative to VCDT } \\
\text { (in \%o) }\end{array}$ \\
\hline $1.7 / 1$ & 10 & 12.4 & 0.55 \\
\hline $1.4 / 2$ & 15 & 13.1 & 0.72 \\
\hline $1.4 / 3$ & 15 & 11.2 & 0.87 \\
\hline $1.4 / 4$ & 20 & 14.0 & 1.08 \\
\hline $1.4 / 5$ & 30 & 13.7 & 1.20 \\
\hline $1.4 / 6$ & 90 & 22.6 & 1.70 \\
\hline $0.8 / 1$ & 10 & 5.4 & 0.66 \\
\hline $0.8 / 2$ & 10 & 5.6 & 0.69 \\
\hline $0.8 / 3$ & 20 & 11.1 & 0.73 \\
\hline $0.8 / 4$ & 20 & 10.4 & 0.86 \\
\hline $0.8 / 5$ & 30 & 13.2 & 0.93 \\
\hline $0.8 / 6$ & 90 & 28.3 & 1.25 \\
\hline
\end{tabular}

1 where $100 \%$ includes sulfide remaining in the solution at the end of the experiment.

of this result, an effort was made in the $0.8 \mathrm{~L} \mathrm{~N}$ /minute experiment to oxidize dissolved sulfur species with intermediate oxidation states. After the sulfide collection portion of the experiment was complete, solution from the carboy was poured into two clean buckets and the remaining sulfide stripped at nitrogen flow rate of $7.7 \mathrm{~L}$ minute or greater. After $\mathrm{S}^{2-}$ analyses indicated that stripping was complete, $10 \mathrm{~mL}$ of 30 percent $\mathrm{H}_{2} \mathrm{O}_{2}$ solution was added to one of the buckets in an effort to oxidize sulfur species such as sulfite and thiosulfate to sulfate. Dissolved sulfate in the solution from the two buckets was collected on separate anion exchange resin cartridges. Nearly identical, small amounts of $\mathrm{BaSO}_{4}$ were produced from each of these solutions indicating that the amount of sulfide converted to sulfate in the entire carboy $(48 \mathrm{~L})$ was only $2.2 \mathrm{mg}$. This represents 11.4 percent of the sulfide that could have been oxidized by the $0.4 \mathrm{mg} / \mathrm{L}$ dissolved oxygen in the starting solution and 2.1 percent of the total sulfide in the experiment. Addition of an oxidizing agent to the bucket did not affect amount of $\mathrm{BaSO}_{4}$ produced. The amount of sulfur not collected as $\mathrm{Ag}_{2} \mathrm{~S}$ or $\mathrm{BaSO}_{4}$ due to its presence as intermediate species appears not to be significant. The sulfur isotopic composition of the $\mathrm{BaSO}_{4}$ precipitate from the two buckets was 
determined separately; $\delta^{34} S$ for sulfate from the bucket not treated with peroxide was 5.3 per mill and $\delta^{34} S$ for sulfate from the peroxide-treated bucket was 4.9 per mill. The sulfate was enriched in ${ }^{34} \mathrm{~S}$ by about 4 per mill relative to the $\mathrm{Ag}_{2} \mathrm{~S}$ collected in this experiment. Nevertheless, because the amount of sulfide oxidized was small (2.1 percent), the effect on the sulfur isotopic composition of the $\mathrm{Ag}_{2} \mathrm{~S}$ collected should be minimal.

\subsubsection{Evaiuation of the suifide-coilection-by-nitrogen-stripping experiments}

The results of the six-trap sulfide collection experiments can be used to determine fractionation factors describing the sulfur isotopic fractionation observed in these experiments. A consistent fractionation factor would allow calculation of $\left(\delta^{34} S\right)_{s o}$, the sulfur isotopic composition of the dissolved sulfide in the ground-water sample from $\left(\delta^{34} S\right) g$, the "instantaneous" sulfur isotopic composition of gaseous $\mathrm{H}_{2} \mathrm{~S}$ stripped from the ground water, which is equivalent to the sulfur isotopic composition of an initial fraction $(1-f \approx 0.1)$ of $A_{2} S$ collected by nitrogen stripping. The important quantities are defined as follows:

$R_{S}={ }^{34} \mathrm{~S} / 32 \mathrm{~S}$ of dissolved $\mathrm{H}_{2} \mathrm{~S}$ (dissolved $\mathrm{H}_{2} \mathrm{~S}$ is the reagent) at any time during the experiment (instantaneous).

$R_{S O}={ }^{34} \mathrm{~S} / 32 \mathrm{~S}$ of dissolved $\mathrm{H}_{2} \mathrm{~S}$ at the beginning of the experiment.

$R_{g}={ }^{34} \mathrm{~S} / 32 \mathrm{~S}$ of gaseous $\mathrm{H}_{2} \mathrm{~S}$ stripped from the solution $\left(\mathrm{H}_{2} \mathrm{~S}(\mathrm{~g})\right.$ is the product). Because conversion of $\mathrm{H}_{2} \mathrm{~S}(\mathrm{~g})$ to $\mathrm{Ag}_{2} \mathrm{~S}$ in the $\mathrm{AgNO}_{3}$ trap is quantitative (see footnote 12), $R_{g}$ also equals ${ }^{34} \mathrm{~S} / 32 \mathrm{~S}$ of the $\mathrm{Ag}_{2} \mathrm{~S}$ at any point during the experiment (instantaneous).

$f=$ the fraction of the dissolved $\mathrm{H}_{2} \mathrm{~S}$ (reagent) remaining in the carboy.

$\alpha=\alpha_{g-s}=$ the fractionation factor $=R_{g} / R_{S}$.

$\left(\delta^{34} S\right)_{g}=$ instantaneous sulfur isotopic composition of gaseous $\mathrm{H}_{2} \mathrm{~S}$ stripped from the ground water, which is equivalent to the sulfur isotopic composition of a corresponding fraction of $\mathrm{Ag}_{2} \mathrm{~S}$.

$\left(\delta^{34} S\right)_{s o}=$ the sulfur isotopic composition of the $\mathrm{H}_{2} \mathrm{~S}(\mathrm{aq})$ in the ground-water sample, that is, the original dissolved sulfide before any stripping takes place. This is the quantity we would like to measure.

The Rayleigh distillation equation is written thus:

$$
f\left(x-1=\frac{R_{S}}{R_{s o}}\right.
$$


The definition of $\alpha$ is rearranged to $R_{s}=R_{g} / \alpha$ and substituted into the Rayleigh distillation equation:

$$
\alpha f o-1=\frac{R_{g}}{R_{s o}}
$$

Equation 1 can be written for $R_{\text {so }}$ and $R_{g}$ :

$$
\begin{aligned}
\left(\delta^{34} S\right)_{S O} & =\left(\frac{R_{S O}-R_{V C D T}}{R_{V C D T}}\right) \times 1000 \\
\left(\delta^{34} S\right)_{g} & =\left(\frac{R_{g}-R_{V C D T}}{R_{V C D T}}\right) \times 1000
\end{aligned}
$$

and rearranged to:

$$
\begin{aligned}
R_{S O} & =\frac{R_{V C D T}\left[\left(\delta^{34} S\right)_{S O}+1000\right]}{1000} \\
R_{g} & =\frac{R_{V C D T}\left[\left(\delta^{34} S\right)_{g}+1000\right]}{1000}
\end{aligned}
$$

Equation 3 is converted to $\delta$ notation by substituting in the relations for $R_{s o}$ and $R_{g}$ in Equations 4 and 5 to obtain:

$$
\alpha f^{-1}=\frac{\left[\left(\delta^{34} S\right)_{g}+1000\right]}{\left[\left(\delta^{34} S\right)_{s o}+1000\right]}
$$

Rearranging and taking the natural logarithm of this equation:

$$
\ln \left[\left(\delta^{34} S\right)_{g}+1000\right]=(\alpha-1) \ln f+\ln \left\{\alpha\left[\left(\delta^{34} S\right)_{s o}+1000\right]\right\}
$$

On a plot of $\ln \left[\left(\delta^{34} S\right) g+1000\right]$ versus $\ln f$, equation 6 produces a line with a slope of $(\alpha-1)$ and the intercept $=\ln \left\{\alpha\left[\left(\delta^{34} S\right)_{s o}+1000\right]\right\}$. The data in tables 28 and 29 are plotted in figure 17. Linear regression is used to fit the data with a straight line, allowing us to solve for $\alpha$ and $\left(\delta^{34} S\right)_{\text {so. }}$. Note that the "Fraction of total sulfide collected in trap (in \%)" in tables 28 and 29 is converted to $f$ by dividing by 100 and subtracting from 1. Results are summarized in table 30 . Data for these two pairs of experiments yield very similar fractionation factors, suggesting that it may be possible to calculate $\left(\delta^{34} S\right)_{\text {so }}$ from $\left(\delta^{34} S\right)_{g}$, obtained by collecting a small fraction of the sulfide as $\mathrm{Ag}_{2} \mathrm{~S}$ by nitrogen stripping. The wider applicability of this fractionation factor can be tested by calculating $\left(\delta^{34} S\right)_{\text {so }}$ for the one-trap laboratory and field experiments and also for selected early fractions of the fractional experiments. Data are selected from tables 24, 26, 28 and 29. Calculated $\left(\delta^{34} S\right)_{\text {so }}$ values, normalized to the expected $\delta^{34} S$ values from the direct precipitation experiments, are plotted in figure 18. 

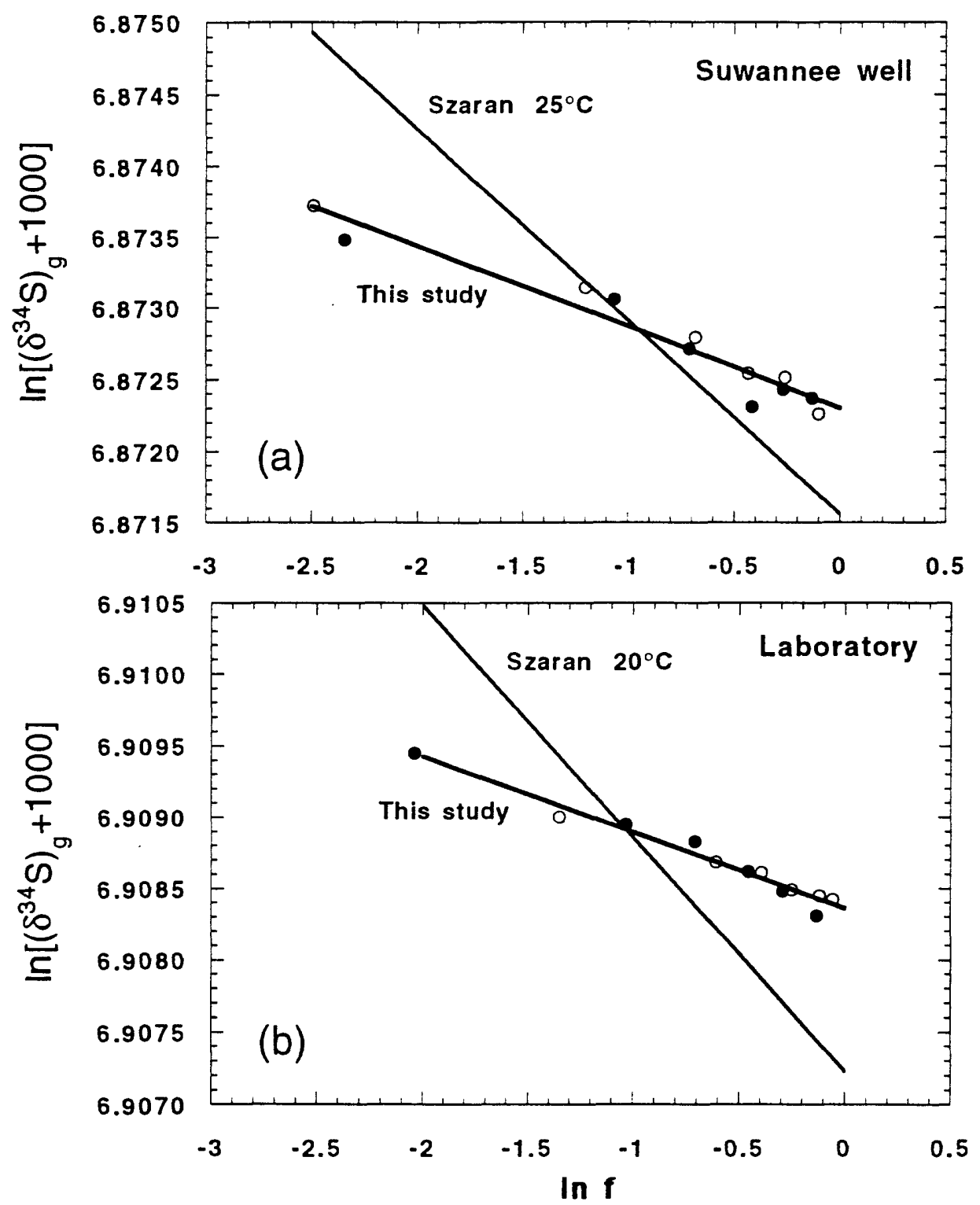

Figure 17. Plots of $\ln \left[\left(\delta^{34} S\right) g+1000\right]$ versus $\ln f$ for six-trap sulfide collection experiments at the Suwannee well (a) and in the laboratory (b). $\left(\delta^{34} S\right)_{\mathrm{g}}$ is the sulfur isotopic composition of $\mathrm{Ag}_{2} \mathrm{~S}$ collected in each successive trap and $f$ is the fraction of $\mathrm{H}_{2} \mathrm{~S}$ remaining in the carboy. Equation 6 indicates that there is a linear relationship between these quantities and that the fractionation factor $\alpha$ can be calculated from the slope. (a) Solid circles are data from experiment 13 and open circles are data from experiment 27 at the Suwannee well (data in table 28). The line through these data points is fitted by linear regression $\left(r^{2}=0.9409\right)$. The $\alpha$ calculated from the slope of this line is 0.99943 . This line is compared to a line based on the $\mathrm{H}_{2} \mathrm{~S}(\mathrm{aq})-\mathrm{H}_{2} \mathrm{~S}(\mathrm{~g})$ equilibrium experiments of Szaran (1996) at $25^{\circ} \mathrm{C}\left(\alpha=0.9987,\left(\delta^{34} S\right)_{s o}=-34.245\right)$ which indicates how the data would have plotted if the equilibrium fractionation factor applied to the fractionation observed in the sulfide collection experiments. Instead, the fractionation observed is a kinetic fractionation factor, describing a smaller degree of fractionation between $\mathrm{H}_{2} \mathrm{~S}(\mathrm{aq})$ and $\mathrm{H}_{2} \mathrm{~S}(\mathrm{~g})$ than that observed by Szaran (1996). (b) Solid circles are data from the laboratory experiment with 1.4 L/minute nitrogen flow rate and open circles are data from the laboratory experiment with 0.8 $\mathrm{L}$ minute nitrogen flow rate (data in table 29). The line through these data points is fitted by linear regression $\left(r^{2}=0.9684\right)$. The $\alpha$ calculated from the slope of this line is 0.99943 . This line is compared to a line based on the $\mathrm{H}_{2} \mathrm{~S}(\mathrm{aq})-\mathrm{H}_{2} \mathrm{~S}(\mathrm{~g})$ equilibrium experiments of Szaran (1996) at $20^{\circ} \mathrm{C}\left(\alpha=0.9984,\left(\delta^{34} S\right)_{\text {so }}=1.10\right)$ which indicates how the data would have plotted if the equilibrium fractionation factor applied to the fractionation observed in the sulfide collection experiments. Again, fractionation observed in the sulfide collection experiments is best described by a kinetic fractionation factor. 
Table 30. Fractionation factors and sulfur isotopic composition of original dissolved sulfide $\left(\delta^{34} S\right)_{\text {so }}$ calulated from linear regressions to the data in figure 17 [exps., experiments]

$\begin{array}{ccc}\text { Experiments } & \begin{array}{c}\text { Fractionation } \\ \text { factor } \alpha\end{array} & \begin{array}{c}\text { Calculated } \\ \left(\delta^{34} S\right)_{\text {so }}\end{array}\end{array}$

\begin{tabular}{cc}
$\begin{array}{c}\text { Integrated } \\
\text { average } \delta^{34} S \text { for }\end{array}$ & $\begin{array}{c}\delta^{34} S \text { from direct } \\
\text { precipitation } \\
\text { nitrogen stripping } \\
\text { experiments }\end{array}$ \\
\hline
\end{tabular}

Suwannee well, exps. 13 and 27

0.999431

$-34.29 \%$

$-34.25 \%$

$-33.81 \%$

Laboratory exps. at

1.4 and $0.8 \mathrm{~L}$ minute

0.999467

$1.14 \%$

$1.10 \% 0^{1}$

$1.35 \%$

Average $\alpha=$ 0.999449

1 Value from $1.4 \mathrm{~L} /$ minute experiment which had a larger fraction of sulfide collected than the 0.8 L/minute experiment.

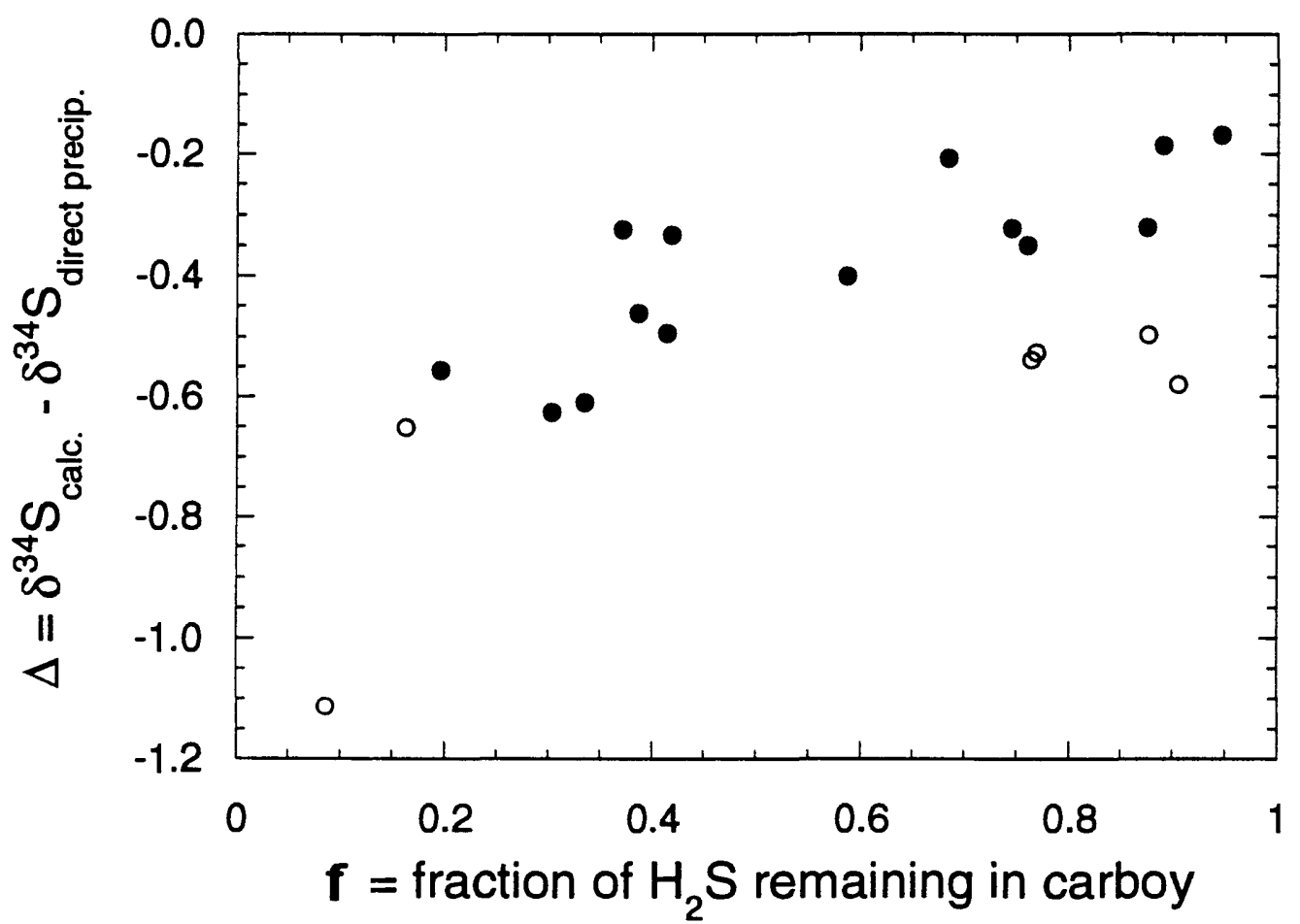

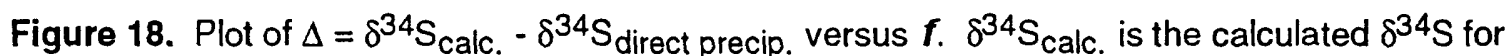
one-trap experiments (table 24) and for initial fractions of the six-trap experiments (tables 28 and 29) using an exponential version of equation 6 and fractionation factor $\alpha=0.9994(49)$. Solid circles are for the laboratory experiments $\left(\delta^{34} S_{\text {direct precip. }}=1.35\right.$ per mill $)$ and open circles are for field experiments $\left(\delta^{34} S_{\text {direct precip. }}=-33.81\right.$ per mill). The plot shows that calculated $\delta^{34} S$ is closest to the value obtained by direct precipitation if the fraction of sulfide collected is small (i.e., the fraction of sulfide remaining in the carboy ( $f$ ) is large). This is because, when only a small fraction of $\mathrm{H}_{2} \mathrm{~S}$ is collected as $\mathrm{Ag}_{2} \mathrm{~S}, \delta^{34} \mathrm{~S}$ of the $\mathrm{Ag}_{2} \mathrm{~S}$ collected more closely approximates an "instantaneous" $\left(\delta^{34} S\right)_{g}$ than $\delta^{34} \mathrm{~S}$ of $\mathrm{Ag}_{2} \mathrm{~S}$ when a large fraction of the $\mathrm{H}_{2} \mathrm{~S}$ is collected. 
Figure 18 shows that, for higher values of $f$, i.e., small fractions of $A_{2} S$ collected, the $\delta^{34} S_{s o}$ value can be calculated about as well as $\delta^{34} S$ of the ground water can be measured for longer ( 3 to 6 hour) sulfide collections by nitrogen stripping. $\delta^{34} S$ obtained from these longer sulfide collections ( 3 to 6 hours) are depleted in ${ }^{34} S$ relative to the $\delta^{34} S$ from the direct precipitation experiments by 0.2 to 0.5 per mill (figures 14 and 16). Calculated $\delta^{34} S_{s o}$ for small fractions of $\mathrm{Ag}_{2} \mathrm{~S}$ collected ( $\boldsymbol{f}$ greater than 0.6 ) have similar uncertainty. The time to collect these smaller fractions of $\mathrm{Ag}_{2} \mathrm{~S}$ ranged from 10 minutes to 1 hour, a significant time savings over a 3-hour sulfide collection. Ten minute to 1 hour collection times are for ground-water samples with about $3 \mathrm{mg} / \mathrm{L}$ dissolved sulfide. Longer collection times are required for more dilute water samples.

The process of stripping $\mathrm{H}_{2} \mathrm{~S}(\mathrm{~g})$ from a carboy does not allow equilibration between $\mathrm{H}_{2} \mathrm{~S}(\mathrm{~g})$ and $\mathrm{H}_{2} \mathrm{~S}(\mathrm{aq})$. Therefore, fractionation factors derived for the nitrogen stripping experiments are kinetic fractionation factors and are not equilibrium fractionation factors. It is instructive to compare fractionation factors for the nitrogen stripping experiments (table 30 ) to the equilibrium fractionation factors for coexisting $\mathrm{H}_{2} \mathrm{~S}(\mathrm{~g})$ and $\mathrm{H}_{2} \mathrm{~S}(\mathrm{aq})$ determined by Szaran (1996). The fractionation factors listed in Szaran's table 4 (p. 227) are:

$$
\alpha_{u-g}=\frac{R_{u}}{R_{g}}=\frac{R_{s}}{R_{g}}
$$

(" $u$ " = undissociated, aqueous hydrogen sulfide, which is equivalent to our subscript " $s$ "). This is the inverse of the $\alpha_{g-s}$ defined above. Therefore, the $\alpha$ 's from Szaran's table 4 are compared to those in table 30 by taking the inverse $\left(\alpha_{g-s}=1 / \alpha_{u-g}\right)$.

The sense of the equilibrium fractionation determined by Szaran is the same as that observed in our experiments: $\mathrm{H}_{2} \mathrm{~S}(\mathrm{~g})$ is depleted in ${ }^{34} \mathrm{~S}$ relative to the $\mathrm{H}_{2} \mathrm{~S}(\mathrm{aq})$ from which it is derived. However, the magnitude of the equilibrium fractionation observed by Szaran is larger than the magnitude of the fractionation produced by nitrogen stripping in our experiments. This is manifested in the fractionation factors: Szaran's fractionation factors $\left(\alpha_{g-u}\right)$ at $25^{\circ}$ and $20^{\circ} \mathrm{C}$ are 0.9987 and 0.9984 , respectively, whereas the average fractionation factor $\left(\alpha_{g-s}\right)$ for the fractional nitrogen stripping experiments is 0.9994 . Szaran's fractionation factors were plugged into equation 6 and used to calculate equations for lines, which are plotted in figure 17. These trends indicate how the data from the nitrogen stripping experiments would have plotted if the equilibrium fractionation factors for $\mathrm{H}_{2} \mathrm{~S}(\mathrm{aq}) \rightarrow \mathrm{H}_{2} \mathrm{~S}(\mathrm{~g})$ were applicable. The fractionation factors derived for the 6-trap sulfide-collection-by-nitrogen-stripping experiments (table 30) are clearly not for an equilibrium situation but instead are kinetic fractionation factors. 


\subsubsection{Conclusions regarding the sulfide-collection-by-nitrogen-stripping technique}

The experiments discussed in sections 4.5.1 through 4.5.4 illustrate that fractionation of the sulfur isotopes occurs in the process of collecting sulfide as $\mathrm{Ag}_{2} \mathrm{~S}$ by nitrogen stripping. The results of these experiments (figures 14 and 16) suggest that the magnitude of this fractionation ${ }^{14}$ is -0.2 to -0.5 per mill for an approximately 3-hour sulfide collection experiment. Because this fractionation is relatively small and because the nitrogen-stripping technique has a number of advantages (section 2.2) over other sulfide collection techniques, we recommend its continued use, at least at dilute wells (dissolved sulfide less than $\sim 0.5 \mathrm{mg} / \mathrm{L}$ ) where direct precipitation of $\mathrm{Ag}_{2} \mathrm{~S}$ is impractical, until a better method can be demonstrated.

An alternative to stripping sulfide from a ground-water sample for 3 hours or more would be to collect $\mathrm{Ag}_{2} \mathrm{~S}$ for a short period of time (about 30 minutes, or long enough to collect at least 30 to $40 \mathrm{mg} \mathrm{Ag} 2 \mathrm{~S}$ ) and use a kinetic fractionation factor, derived as discussed in section 4.5.5, to calculate the sulfur isotopic composition of sulfide in the original ground water. We hesitate to recommend that the fractionation factor derived for the experiments in this study, 0.9994(49) be universally applied. It is likely that the kinetic fractionation factor is dependent on the exact equipment used. Variables such as the number and placement of gas-dispersion tubes in the carboy, changes in the configuration of the traps (e.g., using bottles instead of graduated cylinders for traps 1 to 3 , figure 4) and length of tubing between traps may affect the kinetic fractionation factor. Surprisingly, however, the kinetic fractionation factor does not seem to be dependent on nitrogen flow rate, since the results of both laboratory sulfide collection experiments are approximately colinear in figure $17 \mathrm{~b}$, in spite of the fact that the nitrogen flow rate differed by nearly a factor of two (1.4 versus 0.8 $\mathrm{L} /$ minute) between these experiments. The best results will be obtained for this altemate short-collection method if a fractional collection experiment similar to those discussed above is conducted by each user on his/her own sulfide collection apparatus to determine the kinetic fractionation factor for that apparatus.

Isotopic fractionation associated with this technique can be minimized by following these guidelines. (1) Select the well capable of producing the most water in the aquifer or area of interest from which the dissolved sulfide sample will be collected. This will allow the fastest possible filling of the carboy(s) and minimize the loss of $\mathrm{H}_{2} \mathrm{~S}$ to the air (loss of sulfide during filling of the carboys apparently caused most of the scatter seen in the data from the Upper Intermediate well). (2) Use the highest $\mathrm{N}_{2}$ flow rate permitted by the equipment. For the equipment show in figure 4 , the maximum flow rate is $1.4 \mathrm{~L}$ minute. Bubbling in the $\mathrm{AgNO}_{3}$ trap should be rapid, but overflow of $\mathrm{AgNO}_{3}$ solution into

14 That is, the difference in the sulfur isotopic composition of sulfide collected by the nitrogen stripping technique and sulfide collected by direct precipitation, which we infer reflects the sulfur isotopic composition of sulfide in the ground water, $\left(\delta^{34} S\right)_{\text {so }}$. 
trap 3, and overflow of ground water into trap 1, should be avoided or minimized and care must be taken not to dislodge the caps from the tops of the traps. (3) To maximize the recovery of sulfide, allow the sulfide extraction to proceed as long as is practical relative to your field schedule, or determine the kinetic fractionation factor for your equipment and use the alternative, short-collection method discussed above.

Analyze the dissolved sulfide remaining in the carboy at the end of the experiment and calculate the fraction of sulfide collected and the fraction left in the carboy. Check whether these add up to the total sulfide expected based on the dissolved sulfide concentration of the ground water measured with the spectrophotometer. If these do not add up to the amount of sulfide expected, calculate the fraction of $\mathrm{H}_{2} \mathrm{~S}$ lost during filling of the carboys. The $\delta^{34} \mathrm{~S}$ values obtained on $\mathrm{Ag}_{2} \mathrm{~S}$ from a high-recovery (greater than 90 percent) sulfidecollection run will likely be only slightly more negative (about 0.2 per mill) than the "actual" $\delta^{34} S$ value, $\left(\delta^{34} S\right)_{\text {so, }}$, for dissolved sulfide in the ground water. If collection time is short, calculate $\left(\delta^{34} S\right)_{\text {so }}$ as discussed in section 4.5.5. On the other hand, if sulfide recovery is low (less than 35 percent) due to loss of $\mathrm{H}_{2} \mathrm{~S}(\mathrm{~g}$ ) during filling of the carboys, the $\delta^{34} S$ value obtained from this $A_{2} S$ may be more positive than the "actual" $\delta^{34} S$ of the dissolved sulfide in the ground water by 1.0 per mill or more. Potential fractionation resulting from loss of $\mathrm{H}_{2} \mathrm{~S}(\mathrm{~g})$ during slow filling of the carboys is significantly larger ( +1 per mill or more) than the fractionation attributed to the nitrogen stripping method for sulfide collection $(-0.2$ to -0.5 per mill).

\section{SUMMARY AND CONCLUSIONS}

This paper describes methods for the collection of sufficiently large, isotopically unfractionated samples of dissolved sulfate and sulfide and the production of pure precipitates $\left(\mathrm{Ag}_{2} \mathrm{~S}\right.$ and $\left.\mathrm{BaSO}_{4}\right)$ for isotopic analysis. On the basis of the results of our experiments testing these methods, the following techniques are recommended.

1. Sulfate in water with concentrations of greater than $20 \mathrm{mg} / \mathrm{L} \mathrm{SO}_{4}{ }^{2-}$ is collected by precipitating $\mathrm{BaSO}_{4}$ from an acidified sample (up to 2 liters volume). $\mathrm{BaSO}_{4}$ can be precipitated and filtered in the laboratory or in the field. Fractionation of the sulfur isotopes is not observed in samples collected by this method (sections 2.1.4, 4.1 and 4.3.2).

2. Anion exchange resin can be used to collect sulfate from samples in which sulfate concentrations are less than $20 \mathrm{mg} / \mathrm{L}$ (section 2.1.5). As a dilute water sample is pumped through the resin, $\mathrm{SO}_{4}{ }^{2-}$ replaces $\mathrm{Cl}^{-}$on the resin's exchange sites. In the laboratory (section 3.2), a small volume of concentrated chloride solution is used to elute the sulfate from the resin. In this way, sulfate from many liters of a dilute sample is concentrated in $200 \mathrm{~mL}$ of chloride solution; precipitation and filtering of $\mathrm{BaSO}_{4}$ are very much simplified. In some 
of the experiments, less-than-optimal recovery of sulfate (approximately 80 to 85 percent) compared to direct precipitation, and slight fractionation of the sulfur isotopes by about -0.2 per mill relative to $\delta^{34} S$ measured on directlyprecipitated sulfate is attributed to chloride in solution with the sulfate or to incomplete elution. Because naturally-occurring chloride in the water sample elutes sulfate from the resin, it is not possible to collect all the sulfate present in water samples high in chloride by using the anion exchange resin tested in this study. Incomplete elution of the sulfate will also cause a small fractionation of the sulfur isotopes (section 4.2.3). But recent experiments have shown that sulfate from low-chloride water samples can be collected on and eluted from anion exchange resin without measurable fractionation of the sulfur isotopes, using the methods discussed in sections 2.1.5 and 3.2.

3. Measurement of dissolved sulfide concentrations greater than $0.6 \mathrm{mg} / \mathrm{L}$ with a field spectrophotometer has been problematic. Two dilution methods were tested in this study. The "DI water first" dilution method gave $\mathrm{S}^{2-}$

concentrations that ranged from less than 10 percent to greater than 35 percent too low. In contrast, the "Reagents first" dilution method gave $S^{2-}$ concentrations that range from less than 15 percent to greater than 40 percent too high. Strategies for dealing with this problem are discussed in section 4.3.1.

4. When a water sample from which dissolved sulfate will be collected for isotopic analysis also contains dissolved sulfide (greater than $0.01 \mathrm{mg} / \mathrm{L}$ ), the sulfide should be removed by nitrogen stripping to avoid contamination of the sulfate sulfur by oxidized sulfide sulfur with very different isotopic composition. The rate of removal of $\mathrm{H}_{2} \mathrm{~S}$ is dependent on the flow rate of the nitrogen; a flow rate of $8 \mathrm{~L} /$ minute of nitrogen is recommended to insure rapid stripping and to minimize oxidation of sulfide to sulfate. If the concentration of $\mathrm{SO}_{4}{ }^{2-}$ is much greater than $\mathrm{S}^{2-}\left(\mathrm{SO}_{4}{ }^{2-1} \mathrm{~S}^{2-}\right.$ of 40 or more, on a molar basis $)$ and $\mathrm{SO}_{4}{ }^{2-}$ is collected by either direct precipitation in the field or on anion exchange resin, sulfate can be collected without first stripping sulfide with no measurable effect on the sulfur isotope composition of the sulfate (sections 2.1.2, 2.1.3 and 4.3.2).

5. A method for collection of dissolved sulfide by nitrogen stripping and precipitation of $\mathrm{Ag}_{2} \mathrm{~S}$ in an $\mathrm{AgNO}_{3}$ trap has been tested and found to cause a small fractionation of the isotopic composition of the sulfide. Experiments show that the first sulfide collected is depleted in ${ }^{34} \mathrm{~S}$. $\mathrm{Ag}_{2} \mathrm{~S}$ collected gradually becomes enriched in ${ }^{34} S$ with fraction of sulfide collected, but unless all the sulfide from the water sample is collected as $\mathrm{Ag}_{2} \mathrm{~S}$, sulfide collected will be slightly isotopically fractionated $(-0.2$ to -0.5 per mill) relative to that in the original sample (sections 2.2 and 4.5). We recommend two approaches to minimize this fractionation. (1) Collect sulfide by nitrogen stripping for 3 hours or more to minimize the amount of sulfide left in the carboy and, thus, the fractionation produced. (2) Determine the kinetic fractionation factor $(\alpha)$ for the collection apparatus and use this $\alpha$ to calculate the original sulfur isotopic 
composition of the dissolved sulfide in the ground water from $\mathrm{Ag}_{2} \mathrm{~S}$ collected for a short time (about 30 minutes).

6. Another alternative method (for samples with dissolved sulfide concentration greater than about $0.5 \mathrm{mg} / \mathrm{L}$ ) is to collect the dissolved sulfide by direct precipitation of $\mathrm{Ag}_{2} \mathrm{~S}$ by adding $\mathrm{AgNO}_{3}$ to the water sample. The precipitate produced in this way will be impure $\left(\mathrm{Ag}_{2} \mathrm{~S}\right.$ mixed with $\left.\mathrm{AgCl}\right)$. This $\mathrm{Ag}_{2} \mathrm{~S}$ can be purified in the laboratory by treating with $\mathrm{NH}_{4} \mathrm{OH}$ solution. Care must be taken to add sufficient $\mathrm{AgNO}_{3}$ to precipitate all the sulfide present, or the sulfide sample will be fractionated (sections 2.2 and 4.4).

Isotopic analysis of the resulting pure $\mathrm{Ag}_{2} \mathrm{~S}$ and $\mathrm{BaSO}_{4}$ precipitates is accomplished by combining the precipitate with $\mathrm{Cu}_{2} \mathrm{O}$ and $\mathrm{SiO}_{2}$ (for sulfate). The samples are combusted at high temperature and the resulting $\mathrm{SO}_{2}$ is purified by vacuum distillation and analyzed on an isotope-ratio mass spectrometer. Corrections are applied to the data to correct for first- and second-order (for sulfates) oxygen isotope effects and to report the data relative to the Vienna Canyon Diablo troilite (VCDT) standard. Uncertainty resulting from vacuum extraction and analysis of the samples is \pm 0.15 per mill $(1 \sigma)$.

\section{Acknowledgments}

We wish to acknowledge several U. S. G. S. colleagues whose assistance was of critical importance to this study. Laura Sacks provided information on dissolved sulfide- and sulfate-bearing wells and logistical assistance without which the field portion of this study would have been impossible to carry out. Julian Wayland provided field assistance for the experiments at the wells in Florida. Jessica Hopple, My-Chau Tran, Barbara Davis, Janet Hannon, Braxton Baldridge and Jacqueline Mann assisted with experiments and sample preparation in the laboratory. Rebecca Neuschatz carried out the "wet chemistry" for the for the latest round of sulfate collection experiments (in 1996).

Discussions with J. K. Böhlke were critical to planning the experiments in 1996. Robert Seal provided advise on sample preparation and mass spectrometric techniques and he and Laura Sacks shared data on the sulfur isotope composition of dissolved sulfate and sulfide at the Suwannee and Upper Intermediate wells. Laura Sacks and W. C. Shanks, III provided helpful reviews of an early version of the manuscript. Timothy Hayes and Robert Seal provided insightful technical reviews of a later version of the manuscript. 


\section{REFERENCES CITED}

Bailey, S. A. and Smith, J. W., 1972, Improved method for the preparation of sulfur dioxide from barium sulfate for isotope ratio studies: Analytical Chemistry, v. 44, p. 1542-1543.

Beaudoin, G., Taylor, B. E., Rumble, D., III, and Thiemens, M., 1994, Variations in the sulfur isotope composition of troilite from the Cañon Diablo iron meteorite: Geochimica et Cosmochimica Acta, v. 58, p. 4253-4255.

Böhlke, J. K. and Coplen, T. B., 1995, Interlaboratory comparison of reference materials for nitrogen-isotope-ratio measurements, in Reference and intercomparison materials for stable isotopes of light elements -- Proceedings of a consultants meeting held in Vienna [Austria], 1-3 December 1993: Vienna, Austria, International Atomic Energy Agency, p. 51-66.

Busby, J. F., Plummer, L. N., Lee, R. W. and Hanshaw, B. B., 1991, Geochemical evolution of water in the Madison aquifer in parts of Montana, South Dakota, and Wyoming: U. S. Geological Survey Professional Paper 1273-F, p. F1-F89.

Coleman, M. L. and Moore, M. P., 1978, Direct reduction of sulfates to sulfur dioxide for isotopic analysis: Analytical Chemistry, v. 50, p. 1594-1595.

Coplen, T. B., and Krouse, H. R., 1998, Sulphur isotope data consistency improved: Nature, v. 392, p. 32.

Fouillac, C., Fouillac, A. M. and Criaud, A., 1990, Sulphur and oxygen isotopes of dissolved sulphur species in formation waters from the Dogger geothermal aquifer, Paris Basin, France: Applied Geochemistry, v. 5, p. 415-427.

Fritz, J. S., Yamamura, S. S. and Richard, M. J., 1957, Titration of sulfate following separation with alumina: Analytical Chemistry, v. 29, p. 158-161.

Fritz, P., Drimmie, R. J. and Nowicki, V. K., 1974, Preparation of sulfur dioxide for mass spectrometer analyses by combustion of sulfides with copper oxide: Analytical Chemistry, v. 46, p. 164-166.

Fritz, P., Frape, S. K., Drimmie, R. J., Appleyard, E. C. and Hattori, K., 1994, Sulfate in brines in the crystalline rocks of the Canadian Shield: Geochimica et Cosmochimica Acta, v. 58, p. 57-65.

Gavelin, S., Parwell, A. and Ryhage, R., 1960, Sulfur isotope fractionation in sulfide mineralization: Economic Geology, v. 55, p. 510-530. 
Gonfiantini, R., Stichler, W. and Rozanski, K., 1995, Standards and intercomparison materials distributed by the International Atomic Energy Agency for stable isotope measurements, in Reference and intercomparison materials for stable isotopes of light elements -- Proceedings of a consultants meeting held in Vienna [Austria], 1-3 December 1993: Vienna, Austria, International Atomic Energy Agency, p. 13-29.

Grundl, T., 1980, A stable-isotope view of the Cambro-Ordovician aquifer system in northern Illinois: DeKalb, IIl., Northern Illinois University, Master's thesis. $88 \mathrm{p}$.

Gustafsson, L., 1960, Determination of ultramicro amounts of sulphate as methylene blue -- I The colour reaction: Talanta, v. 4, p. 227-235.

Hach Company, 1988, DR/2000 spectrophotometer procedures manual: Loveland, Colorado, $526 \mathrm{p}$.

Halas, S. and Wolacewicz, W. P., 1981, Direct extraction of sulfur dioxide from sulfates for isotopic analysis: Analytical Chemistry, v. 53, p. 686-689.

Holt, B. D. and Engelkemeir, A. G., 1970, Thermal decomposition of barium sulfate to sulfur dioxide for mass spectrometric analysis: Analytical Chemistry, v. 42, p. $1451-1453$.

Kaplan, I. R., Smith, J. W. and Ruth, E., 1970, Carbon and sulfur concentration and isotopic composition in Apollo 11 lunar samples: Proceedings of the Apollo 11 Lunar Science Conference, v. 2, p. 1317-1329.

Krouse, H. R., and Coplen, T. B., 1997, Reporting of relative sulfur isotope-ratio data: Pure and Applied Chemistry, v. 69, p. 293-295.

Lide, D. R. and Frederikse, H. P. R., eds., 1994, CRC handbook of chemistry and physics (75th edition): Boca Raton, Florida, CRC Press, Inc., p. 4-47 to 4-113.

Lindsay, S. S. and Baedecker, M. J., 1988, Determination of aqueous sulfide in contaminated and natural water using the methylene blue method. in Collins, A. G. and Johnson, A. I., eds., Ground-water contamination: field methods, ASTM STP 963: Philadelphia, American Society for Testing and Materials, p. 349-357.

Moncaster, S. J. and Bottrell, S. H., 1991, Extraction of low-level sulphide from groundwaters for sulphur isotope analysis: Chemical Geology, Isotope Geoscience Section, v. 94, p. 79-82. 
Pearson, F. J. Jr. and Rightmire, C. T., 1980, Sulphur and oxygen isotopes in aqueous sulphur compounds, in Fritz, P. and Fontes, J. C., eds., Handbook of environmental isotope geochemistry, vol. 1: the terrestrial environment: New York, Elsevier Scientific Publ. Co., p. 227-258.

Perry, E. C., Grundl, T., and Gilkeson, R. H., 1982, H, O, and S isotopic study of the groundwater in the Cambrian-Ordovician aquifer system of northern Illinois, in Perry and Montgomery, eds., Isotope studies of hydrologic processes: DeKalb, III., Northern Illinois University Press, p. 35-43.

Rees, C. E., 1978, Sulphur isotope measurements using $\mathrm{SO}_{2}$ and $\mathrm{SF}_{6}$ : Geochimica et Cosmochimica Acta, v. 42, p. 383-389.

Rees, C. E., Jenkins, W. J. and Monster, J., 1978, The sulphur isotopic composition of ocean water sulphate: Geochimica et Cosmochimica Acta, v. 42, p. $377-381$.

Robinson, B. W., 1973, Sulphur isotope equilibrium during sulphur hydrolysis at high temperatures: Earth and Planetary Science Letters, v. 18, p. 443-450.

Robinson, B. W. and Kusakabe, M., 1975, Quantitative preparation of sulfur dioxide, for ${ }^{34} \mathrm{~S} /{ }^{32} \mathrm{~S}$ Analyses, from sulfides by combustion with cuprous oxide: Analytical Chemistry, v. 47, p. 1179-1181.

Rye, R. O., Back, W., Hanshaw, B. B., Rightmire, C. T. and Pearson, F. J. J., 1981 , The origin and isotopic composition of dissolved sulfide in groundwater from carbonate aquifers in Florida and Texas: Geochimica et Cosmochimica Acta, v. 45, p. 1941-1950.

Sacks, L. A., 1996, Geochemical and isotopic composition of ground water, with emphasis on sources of sulfate in the Upper Floridan aquifer in parts of Marion, Sumter and Citrus Counties, Florida: U. S. Geological Survey WaterResources Investigations Report 95-4251, 47 p.

Sacks, L. A., and Tihansky, A. B., 1996, Geochemical and isotopic composition of ground water, with emphasis on sources of sulfate, in the Upper Floridan aquifer and intermediate aquifer system in southwest Florida: U. S. Geological Survey Water-Resources Investigations Report 96-4146, 54 p.

Szaran, J., 1996, Experimental investigation of sulphur isotopic fractionation between dissolved and gaseous $\mathrm{H}_{2} \mathrm{~S}$ : Chemical Geology, Isotope Geoscience Section, v. 127, p. 223-228. 
Tabatabai, M. A., 1992, Methods of measurement of sulphur in soils, plant materials and water, in Howarth, R. W., Stewart, J. W. B., and Ivanov, M. V., eds., Sulphur cycling on the continents: New York, John Wiley and Sons, p. 307-344.

Thode, H. G., Macnamara, J. and Collins, C. B., 1949, Natural variations in the isotopic content of sulphur and their significance: Canadian Journal of Research, v. 27, p. 361-373.

Thode, H. G., Monster, J. and Dunford, H. B., 1961, Sulphur isotope geochemistry: Geochimica et Cosmochimica Acta, v. 25, p. 159-174.

Turk, J. T., Campbell, D. H. and Spahr, N. E., 1993, Use of chemistry and stable sulfur isotopes to determine sources of trends in sulfate of Colorado lakes: Water, Air, and Soil Pollution, v. 67, p. 415-431.

Ueda, A. and Krouse, H. R., 1986, Direct conversion of sulphide and sulphate minerals to $\mathrm{SO}_{2}$ for isotope analyses: Geochemical Journal, v. 20, p. 209212.

van Everdingen, R. O., Shakur, M. A. and Krouse, H. R., 1982, Isotope geochemistry of dissolved, precipitated, airborne, and fallout sulfur species associated with springs near Paige Mountain, Norman Range, N.W.T.: Canadian Journal of Earth Science, v. 19, p. 1395-1407.

Yanagisawa, F. and Sakai, H., 1983, Thermal decomposition of barium sulfate vanadium pentoxide - silica glass mixtures for preparation of sulfur dioxide in sulfur isotope ratio measurements: Analytical Chemistry, v. 55, p. 985-987. 


\section{APPENDIX}

\section{Correction of data to Vienna Canyon Diablo Troilite (VCDT) scale}

The Vienna Canyon Diablo Triolite (VCDT) scale for reporting sulfur isotoperatio data is defined in section 1.1 (see also definitions). All $\mathrm{SO}_{2}$ samples analyzed on an isotope-ratio mass spectrometer for this study are compared to a laboratory reference gas called "Tank $\mathrm{SO}_{2}$ ". This standard has a $\delta^{34} \mathrm{~S}$ value of about +4.3 per mill compared to Vienna Canyon Diablo Troilite (VCDT). In order to convert raw data from the mass spectrometer, which is reported relative to Tank $\mathrm{SO}_{2}$, to the VCDT scale, three reference materials with a range of sulfur isotopic compositions are analyzed relative to Tank $\mathrm{SO}_{2}$ to establish a correction scheme via linear regression. This correction method, utilizing sulfur isotopic measurements on these materials by the $\mathrm{SF}_{6}$ technique, was recommended by Rees (1978). The three standards used are NBS 123 ( $Z n S$ with $\delta^{34} S$ relative to VCDT of +17.09 per mill), NZ1 ( $\mathrm{Ag}_{2} \mathrm{~S}$ with $\delta^{34} \mathrm{~S}$ relative to VCDT of -0.30 per mill) and "Maine Light" ( $\mathrm{Ag}_{2} \mathrm{~S}$ with $\delta^{34} \mathrm{~S}$ relative to VCDT of -30.71 per mill15). $\mathrm{SO}_{2}$ gases prepared from these reference materials according to the methods described above (different weight proportions of $\mathrm{ZnS}$ and $\mathrm{Cu}_{2} \mathrm{O}$ are combined to maintain the same molar sulfur to oxygen ratio as that used for $\mathrm{Ag}_{2} \mathrm{~S}$ ) are analyzed against the Tank $\mathrm{SO}_{2}$. A linear regression is calculated for the $\delta^{34} S$ values measured on $\mathrm{SO}_{2}$ versus the $\mathrm{SF}_{6}$-determined $\delta^{34} S$ values relative to VCDT for these reference materials. The regression is used to convert $\delta^{34} S$ of the unknowns from the Tank $\mathrm{SO}_{2}$ scale to the VCDT scale. This process is illustrated graphically in figure 19.

\section{Oxygen-isotope correction for sulfate samples}

It has long been known that a correction must be applied to sulfur isotope compositions of $\mathrm{SO}_{2}$ gas because the mass spectrometer cannot distinguish between the ions ${ }^{34} \mathrm{~S}^{16} \mathrm{O}_{2}+$ and ${ }^{32} \mathrm{~S}^{16} \mathrm{O}^{18} \mathrm{O}+$ (e.g., Rees (1978) and references therein). A uniform oxygen isotope composition between sulfide samples and standards is assumed to be maintained by using the same $\mathrm{Cu}_{2} \mathrm{O}$ to prepare $\mathrm{SO}_{2}$ from samples and from the three reference materials NBS 123, NZ1 and Maine Light. A first-order oxygen isotope correction is made by the ISODAT program. A second-order oxygen isotope correction is not required for $\mathrm{SO}_{2}$ from sulfides.

$\mathrm{BaSO}_{4}$ samples, however, require a second-order correction because in this case, some of the oxygen that is reacting to form $\mathrm{SO}_{2}$ is derived from the $\mathrm{BaSO}_{4}$ itself. The same batches of reagents are used (i.e., uniform $18 \mathrm{O} / 16 \mathrm{O}$ ) for several months' worth of extractions. The influence of the unknown oxygen isotopic composition of the sulfate sample is minimized by combining $\mathrm{BaSO}_{4}$ with $\mathrm{Cu}_{2} \mathrm{O}$ and $\mathrm{SiO}_{2}$ to overwhelm the influence of the sample $18 \mathrm{O} / 16 \mathrm{O}$ ratio with oxygen of

\footnotetext{
${ }^{15}$ The value of -30.71 per mill for the in-house reference material "Maine Light" was determined by Tom Hoering on $S_{6}$ prepared from this material (W. C. Shanks, III, oral comm., 1996).
} 


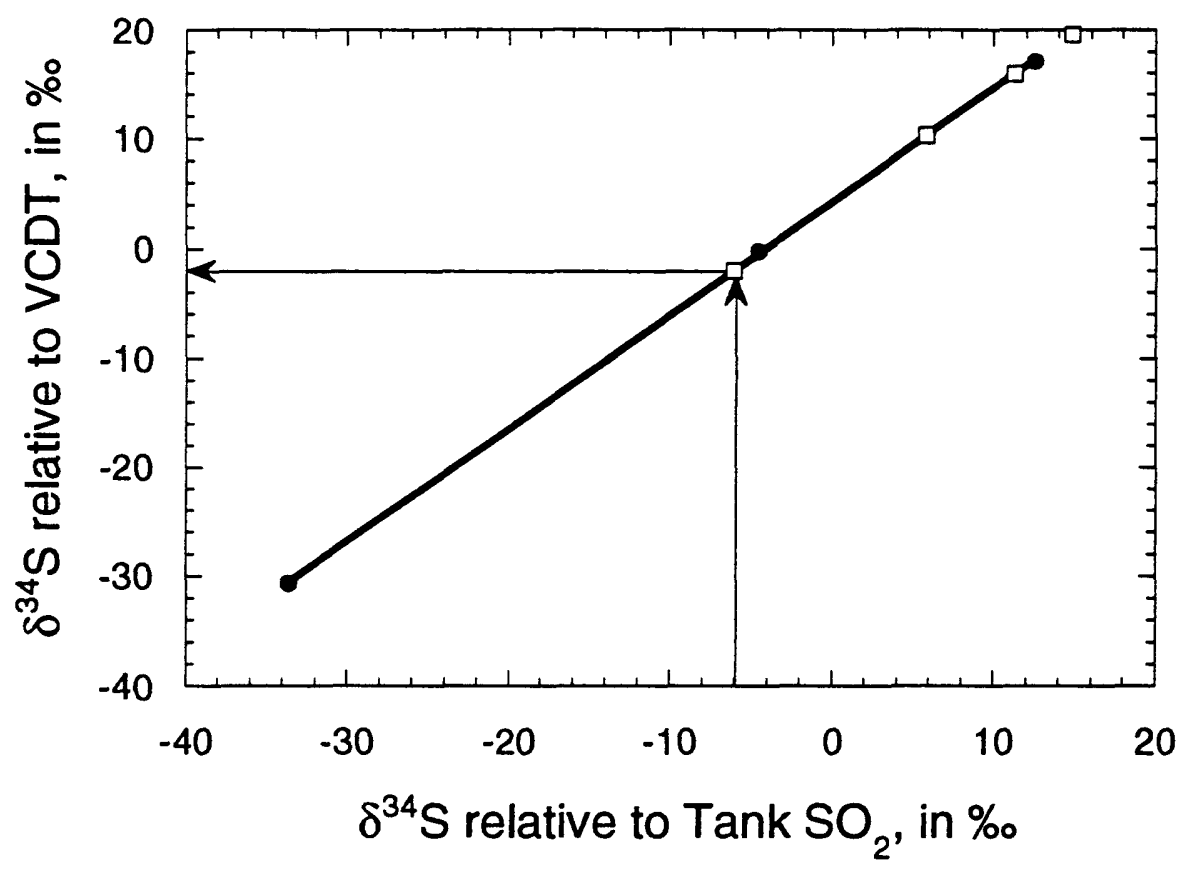

Figure 19. Diagram showing the scheme for correction of sulfur isotope data from the Tank $\mathrm{SO}_{2}$ scale to the VCDT scale. $\mathrm{SO}_{2}$ from three reference materials (solid circles) are analyzed against the Tank $\mathrm{SO}_{2}$ standard. A linear regression is calculated for these reference materials, and the slope and intercept of this calculated line is used to correct the samples from the Tank $\mathrm{SO}_{2}$ scale to the VCDT scale. The samples (open squares) are the same as those listed in table 31 . For example, unknown \#1 had $\delta^{34} \mathrm{STankSO}_{2}$ of -6.05 per mill. The arrows show how the $\delta^{34} \mathrm{~S}$ of the sample relative to VCDT $(=-2.05$ per mill) could be read graphically from this plot.

Table 31. Corrections applied to sulfur isotope analyses of sulfate samples. These samples extracted on June 14 and analyzed on June 15, 1994

\begin{tabular}{|c|c|c|c|}
\hline Column \# & 2 & 3 & 4 \\
\hline Sample \# & $\begin{array}{c}\delta^{34} S \text { relative to TankSO} 2 \\
\text { (raw data from mass } \\
\text { spectrometer) }\end{array}$ & $\begin{array}{c}\delta^{34} S \text { relative to VCDT but } \\
\text { before NBS } 127 \\
\text { correction }{ }^{2}\end{array}$ & $\begin{array}{l}\text { "True" } \delta^{34} S \\
\text { relative to VCDT }\end{array}$ \\
\hline NBS 127 & $1+14.83 \%$ & $+19.59 \%$ & $+20.91 \%$ \\
\hline Unknown \#1 & $-6.05 \%$ & $-2.05 \%$ & $-0.73 \%$ \\
\hline Unknown \#2 & $+5.84 \%$ & $+10.28 \%$ & $+11.59 \%$ \\
\hline Unknown \#3 & $+11.31 \%$ & $+15.94 \%$ & $+17.25 \%$ \\
\hline
\end{tabular}

1 Sulfur isotopic values are normally reported to tenths of a per mill. Due to the analytical uncertainty of \pm 0.15 per mill, the second decimal place is not considered significant. Values are reported here to two decimal places because these values were used in the calculations.

$2 \mathrm{~A}$ linear regression on $\delta^{34} \mathrm{STankSO}_{2}$ versus $\delta^{34} \mathrm{~S}$ values relative to VCDT for three sulfide standards (NBS 123, NZ1 and Maine Light) yields $\delta^{34}$ SVCDT $=1.03611\left(\delta^{34} S_{\text {TankSO }}\right)+4.22119$ $\left(R^{2}=0.99954\right)$. This equation relates the values in the second column to the values in the third column.

3 An NBS 127 correction of $20.91-19.59=+1.32$ per mill is applied to all the data in the third column to arrive at the "true" $\delta^{34} \mathrm{~S}$ values in the fourth column. 
uniform isotopic composition. In addition, an aliquot of NBS 127 is extracted along with every group of sulfate samples. Typically, $\delta^{34}$ S of NBS 127 is about 1.3 per mill lower than the $\mathrm{SF}_{6}$-determined value of 20.91 per mill ${ }^{16}$ after the correction illustrated in figure 19 has been applied. The second-order correction based on the difference between the "measured" $\delta^{34}$ SVCDT of NBS 127 and the $\mathrm{SF}_{6}$-determined $\delta^{34} \mathrm{SVCDT}$ value is applied to the $\delta^{34} S$ values of the unknown sulfate samples to obtain "true" $\delta^{34} S$ values for the unknowns. Examples of corrections applied to sulfate samples are given in table 31 .

\section{Long-term reproducibility and uncertainty of $\delta^{34} S$ data}

The oxygen isotope correction is based on an NBS 127 standard extracted on the same day as the unknowns. There are occasional outliers among the daily NBS 127 analyses, however, and correcting the unknowns based on these analyses did not produce the expected $\delta^{34} \mathrm{~S}$ value on duplicate samples. A record of $\delta^{34} S$ of NBS 127 with time (figure 20) can be used in a quantitative and sensible scheme for eliminating occasional outliers among the NBS 127 analyses (technique for eliminating outliers follows Böhlke and Coplen, 1995) and for illustrating the overall precision of the sulfur isotopic extraction and analysis techniques described here. Table 32 shows $\delta^{34} S$ values for 14 analyses of NBS 127 made between February 7 and June 15, 1994. Values reported in table 32 have been corrected as described above (column 3 in table 31). The data in table 32 are plotted in figure 20.

An analysis of NBS 127 is considered acceptable if it falls within two standard deviations of the average value. In this case, the oxygen isotopic correction will be based on the NBS 127 extraction performed on the same day that the unknowns were extracted. The small day-to-day shifts in the $\delta^{34} S$ of NBS 127 are thought to reflect slight changes in furnace temperature, vacuum pump performance, laboratory temperature and humidity, and perhaps other factors. These factors should have the same effect on the $\delta^{34} S$ of the unknowns as on the standard, so correcting the data to a standard extracted on the same day is thought to correct for these influences on the data. On those occasions when the NBS 127 value is clearly out of line (greater than 2 standard deviations from the average), the average NBS 127 value is used to apply the second-order oxygen isotopic (NBS 127) correction to the data.

Table 32 also shows that the standard deviation on the fourteen NBS 127 analyses is 0.15 per mill. This represents the uncertainty associated with the weighing, extraction and mass spectrometric methods discussed in this study.

\footnotetext{
${ }^{16}$ This value for NBS 127 was measured by Tom Hoering and is similar to the average SF $_{6}$ determined value for seawater of 20.99 per mill reported by Rees and others (1978).
} 

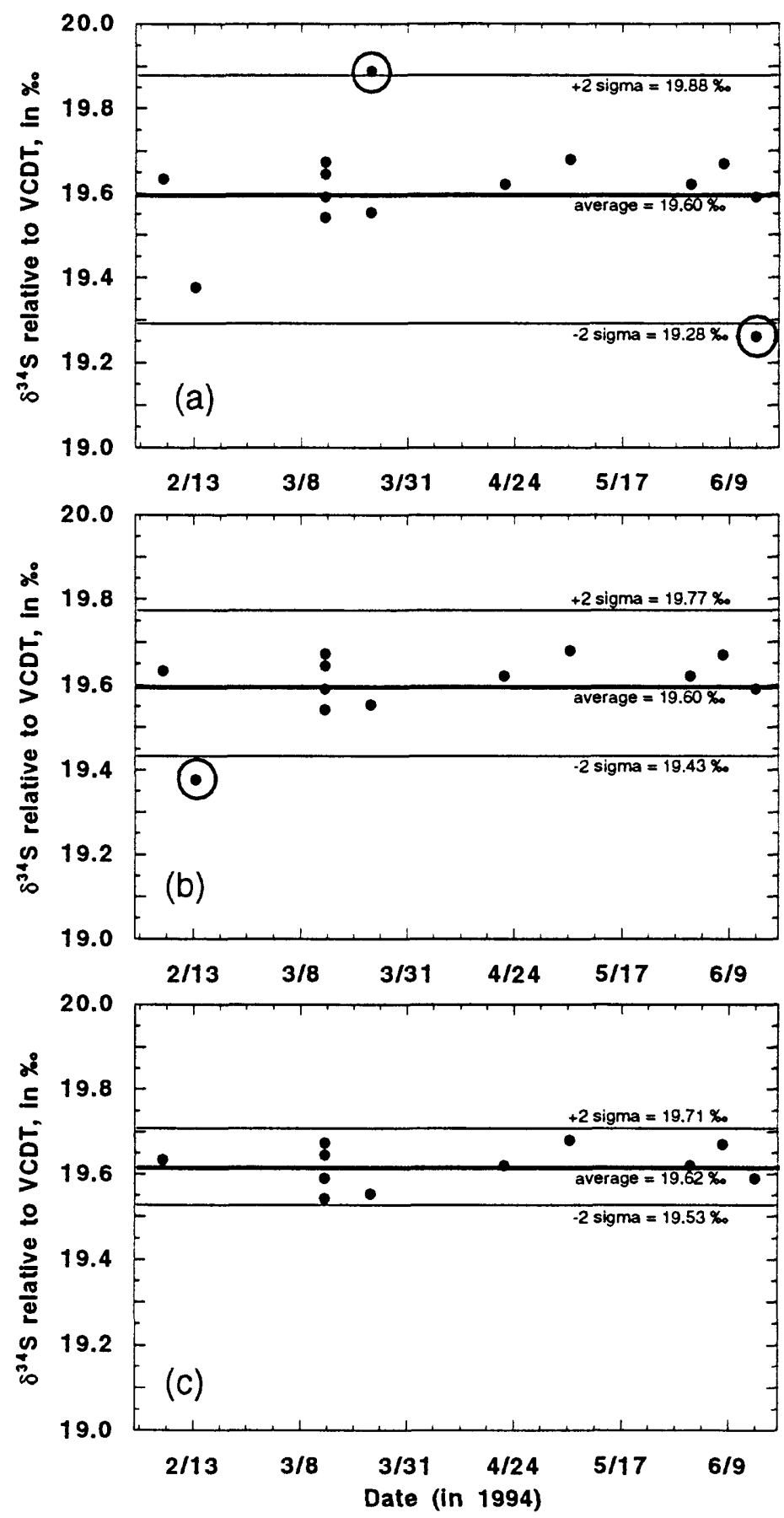

Figure 20. These plots show 14 analyses of NBS 127 performed between February and June 1994 and illustrates the scheme used to decide whether a particular analysis is within the expected range or is a outlier. The technique used here to differentiate between acceptable data and outliers follows Böhlke and Coplen (1995). Data plotted in this figure are listed in table 32. (a) All 14 analyses are plotted along with horizontal lines representing the average of these 14 analyses and two standard deviations above and below the average. Note that two analyses fall outside this range (circled) and are eliminated in the next iteration. (b) The average and standard deviation are calculated for the remaining 12 analyses. In this plot, one additional data point falls outside the 2 standard deviation range (circled) and is eliminated in the next iteration. (c) The average and standard deviation are recalculated for the remaining 11 analyses and replotted in this diagram. The remaining data fall within two standard deviations of the average. The average and standard deviation are recalculated as additional analyses are performed. NBS 127 analyses that fall beyond this range will be considered outliers and will not be used to apply an oxygen isotope correction to sulfate data. Instead the "rinning average" will be used. 
Table 32. Analyses of NBS 127 made between February 7 and June 15, 1994

\begin{tabular}{|c|c|c|c|c|}
\hline Column \# & 2 & 3 & 4 & 5 \\
\hline Correction Date & Extraction \# & $\begin{array}{l}\text { " } \delta^{34} S \text { relative to } \\
\text { VCDT" (in \%o) }\end{array}$ & $\begin{array}{l}\delta^{34} S \text { relative to } \\
\text { VCDT (in \%o) } \\
\text { 2nd iteration } 2\end{array}$ & $\begin{array}{l}\delta^{34} S \text { relative to } \\
\text { VCDT (in \%o) } \\
\text { 3rd iteration }{ }^{3}\end{array}$ \\
\hline $2 / 7 / 94$ & W106SO3 & +19.63 & +19.63 & +19.63 \\
\hline $2 / 14 / 94$ & W107SO1 & +19.38 & +19.38 & \\
\hline $3 / 14 / 94$ & W114SO2 & +19.65 & +19.65 & +19.65 \\
\hline $3 / 14 / 94$ & W124SO1 & +19.67 & +19.67 & +19.67 \\
\hline $3 / 14 / 94$ & W124SO2 & +19.59 & +19.59 & +19.59 \\
\hline $3 / 14 / 94$ & W126SO1 & +19.54 & +19.54 & +19.54 \\
\hline $3 / 24 / 94$ & W126SO2 & +19.89 & & \\
\hline $3 / 24 / 94$ & W127SO2 & +19.55 & +19.55 & +19.55 \\
\hline $4 / 22 / 94$ & W127SO3 & +19.62 & +19.62 & +19.62 \\
\hline $5 / 6 / 94$ & W145SO2 & +19.68 & +19.68 & +19.68 \\
\hline $6 / 1 / 94$ & W145SO3 & +19.62 & +19.62 & +19.62 \\
\hline $6 / 8 / 94$ & W160SO3 & +19.67 & +19.67 & +19.67 \\
\hline $6 / 15 / 94$ & W161SO3 & +19.26 & & \\
\hline \multirow[t]{2}{*}{$6 / 15 / 94$} & W161SO2 & +19.59 & +19.59 & +19.59 \\
\hline & Average $=$ & +19.60 & +19.60 & +19.62 \\
\hline Standard & deviation = & $\pm 0.15 \%$ & $\pm 0.08 \%$ & $\pm 0.05 \%$ \\
\hline
\end{tabular}

${ }^{1} \delta^{34} S$ data expressed relative to VCDT but no second-order oxygen isotopic correction has been applied.

2 Same as column 3 , but eliminating those data that fall greater than 2 standard deviations from the average $\delta^{34} S$ measured on NBS 127 in column 3 .

3 Same as column 4, but eliminated one data point that fell greater than 2 standard deviations from the average in column 4. 